\title{
Autoimmune Pemphigus: Latest Advances and Emerging Therapies
}

\author{
Yen Loo Lim ${ }^{1}$, Gerome Bohelay ${ }^{2}$, Sho Hanakawa ${ }^{3}$, Philippe Musette ${ }^{2}$ and \\ Baptiste Janela $3,4,5,6$ *
}

\begin{abstract}
${ }^{1}$ Department of Dermatology, National Skin Centre, Singapore, ${ }^{2}$ Department of Dermatology and INSERM U1125, Avicenne Hospital, Bobigny, France, ${ }^{3} A^{*}$ STAR Skin Research Labs (ASRL), Agency for Science, Technology and Research (A*STAR), Singapore, ${ }^{4}$ Skin Research Institute of Singapore (SRIS), Agency for Science, Technology and Research (A*STAR), Singapore, ${ }^{5} A^{*}$ STAR Infectious Diseases Labs, Agency for Science, Technology and Research (A*STAR), Singapore, ${ }^{6}$ Singapore Immunology network, Agency for Science, Technology and Research (A*STAR), Singapore
\end{abstract}

\section{OPEN ACCESS}

Edited by:

Ryan O'Shaughnessy,

Queen Mary University of London, United Kingdom

Reviewed by:

Vani J.,

Indian Institute of Technology Madras,

Takashi Hashimoto,

Osaka City University, Japan

*Correspondence:

Baptiste Janela

Baptiste_Janela@asrl.a-star.edu.sg

Specialty section:

This article was submitted to

Cellular Biochemistry,

a section of the journal

Frontiers in Molecular Biosciences

Received: 03 November 2021 Accepted: 20 December 2021

Published: 04 February 2022

Citation:

Lim YL, Bohelay G, Hanakawa S, Musette $P$ and Janela B (2022)

Autoimmune Pemphigus: Latest

Advances and Emerging Therapies.

Front. Mol. Biosci. 8:808536.

doi: 10.3389/fmolb.2021.808536
Pemphigus represents a group of rare and severe autoimmune intra-epidermal blistering diseases affecting the skin and mucous membranes. These painful and debilitating diseases are driven by the production of autoantibodies that are mainly directed against the desmosomal adhesion proteins, desmoglein 3 (Dsg3) and desmoglein 1 (Dsg1). The search to define underlying triggers for anti-Dsg-antibody production has revealed genetic, environmental, and possible vaccine-driven factors, but our knowledge of the processes underlying disease initiation and pathology remains incomplete. Recent studies point to an important role of T cells in supporting auto-antibody production; yet the involvement of the myeloid compartment remains unexplored. Clinical management of pemphigus is beginning to move away from broad-spectrum immunosuppression and towards B-cell-targeted therapies, which reduce many patients' symptoms but can have significant side effects. Here, we review the latest developments in our understanding of the predisposing factors/conditions of pemphigus, the underlying pathogenic mechanisms, and new and emerging therapies to treat these devastating diseases.

Keywords: pemphigus, pemphigus treatment, autoimmunity, autoimmune bullous diseases, advance in pemphigus

\section{INTRODUCTION}

Autoimmune bullous diseases (AIBDs) occur when self-reactive immune responses target the basement membrane or desmosomes of the skin and mucous membrane, leading to loss of epithelium integrity and varying severities of painful blistering (Schmidt et al., 2019). As a primary role of the skin is to protect from invading microorganisms, patients with bullous diseases can suffer recurrent, and potentially life-threatening infections, as well as chronic pain and lowered quality of life (Hsu et al., 2016). AIBDs are separated in two main subtypes, pemphigus and pemphigoid diseases. Pemphigus, from the Greek word "pemphix" (blister), is a heterogenous group of AIBDs affecting the stratified squamous epithelia, responsible for intraepithelial blistering, which is caused by inter-keratinocytic deposits of autoantibodies. Pemphigoid group in contrast affects the subepithelial layers of the skin and/or mucous membranes, responsible for subepithelial blistering, and thus exhibit distinct clinical features. In comparison with subepithelial AIBDs, most types of pemphigus do not involve the basement membrane. Among the pemphigus family are those more common variants, pemphigus vulgaris $(\mathrm{PV})$ and pemphigus foliaceus $(\mathrm{PF})$, as well as the rarer paraneoplastic pemphigus (PNP), pemphigus herpetiformis ( $\mathrm{PH}$ ), and IgA pemphigus (Joly and Litrowski, 2011; Kasperkiewicz et al., 2017). 
TABLE 1 | Types of pemphigus.

\begin{tabular}{|c|c|c|c|c|}
\hline Clinical variant & $\begin{array}{c}\text { General } \\
\text { frequency }\end{array}$ & $\begin{array}{l}\lg \\
\text { subtype }\end{array}$ & Autoantigen & Clinical hallmarks \\
\hline Pemphigus vulgaris & 70 to $90 \%$ & $\lg G$ & Dsg3, Dsg1 & $\begin{array}{l}\text { Mainly oral mucosal lesions affecting the gingiva, palate, floor } \\
\text { of the mouth, buccal mucosa, lips, tongue, nasal, pharyngeal, } \\
\text { laryngo-oesophageal, urethral, genital (glans penis, vulva), } \\
\text { perianal and conjunctival mucosae }\end{array}$ \\
\hline $\begin{array}{l}\text { Pemphigus } \\
\text { foliaceus }\end{array}$ & 10 to $30 \%$ & $\lg G$ & Dsg1 & $\begin{array}{l}\text { Flaccid and fragile blisters involving skin; no mucous lesions; } \\
\text { erythroderma, puff pastry-like scales and crusts affecting } \\
\text { seborrheic areas (scalp, face, presternal, interscapular skin) }\end{array}$ \\
\hline $\begin{array}{l}\text { Paraneoplastic } \\
\text { pemphigus }\end{array}$ & $5 \%$ & $\lg G$ & $\begin{array}{l}\text { Dsg3, Dsg1, desmoplakin I and II, envoplakin, } \\
\text { periplakin, plectin, BP230, BP180, A2ML1, Dsc1, } \\
\text { epiplakin }\end{array}$ & $\begin{array}{l}\text { Severe mucocutaneous lesions with erosions and ulcers } \\
\text { involving tongue, lips and vermillion border, nasal, conjunctival } \\
\text { and genital mucosa; skin involvement are polymorphic, with } \\
\text { pustular, erythema multiform-like or lichenoid lesions; } \\
\text { association with lymphoproliferative disorder, lymphoma, } \\
\text { leukaemia, carcinomas, sarcomas }\end{array}$ \\
\hline $\begin{array}{l}\text { Pemphigus } \\
\text { vegetans }\end{array}$ & $1-2 \%$ & $\lg G$ & Dsg3, Dsg1, periplakin & $\begin{array}{l}\text { Hypertrophic papillomatous vegetative skin lesions affecting } \\
\text { intertriginous sites (axillae, inframammary folds, umbilicus, } \\
\text { inguinal creases, anogenital skin, scalp, neck), flaccid blisters } \\
\text { and erosions with fetid-odoured }\end{array}$ \\
\hline IgA pemphigus & $<2 \%$ & $\lg A$ & Dsg3, Dsg1, Dsc1 & $\begin{array}{l}\text { Annular erosive plaques, pustules affecting the skin of the } \\
\text { trunk, proximal extremities, and intertriginous regions; } \\
\text { uncommon mucosal involvement }\end{array}$ \\
\hline $\begin{array}{l}\text { Pemphigus } \\
\text { herpetiformis }\end{array}$ & $<2 \%$ & $\lg G$ & Dsg3, Dsg1, Dsc & $\begin{array}{l}\text { Pruritic herpetiform blisters, annular urticarial plaques with or } \\
\text { without erosions, scaly erosive patches mimicking eczema }\end{array}$ \\
\hline
\end{tabular}

Dsg, desmoglein; Dsc, desmocollin; BP230 or 180, bullous pemphigoid 230 or 180; A2ML1, $\alpha$-2 microglobulin-like 1.

Although clinically and aetiologically distinct, all pemphigus variants induce the formation of flaccid blisters and erosions on the skin and/or mucous membranes, and are characterised histologically by acantholysis, in which keratinocytes separate from each other (Amagai et al., 1991). In this case, acantholysis is caused by autoimmune disruption of the desmosomes specialized adhesive protein complexes that connect neighbouring keratinocytes to each other - as a result of the generation and deposition of IgG auto antibodies against the desmosomal structural proteins desmoglein (Dsg) 1 and/or Dsg3 (Amagai et al., 1991). While the main antigenic targets of these autoimmune skin conditions were discovered several decades ago, our understanding of the factors underpinning the initiation and progression of pemphigus remains incomplete. Moreover, despite recent advances in the treatment of pemphigus, many patients continue to suffer repeated relapses of their condition and/or treatment side-effects, and a significant proportion of cases remain refractory to currently available therapies. Pemphigus mortality rates is elevated compared to the general population (Kridin et al., 2017; Jelti et al., 2019).

In this review we will bring together recent progress in our understanding of the aetiology and pathogenic mechanisms of pemphigus and note those areas in which our knowledge remains incomplete. We will also discuss the latest advances and clinical trials aiming to offer better treatment of this challenging set of diseases and highlight key areas for future research and development.

\section{THE PEMPHIGUS FAMILY OF AUTOIMMUNE SKIN DISEASES: CLINICAL FEATURES AND DIAGNOSIS}

All patients with pemphigus variants exhibit autoantibodies against desmosomal structural proteins, but the discrimination of each variant is based on specificities in clinical presentation and/or histological features or in most commonly autoantibodies encountered (Hertl et al., 2015) (Table 1). Understanding the features that distinguish between variants and sub-variants is necessary to allow accurate and rapid diagnosis; moreover, it is hoped that, as we increased our understanding, variant-specific therapies will begin to emerge as part of personalised treatment strategies that take into account any comorbidities in this fragile patient population.

\section{Pemphigus Vulgaris}

Pemphigus vulgaris (PV) ("vulgus" which means "common" in Latin) accounts for up to $70 \%$ of pemphigus cases (Joly and Litrowski, 2011; Jelti et al., 2019) with an estimated incidence of between one and five cases per million inhabitants per year (Bastuji-Garin et al., 1995, 1996; Jelti et al., 2019). However, incidence varies greatly between different regions and ethnicities: while PV occurs at a rate of less than 0.76 per million population in Finland or less than 0.5 per million population in Germany (Hübner et al., 2016), its incidence is more than twenty times higher in the United States and Israel (Hammers and Stanley, 
A

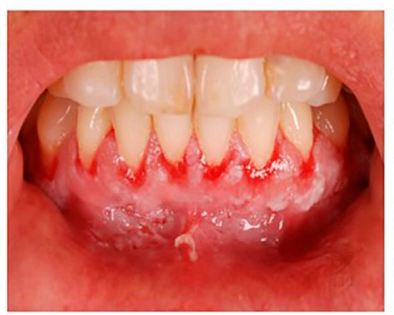

C

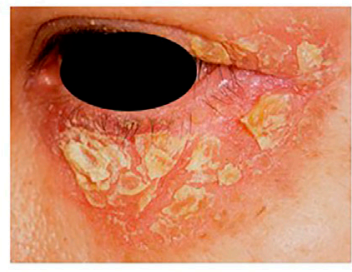

D1

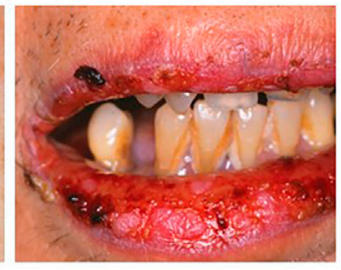

D2

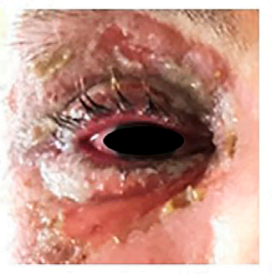

D3

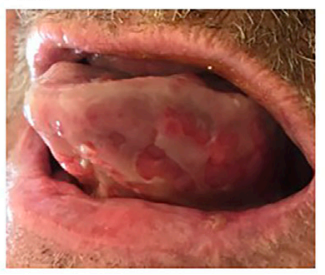

E

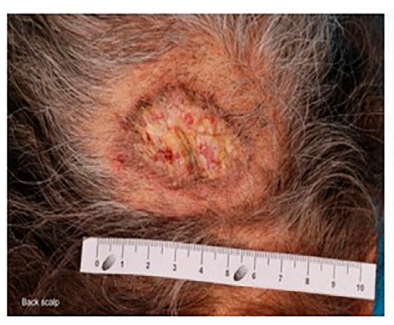

F

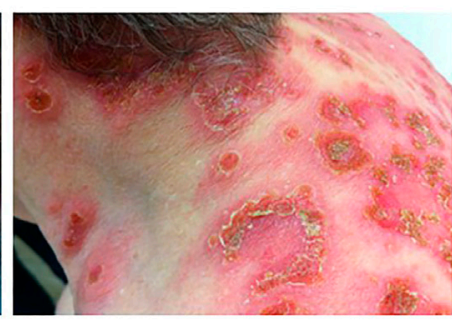

G

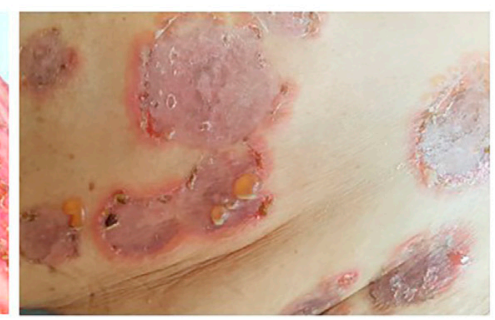

FIGURE 1 | Erosions of the alvealor gingiva and attached mucosa (A) and conjuctival involvement with episcleritis (B) in patients with pemphigus vulgaris. Puff pastry-like scales and crusts on the periorbital skin of a patient with pemphigus foliaceus (C). Severe stomatitis crusting and bleeding erosions on the lips that extended beyond the vermilion (D1), severe pseudomembranous conjuctivitis with mucus discharge and eyelid erosions (D2), diffuse lingual erotions (D3) in patient with paraneoplastics pemphigus. Vegetative plaque of pemphigus vegetans on the patient's occipital scalp (E). Post-pustular crusts with rounded or annular disposition in the trunk and neck in a patient with profuse IgA pemphigus (F). Trunk lesions with annular lesions in a pemphigus herpetiformis patient (G).

2016; Kridin, 2018). Regardless of the population, PV typically affects adults between the age of 45 and 65 years, with a slight female predominance (Joly and Litrowski, 2011; Didona et al., 2019). PV cases are extremely rare in children and its incidence increases with age (Kneisel and Hertl, 2011b). Almost all PV cases will develop oral mucosal lesions during the course of the disease; oral mucosal lesions being the first site involved in more $50-70 \%$ (Shamim et al., 2008; Pollmann et al., 2018) with lesions affecting the gingiva, palate, floor of the mouth, buccal mucosa, lips and tongue (Kneisel and Hertl, 2011a). Blistering in these sites can cause symptoms ranging from mild discomfort to such severe pain during eating that rapid weight loss ensues. Other mucous membranes may also be involved, including the nasal, pharyngeal, laryngo-oesophageal, urethral, genital (glans penis, vulva), perianal and conjunctival mucosae (Bystryn and Rudolph, 2005; Kneisel and Hertl, 2011a) (Figures 1A,B).

In muco-cutaneous variants, non-scarring skin lesions (flaccid blisters, crusts, erosions) arise during the course of the disease. Although any parts of the body can be affected, the predilection sites of PV lesions encompass face, neck, axillary folds, scalp and trunk, notably in seborrheic areas or exposed to mechanical stress. Recent studies have also revealed other manifestations, such as nail involvement in patients with extensive disease (Pietkiewicz et al., 2018; De et al., 2019), and postinflammatory hyperpigmentation that can last for months in patients with darker skin (Tamazian and Simpson, 2020). In case of cutaneous involvement, erosions can be induced in perilesional skin by applying tangential pressure, also known as Nikolsky's sign. The diagnosis of pemphigus is evoked upon clinical examination; histological analysis of a skin/mucous membrane biopsy taken in a lesional area and showing acantholysis is required to support the diagnosis. Direct immunofluorescence examination of biopsy samples taken in perilesional areas is considered the "gold standard" to confirm PV diagnosis, revealing intercellular deposits of $\mathrm{IgG}$ and/or $\mathrm{C} 3$ on the surface of keratinocytes in the epidermis or mucosa (Harman et al., 2017; Joly et al., 2020), but with the disadvantage of requiring invasive sampling. Additional immunological tests are carried out in parallel, including detection of autoantibodies in serum targeting the epithelial cell by indirect immunofluorescence (IIF) on monkey oesophagus or human skin, and by enzyme-linked immunosorbent assays (ELISA) to 
detect circulating anti-desmoglein autoantibodies surface (antiDsg3 alone where there is mucosal involvement only, or antiDsg3 and anti-Dsg 1 in patients with mucocutaneous disease) (Joly et al., 2020). Of note, anti-Dsg ELISA is positive in 95\% of cases and anti-Dsg values correlate with disease activity (Joly et al., 2020).

\section{Pemphigus Foliaceus}

Pemphigus foliaceus (PF) ("folium" meaning "leaf" in Latin) is the second most common type of pemphigus and accounts for 27\% of cases in France (Gonçalves et al., 2011; Jelti et al., 2019). Unlike PV, PF overall affects a broader age range of individuals due to the varied age of onset of several PF sub-variants (Chapman et al., 2018). PF-associated acantholysis occurs within the subcorneal layer of the epidermis, leading to more flaccid and fragile blisters that involve the skin and spare the mucous membranes (Joly and Litrowski, 2011). PF blistering and erosions typically exhibit "puff pastry-like" scales and crusts which tend to affect the seborrheic areas on the body: the scalp, face, presternal and interscapular skin (Figure 1C). In severe forms, PF might present as an erythroderma (chronic erythema involving more than $90 \%$ of the body's surface area), in contrast with the large erosive areas found in PV. Subcorneal pustules or acantholytic clefts in the granular layer of the epidermis are distinguishing histological features of PF, which are important because both direct and indirect immunofluorescence findings are similar to those seen in PV. However, only anti-Dsg1 antibodies are present, accounting for the absence of mucosal lesions in PF (see Dsg 1/Dsg 3 compensation theory, below, and Mahoney et al. (1999)).

Several clinical sub-variants of PF which have been characterised have interesting and distinctive features. Notably, pemphigus erythematosus (PE) (also known as Senear-Usher syndrome) has a milder presentation with lesions often confined to or first seen in the malar area of the face in a butterfly shape, as typically found in lupus erythematosus (Amerian and Ahmed, 1985; Khachemoune et al., 2006; Hobbs et al., 2021). More extensive involvement might be seen in photodistributed areas. Patients with PE also present with laboratory findings suggestive of systemic lupus erythematosus, including the presence of anti-nuclear antibodies in $30-80 \%$ of cases (Malik and Ahmed, 2007; Oktarina et al., 2012; Pérez-Pérez et al., 2012). It is not yet known how or whether these antibodies are related to the pathology seen in PE.

In addition to $\mathrm{PE}$, three $\mathrm{PF}$ sub-variants restricted to particular locations or populations have been described. The first such "endemic" form to be described, in 1903, was fogo selvagem, which is found in subtropical areas of Brazil (Diaz et al., 1989; Aoki et al., 2015), where its prevalence can be as high as $3-5 \%$ of inhabitants (Gonçalves et al., 2011). While PF in children is generally rare (Kanwar and Kaur, 1991; Mintz and Morel, 2011), up to $30 \%$ of those affected by fogo selvagem are children or young adults (Diaz et al., 1989; Aoki et al., 2015). Colombian pemphigus foliaceus is a PF sub-variant that occurs within the El Bagre area of Northern Colombia (Abrèu-Velez et al., 2003a; Abrèu-Velez et al., 2003b), and closely resembles fogo selvagem, except for its male preponderance (Abrèu-Velez et al., 2003b).
The third endemic form is found in north African Arab countries, mostly in the southern area of Tunisia but also in Algeria and Morocco (Morini et al., 1993; Abida et al., 2009), and some subSaharan countries, such as Mali (Mahé et al., 1996). A predominance of cases among young women aged 25 to 34 years had been described in Tunisia (Bastuji-Garin et al., 1995, 1996) and familial cases have also been reported (Morini et al., 1993). The geographical restriction, the age and the more extensive lesions of these sub-variants pose intriguing questions on the aetiology of the disease, which in some cases has been partially resolved (see below).

\section{Paraneoplastic Pemphigus}

Paraneoplastic pemphigus (PNP) was first recognised in 1990 (Anhalt et al., 1990), and represents about 5\% of pemphigus cases (Paolino et al., 2017). PNP is seen almost exclusively in patients with co-occurring neoplasms including lymphoproliferative disorders such as Castleman's disease and non-Hodgkin lymphoma, as well as thymoma, chronic lymphocytic leukaemia, and various carcinomas and sarcomas (Anhalt et al., 1990; Joly et al., 2000; Leger et al., 2012; Ohzono et al., 2015; Yatim et al., 2019). PNP predominantly affects patients between 45 and 70 years of age, but may also occur in children, particularly when associated with Castleman's disease (Wieczorek and Czernik, 2016). The condition typically presents as PV with severe mucocutaneous lesions, often with erosions and ulcers involving the tongue, and lesions on the lips that frequently extend to the vermillion border (Yatim et al., 2019). Other mucous membrane, such nasal, conjunctival and genital mucosa, may also be involved (Yatim et al., 2019): alongside, PNP-suggestive features of skin involvement are polymorphic, with pustular, erythema multiform-like or lichenoid lesions in addition to the classical flaccid bullous form and typical erosions (Anhalt, 2004; Leger et al., 2012; Ohzono et al., 2015) (Figures 1D1-D3). PNP may also affect internal organs, particularly the lung, and, more rarely, the gastrointestinal mucosa (Odani et al., 2020). The severity of PNP, possibility of multi-organ involvement, and cooccurrence with underlying malignancy together combine to give a high mortality rate (Leger et al., 2012; Ohzono et al., 2015; Wieczorek and Czernik, 2016; Jelti et al., 2019).

Histologically, PNP is characterized by a "tombstone" appearance of acantholytic basal keratinocytes, associated with an interface or lichenoid dermatitis caused by self-reactive CD $4^{+}$ and $\mathrm{CD}^{+} \mathrm{T}$ cells, and with epidermal exocytosis and dyskeratotic or necrotic keratinocytes (Joly et al., 2020). Linear IgG/C3 deposits at the dermal-epidermal junction might also be present, in addition to positive intercellular labelling of the epithelium by DIF (Joly et al., 2020). Patients with PNP may develop IgG autoantibodies against a diverse array of antigens, including: Dsg3 (Amagai et al., 1998; Brandt et al., 2012), and several members of the plakin family (Mahoney et al., 1998) including the desmosomal plaque proteins desmoplakin I and II (Hashimoto et al., 1995), envoplakin (Kim et al., 1997), periplakin (Mahoney et al., 1998; Kazerounian et al., 2000), as well as against hemi-desmosomal adhesion molecules such as plectin and bullous pemphigoid antigen (BP) 230 (also known as 
dystonin-e), BP180 (also known as collagen $\alpha-1[\mathrm{XVII}]$ chain) (Maier et al., 2017) and the proteinase inhibitor a2macroglobulin-like protein 1 (Schepens et al., 2010). In addition, approximately $75 \%$ of patients exhibit antibodies against desmocollins (Dsc) 1, 2 or 3 (Ishii et al., 2015; Ohzono et al., 2015). Anti-epiplakin antibodies are especially significant, both clinically and diagnostically as they are thought to be responsible for the occurrence of often-fatal bronchiolitis obliterans, which results from loss of adhesion of the lung epithelium (Tsuchisaka et al., 2016; Tsuchisaka et al., 2016). Considering these immunological features of PNP, IIF examination of the serum is usually performed using rat bladder to investigate reactivity against plakin proteins (Joly et al., 2000). ELISA for anti-Dsg and anti-envoplakin antibodies are usually made with immunoblots with epidermal extracts or extracts from cultured keratinocytes to investigate IgG reactivity against other antigens, especially anti-plakins (Probst et al., 2009; Joly et al., 2020). In the case of PNP, co-morbid malignancy is clear, and for some time the mechanism of association has been known. The emergence of PNP appears to be related to the generation of antibodies against tumour antigens which cross-react with epithelial antigens, including both desmosomal and hemi-desmosomal proteins. This process is similarly seen in the case of some environmental antigens (see below) in endemic PV, but similar "trigger antigens" have yet to be investigated or defined in other pemphigus variants.

\section{Pemphigus Vegetans}

Pemphigus vegetans, a rare clinical variant of $\mathrm{PV}$ which represents $1-2 \%$ of all pemphigus cases (von Köckritz et al., 2017). Due to it's rarity, only few papers in the literature are specifically devoted to it with most of them are case reports (Mergler et al., 2017; Cuellar et al., 2020; Liu et al., 2020; Verma et al., 2020). Pemphigus vegetans is characterized by hypertrophic papillomatous vegetative skin lesions that preferentially affect intertriginous sites, such as the axillae, inframammary folds, umbilicus, inguinal creases, anogenital skin, scalp, and neck (Jain et al., 1989; Huang et al., 2005; Cozzani et al., 2007) (Figure 1E). Depending on the morphology of the initial lesions and the clinical course, pemphigus vegetans is further subdivided into two types: Neumann and Hallopeau. The Neumann type presents with flaccid blisters and erosions, evolving into fetid-odoured, whitish, macerated, hypertrophic, papillomatous plaques in the intertriginous body folds and lips, and more rarely on the trunk and extremities; the oral mucosa is usually involved (Leroy et al., 1982; Ahmed and Blose, 1984). By contrast, the Hallopeau type is associated with localised, pustular lesions that rupture and coalesce into vegetative erosions, and does not exhibit oral mucosa involvement (Zaraa et al., 2011; Imchen et al., 2014). Autoantibodies in pemphigus vegetans are against Dsg1 and Dsg3, as well as other proteins constituting the desmosome (Hashimoto et al., 1994; Cozzani et al., 2007).

\section{IgA Pemphigus}

IgA pemphigus, even rarer among the pemphigus family, is characterized clinically by annular erosive plaques rimmed by pustules and affects the skin of the trunk, proximal extremities, and intertriginous regions (Figure 1F) (Geller et al., 2014). Mucosal involvement is uncommon (Kridin et al., 2020) and acantholysis is usually absent (Tsuruta et al., 2011). Here, IgA autoantibodies recognising various dermosomal proteins bind the epidermal cell surface and are detectable by direct immunofluorescence; while immune-serological assays are used to detect circulating IgA autoantibodies in these patients (Nishikawa et al., 1991; Geller et al., 2014). Depending on the level of pustule formation, IgA pemphigus can be divided into two major clinical and histological subtypes: intraepidermal neutrophilic dermatosis (IEN), which is characterized by suprabasilar pustules located at the lower or entire epidermis and associated with the presence of IgA antibodies against Dsg1 or Dsg3, and other yet-unidentified antigens; and subcorneal pustular dermatosis (SPD), in which patients exhibit subcorneal pustules in the upper epidermis and auto-reactive IgA binds desmocollin 1 (Dsc1) (Hashimoto et al., 1997; Karpati et al., 2000; Yasuda et al., 2000). IgA pemphigus may also be associated with IgA gammopathies, haematological disorders and ulcerative colitis (Hashimoto et al., 1997; Kridin et al., 2020).

\section{Neonatal Pemphigus Vulgaris}

Neonatal pemphigus vulgaris (NPV) is a transient immunobullous disease induced by transplacental transfer of maternal autoantibodies from a mother with PV to her newborn (Fenniche et al., 2006; Gushi et al., 2008; Turrentine et al., 2014; Carvalho et al., 2019; Fenner et al., 2020; Foster et al., 2021). First reported in 1975 (Salihbegović-Opalić et al., 1975; Zhao et al., 2016), few cases exist in the literature, as female patients with pemphigus can experience infertility, premature delivery and stillbirth (Ouahes et al., 1997). NPV has various clinical manifestations, including skin and mucosa defects, blisters and erosions at birth, and extensive skin exfoliation which can arise early after birth. As maternal-derived antibody levels drop, NPV resolves spontaneously or with mild topical corticosteroid treatment within 4 weeks of birth (Kardos et al., 2009). Importantly, before the development of the neonatal mouse model of PV, clinical observation of NPV gave the first evidence of the direct pathogenicity of pemphigus autoantibodies.

\section{Pemphigus Herpetiformis}

Pemphigus herpetiformis (PH), first named in 1975 (Jablonska et al., 1975), is a rare subtype of pemphigus. It clinically resembles to dermatitis herpetiformis, with patients exhibiting pruritic herpetiform blisters, and/or annular urticarial plaques with or without erosions, or scaly erosive patches mimicking eczema (Tay et al., 2018) (Figure 1G). However, immunological findings are consistent with pemphigus (Kasperkiewicz et al., 2014; Costa et al., 2019). Direct and indirect immunofluorescence demonstrate intercellular deposits of IgG and/or C3, with Dsg as the main target of autoantibodies, with additional recognition of Dsc (1,2 3) and other hemidesmosomal antigens, seen in some patients (Kozlowska et al., 2003; Ohata et al., 2013; Ueda et al., 2013; On et al., 2015). The histology of PH is less specific than that of PV and ranges from intraepidermal eosinophils or neutrophilic spongiosis (Hashimoto et al., 1983) to intraepidermal vesicles 
filled with neutrophils or eosinophils, and may also encompass dermal papillary micro-abscesses (Costa et al., 2019).

\section{THE PATHWAY TO PEMPHIGUS: RISK FACTORS FOR DEVELOPING THE DISEASE}

Many autoimmune diseases have a complex aetiology, and pemphigus is no exception. Factors as diverse as genetics, environment, pre-existing health conditions, medication use and even post-vaccine reactions have been linked with the emergence of pemphigus. In this section we will review some of the most recent observations that are building up the picture of circumstances and pathways leading to the clinical manifestation of pemphigus.

\section{Genetic Risk Factors}

The familial clustering of certain variants of pemphigus, combined with its predilection for some ethnicities and cooccurrence of other autoimmune diseases in patients, all point towards a significant genetic component to susceptibility. To date, the strongest link has been reported for the association between PV and HLA class II genes (Gazit and Loewenthal, 2005; Tron et al., 2006; Vodo et al., 2018). Studies have shown that HLA alleles DRB1 ${ }^{\star}$ 04:02 and DQB1 ${ }^{\star}$ 05:03 represent the most common PV associated alleles (Ahmed et al., 1991; Carcassi et al., 1996; Delgado et al., 1996; Lee et al., 1998; Lombardi et al., 1999; Loiseau et al., 2000; Miyagawa et al., 2002; Geng et al., 2005; Liu et al., 2008; Shams et al., 2009; Tunca et al., 2010; Párnická et al., 2013; Brochado et al., 2016), with the majority of the patients with PV expressing one of these two alleles. While some of the HLA types are more population-specific, there are others that are associated with $\mathrm{PV}$ across numerous ethnic groups: a link between HLA-DRB1 ${ }^{\star} 04: 02$ and $\mathrm{DQB1} 1^{\star} 03: 02$ with $\mathrm{PV}$ in the Jewish population has been highlighted (Gazit and Loewenthal, 2005), while HLA-DQB1 ${ }^{\star} 05: 03$ was found in association with PV in non-Jewish populations (Ahmed et al., 1991). Studies in Han Chinese patients with PV have highlighted $\mathrm{DRB}^{\star}{ }^{\star} 04, \mathrm{DRB} 1^{\star} 14$ and $\mathrm{DQB} 1^{\star} 05: 03$ as relevant risk alleles (Zhou et al., 2003; Geng et al., 2005; Liu et al., 2008; Gao et al., 2018), as well as HLA-DRB ${ }^{\star} 03$ and $\mathrm{HLA}^{-\mathrm{CW}^{\star}} 14$ in the same Chinese population with PNP (Martel et al., 2003; Liu et al., 2008). Meta-analyses of the correlation between PV occurrence and HLA-DRB1 and HLA-DQB1 have shown that $\mathrm{DRB} 1^{\star} 04, \mathrm{DRB} 1^{\star} 08, \mathrm{DRB} 1^{\star} 14, \mathrm{DQB} 1^{\star} 03: 02$ and $\mathrm{DQB} 1^{\star} 05: 03$ are significant susceptibility factors for $\mathrm{PV}$ while $\mathrm{DRB} 1^{\star} 03$, $\mathrm{DRB}^{\star}{ }^{*} 7, \mathrm{DRB} 1{ }^{\star} 15, \mathrm{DQB} 1^{\star} 02, \mathrm{DQB}^{\star}{ }^{\star}$ 03:03, $\mathrm{DQB} 1^{\star} 05: 01$ and $\mathrm{DQB} 1^{\star} 06: 01$ were less common in patients with PV compared to healthy individuals (Yan et al., 2012; Li et al., 2018). In addition to HLA class II alleles, there may be some association between PV and certain HLA class I alleles within specific ethnic groups, for example, HLA-A10 and -B15 in the Japanese population (Hashimoto et al., 1977; Miyagawa et al., 2002), and HLA-A3, -A26, and -B60 in the Han Chinese population (Gao et al., 2018). However, although numerous studies have suggested that HLA status could be a key driver of pemphigus disease activity, the mechanistic link between the
HLA genetic profile and the clinical picture within patients remains unclear.

Alongside the HLA susceptibility studies, other research has uncovered associations between PV and autoantigen or immune gene sequences: specific Dsg3 haplotypes were significantly linked with PV in both British and Indian cohorts (Capon et al., 2006); while single nucleotide polymorphisms within the variable region of the immunoglobulin heavy chain $\mathrm{VH} 3$ gene were associated with PF in two patients (Yamagami et al., 2009). Genetic variants of the cytokine genes TNF- $\alpha, I L-6$ and $I L-10$ gene have also been linked with PV (Torzecka et al., 2003; Pereira et al., 2004; Eberhard et al., 2005; Mosaad et al., 2012; Toumi et al., 2013; Dar et al., 2016; Vodo et al., 2016); as have those affecting the TAP2 gene, which encodes a protein involved in peptide assembly and transport to HLA class I (Niizeki et al., 2004; Slomov et al., 2005). Immune-associated SNPs that have been linked with pemphigus include those within the ST18 gene, which encodes a transcription factor involved in inflammation and apoptosis (Sarig et al., 2012; Vodo et al., 2016; Etesami et al., 2018; De Bonis et al., 2019; Radeva et al., 2019; Assaf et al., 2021); and those within the CTLA4 and CD86 genes, whose protein products are expressed on antigen-presenting cells (APC) and are involved in activating T-cells and stimulating IgG production by $\mathrm{B}$ cells (Dalla-Costa et al., 2010; Tanasilovic et al., 2017).

While strong linkages have been found to exist between pemphigus and some of the above HLAs, the vast majority of individuals who carry the PV-associated HLA susceptibility alleles do not develop the disease. This prompted a group of researchers to discover a subset of PV-related differentially expressed genes which suggests a "protection" signature in genetically susceptible individuals from developing PV (DeyRao et al., 2013).

Knowing the genetic susceptibility in pemphigus may spur further research to better understand the interactions between various genetic susceptibility factors, the role of epigenetics and the functional effects of the identified genetic variants in diseaserelevant cells, and hopefully, ultimately, their influence on response to treatment and severity of disease (Petzl-Erler, 2020).

\section{Environmental Risk Factors}

The lived-in environment is a complex mixture of factors that act across time and space, interacting with genetic susceptibility to affect health outcomes. Studying this intricate web of influences has led to the identification of significant factors linked with the development of pemphigus in specific populations.

In the case of endemic pemphigus foliaceus in Brazil, the observation that many of the adults affected by fogo selvagem were outdoor workers living in conditions of poor hygiene and low-quality housing, built in forest areas adjacent to rivers and streams (Diaz et al., 1989; Aoki et al., 2015), led researchers to seek environmental factors causing the disease. These investigations resulted in the identification of sand flies as a triggering factor the salivary protein LJM11 of Lutzomyia longipalpis (also known as black fly) (Culton et al., 2008) cross reacts with Dsg1 (Warren et al., 2000; Qian et al., 2012).

Ultraviolet radiation has been reported to exacerbate or cause new-onset of pemphigus (Fryer and Lebwohl, 1994; Muramatsu 
et al., 1996; Aghassi, 1998; Kano et al., 2000; Makino et al., 2014). A study using medical records review showed that the majority of pemphigus patients had the first manifestation of their disease in spring and summer of Sofia, Bulgaria (Tsankov et al., 2000). Hospitalisation primarily for pemphigus was also noted to be higher in days with higher UV index for Hispanic pemphigus patients in United States (Ren et al., 2019). In a more recent study which looked at seasonal patterns and triggering factors in nonendemic pemphigus foliaceous in Turkey (Sayar and Küçükoğlu, 2021), it was also observed that new onset and relapses of nonendemic pemphigus foliaceous occurred more often during the spring-summer season where UV radiation is at its peak, further supporting the possible role of UV radiation as a trigger factor in this disease. While it has been demonstrated that UVB induces acantholysis and epidermal intercellular deposition of immunoreactants in Fogo selvagem patients (Reis et al., 2000), the molecular pathway still needs to be fully elucidated.

Other environmental risk factors for the development of pemphigus include trauma (Daneshpazhooh et al., 2016), stress (Cremniter et al., 1998; Morell-Dubois et al., 2008), diet (Ruocco et al., 2001). Interestingly, smoking seems to confer a protective effect on pemphigus (Valikhani et al., 2007). Cigarette smoking has also been found to improve pemphigus disease and those who smoked had earlier disease remission (Valikhani et al., 2008). It is postulated that interaction of nicotine and other nicotinic agonists with nicotinic acetylcholine receptors on keratinocytes may promote cell-cell adherence (Grando and Dahl, 2000).

\section{Therapeutic Risk Factors}

Drugs have been reported to trigger pemphigus. The three main groups of drugs which has been reported to be associated with new onset or exacerbation of pemphigus are the thiol drugs, phenol drugs and non-thiol/non-phenol drugs. Thiol drugs have sulfhydryl (-SH) group in their chemical structure and are probably the better studied group of drugs in the pathogenesis of pemphigus. In a systematic review of 170 drug-induced pemphigus (Ghaedi et al., 2021), penicillamine, captopril and bucillamine, which belong to the thiol drugs, were the most commonly reported drugs to induce pemphigus.

Biological thiol substances such as cysteine and glutathione has been shown to induce acantholysis in human skin fragments under certain experimental conditions (Ruocco et al., 1982). In vitro experiments subsequently demonstrated that thiol drugs (D-penicillamine, captopril, thiopronine and piroxicam) induce acantholytic splitting in human skin fragments or skin cultures in the absence of pemphigus antibodies (i.e biochemical acantholysis) (Ruocco et al., 1993). It is postulated that thiol drugs form drugcysteine disulfides which directly interfere with desmoglein adhesions between keratinocytes, or indirectly through antigen modification and autoantibodies production (Wolf and Ruocco, 1997). Plasminogen activator inhibitor, a proteolytic enzyme, has been shown to be important in preventing immunoglobulin-induced acantholysis in pemphigus (Hashimoto et al., 1989). Thiol drugs, on the other hand, stimulate plasminogen activator through inhibition of their natural inhibitors, leading to promotion of acantholysis (Hashimoto et al., 1984; Lombardi et al., 1993).
Other than drugs, vaccines have also been reported to trigger or exacerbate pemphigus. Amongst them are influenza (Mignogna et al., 2000; De Simone et al., 2008), hepatitis B (Berkun et al., 2005), rabies (Yalçin and Alli, 2007), tetanus (Cozzani et al., 2002) and more recently, SARS-COV2 vaccines (Damiani et al., 2021; Koutlas et al., 2021; Lua et al., 2021; Solimani et al., 2021; Thongprasom et al., 2021). While the mechanisms behind vaccine-induced pemphigus has not been worked out, there are several hypotheses other than those proposed for drug-induced pemphigus. These include autoimmunity arising from molecular mimicry of vaccines or their adjuvants with self-antigens (Shoenfeld et al., 2000), and non-specific activation of innate immunity and expansion of autoreactive $\mathrm{T}$ cells (Horwitz and Sarvetnick, 1999). It is however interesting to note that infections which these vaccines are used against, have not been reported as triggers for pemphigus (Brenner et al., 2002).

\section{AUTOIMMUNE PATHWAYS AND PROCESSES IN PEMPHIGUS}

\section{Autoantibodies}

Following the identification of Dsg 1 and 3 as critical pemphigus autoantigens (Eyre and Stanley, 1987, 1988; Hashimoto et al., 1990; Amagai et al., 1991; Mahoney et al., 1999; Amagai and Stanley, 2012), many studies have investigated the autoantibodies and autoreactive $B$ cells that drive pemphigus pathogenesis. The extracellular domains, EC1 and EC2, of Dsg have been defined as the main target region recognised by autoantibodies from pemphigus patients (Amagai et al., 1992, 1995; Futei et al., 2000; Sekiguchi et al., 2001; Payne et al., 2005; Ishii et al., 2008; Chan et al., 2010; Di Zenzo et al., 2012), with some evidence of minor EC4 recognition, and IgG4 is now known to be the major pathogenic antibody isotype (Dmochowski et al., 1992; Allen et al., 1993; Wilson et al., 1993). However, other isotypes may also be pathogenic in some variants or circumstances (Payne et al., 2005; Saleh et al., 2015). Interesting new data have revealed that DSG3-specific memory $B$ cells have an activated phenotype and show signs of ongoing affinity maturation and clonal selection (Cho et al., 2019).

Although Dsg-specific autoantibody titre was long-thought to correlate with disease activity in pemphigus (Amagai et al., 1999; Daneshpazhooh et al., 2007; Abasq et al., 2009; Schmidt et al., 2010), more recent studies have detected anti-Dsg3 IgG antibodies in patients who were in clinical remission, suggesting the existence of non-pathogenic Dsg-specific IgG (Belloni-Fortina et al., 2009; Yoshida et al., 2017; Chernyavsky et al., 2019). This concept of pathogenicity has been confirmed by in vivo and in vitro studies demonstrating that pathogenic IgG autoantibodies preferentially target the $\mathrm{NH} 2$-terminal portion of Dsg3. Non-pathogenic autoantibodies recognize epitopes of the membrane proximal $\mathrm{COOH}$-terminus of the Dsg ectodomains (Amagai et al., 1992; Futei et al., 2000; Bhol and Razzaque Ahmed, 2002; Tsunoda et al., 2003; Chan et al., 2010; Lo et al., 2016). Comparing conventional and EDTA-pretreated anti-Dsg3 commercial ELISA, Kamiya et al. demonstrated the presence 


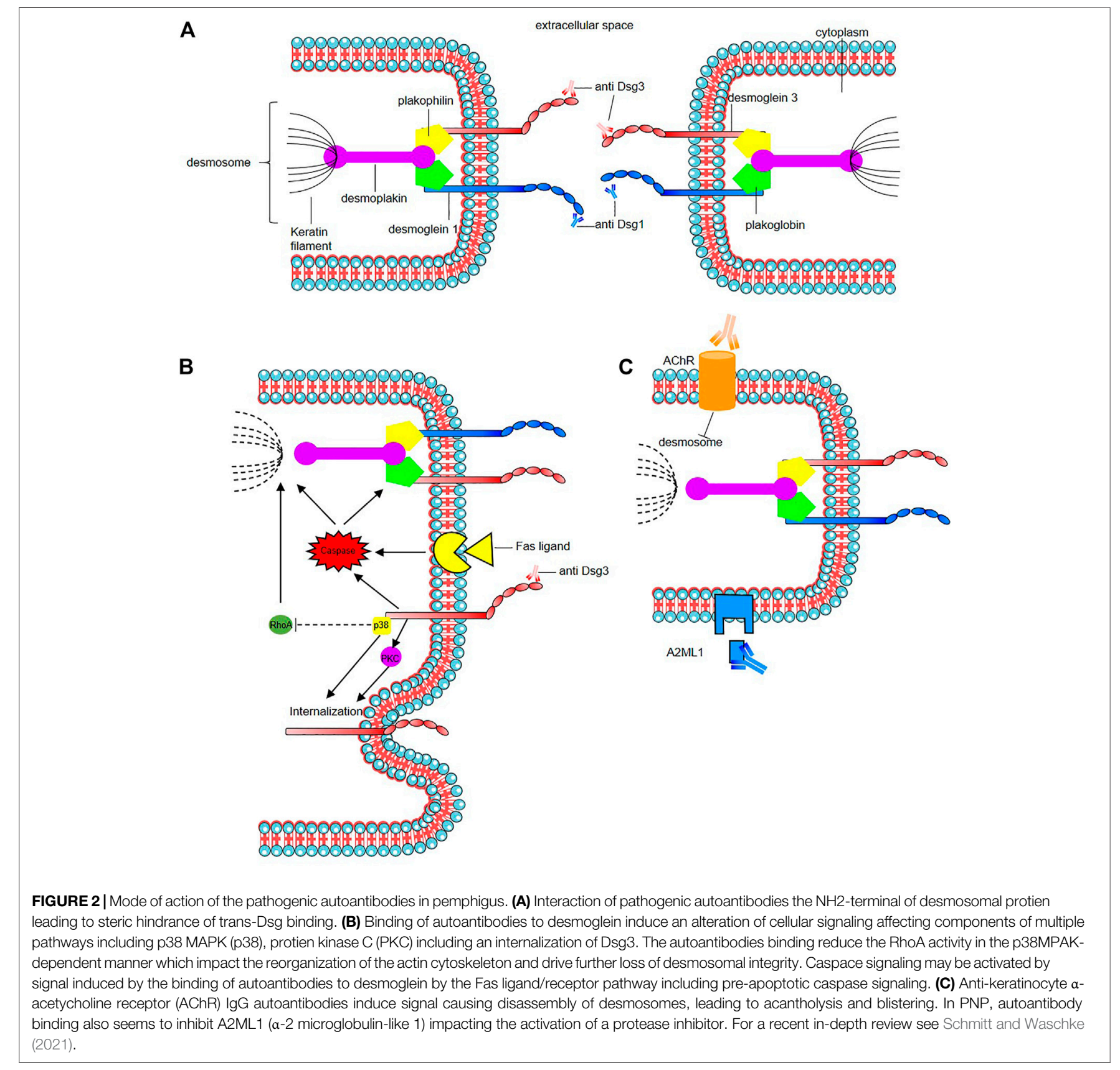

of anti-Dsg antibodies directed against calcium-dependent epitopes targeting the extracellular domains of Dsg3 (Kamiya et al., 2012) and found a higher correlation between antibodies against calcium-dependent epitopes of Dsg3 and clinical activity than with total anti-Dsg3 antibodies (Kamiya et al., 2013). The pathogenic activity of these IgG directed against Ca-dependent epitope is sustained by their ability to induce the keratinocyte dissociation in vivo (Kamiya et al., 2012).

In PF and PV subtypes, Dsg1 and Dsg3 specific antibodies might directly affect the clinical presentation due to their differential expression in skin and mucous membranes. While patients with PV often experience mucosal and cutaneous blistering, and possess both anti-Dsg1 and anti-Dsg3 antibodies, those with PF have antibodies only to Dsg1 and present with cutaneous but not mucosal involvement. Dsg1 is mainly expressed in the upper epidermis and upper layers of the mucosa, while Dsg3 is predominantly expressed in the suprabasal layers of the epidermis and throughout the mucosal epithelium. This differential expression of Dsg1 and Dsg3 in the epidermis and mucosa together with the postulation that the Dsg can compensate for each other's adhesive function when expressed on the same keratinocyte: this is the Dsg1/Dsg3 compensation theory (Amagai, 2009; Amagai and Stanley, 2012). Unfortunately, this concept cannot explain all clinical forms of pemphigus, 
especially those with atypical features, and the factors affecting the ability or extent of functional compensation have yet to be revealed. With better immunological profiling of pemphigus, a modification of the compensation theory and new alternative pathogenic mechanisms need to be evaluated (Koga et al., 2012; Sardana et al., 2013; Carew and Wagner, 2014; Ahmed et al., 2016; Öktem et al., 2018).

The mode of action of the pathogenic autoantibodies found in pemphigus patients is now also well-defined (Figure 2). The desmosomal depletion that leads to acantholysis can be divided into two major mechanisms: firstly, the interaction of $\mathrm{IgG}$ autoantibodies with the NH2-terminal EC1 subdomains of Dsg1 and Dsg3 in PF and PV, respectively, leads to steric hindrance of trans-Dsg binding (Heupel et al., 2008; Jennings et al., 2011; Saito et al., 2012), and also disrupts the interaction between Dsg and flotillin (Völlner et al., 2016), together leading to the loss of desmosomal integrity (Figure 2A). The second mechanism is an alteration to cellular signalling that is induced by autoantibody binding affecting components of multiple pathways including p38 MAPK, protein kinase $\mathrm{C}$ (PKC), c-Jun N-terminal kinases (JNK), RhoA and caspases 3, 6, 8 and 9, which leads to Dsg endocytosis and depletion driving further loss of desmosomal integrity and adhesion (Puviani et al., 2003; Berkowitz et al., 2005, 2006, 2008; Frušić-Zlotkin et al., 2005; Kawasaki et al., 2006; Lee et al., 2009; Cirillo et al., 2010; Mao et al., 2011) (Figure 2B). In PNP, autoantibody binding also seems to inhibit A2ML1 ( $\alpha-2$ microglobulin-like 1) impacting the activation of a protease inhibitor (Inaoki et al., 2001; Schepens et al., 2010; Numata et al., 2013) (Figure 2C). For a recent indepth review of this topic see (Schmitt and Waschke, 2021).

In addition to anti-Dsg IgG autoantibodies, various antibodies targeting other autoantigens have been identified, notably with proteomics studies (Kalantari-Dehaghi et al., 2013), in the sera of a minority of patients with various forms of pemphigus with an unclear pathogenic role (Nguyen et al., 2000b; Ahmed et al., 2016; Amber et al., 2018). IgG and IgA autoantibodies against desmocollins (Dsc1, Dsc2 and Dsc3 being $\mathrm{Ca}^{2}+$-dependent cadherins involved in desmosome assembly) have been detected in variable percentage of pemphigus patients (5-60\%), according cohorts, Dsc subfamily and the type of pemphigus variant (Dmochowski et al., 1993; Müller et al., 2009; Ishii et al., 2015; Mindorf et al., 2017). Their rates are higher in rare variants such as IgA pemphigus, PNP, and pemphigus herpetiformis (Hashimoto et al., 1997; Müller et al., 2009; Ishii et al., 2015; Mindorf et al., 2017). It has been demonstrated that anti-Dsc3 react against extra cellular domains of Dsc3 in human skin model resulting in intraepidermal blister formation, and in loss of intercellular cohesion in keratinocyte culture induced by targeting of the Dsc3/Dsg1 binding on keratinocyte cell surface as Dsc and Dsg are interacting by homophilic and heterophilic trans-interaction (Spindler et al., 2009). Anti-keratinocyte $a$-acetylcholine receptor (AChR) IgG autoantibodies have been also reported in $85 \%$ of $\mathrm{PV}$ and $\mathrm{PF}$ patients (Nguyen et al., 1998; Lakshmi et al., 2017). Inhibition of these receptors which control keratinocyte adhesion and motility may induce signals causing disassembly of desmosomes, leading to acantholysis and blistering (Figure 2C). Autoantibodies against muscarinic AchRs but also against mitochondrial nAChR were found (Chernyavsky et al., 2015). A correlation of anti-muscarinic AchRs antibody titers and anti-Dsg antibody titers with the severity of disease in patients with pemphigus has been reported (Lakshmi et al., 2017). The role of these autoantibodies found in sera from pemphigus is unclear, as the fact that they could result from epitope spreading following the loss of tolerance or have a synergistic action with anti-Dsg in pemphigus pathogenesis (Nguyen et al., 2000a; Grando, 2000). Some react mainly against structural components of adhesion molecules such as desmosomes like autoantibodies against desmoplakin 1, desmoplakin 2 (Kim et al., 2001), Dsg4 (Kljuic et al., 2003; Nagasaka et al., 2004), E-cadherin (Evangelista et al., 2008; Oliveira et al., 2013), plakoglobin (Korman et al., 1989; Ishii et al., 2001), plakophilin 3 (Lambert et al., 2010), FCeR1 (Fiebiger et al., 1998), and pemphaxin (Nguyen et al., 2000a) while other impact protease inhibitors such as anti- A2ML1 or antihSPCA1 (Ca21/Mg21-ATPase encoded by ATP2C1 gene) which is involved in Golgi apparatus trafficking and of which impairment could lead to the impairment of proteic assembly and adress to the membrane as in hailey-hailey disease (KalantariDehaghi et al., 2013). Although mouse models have been designed to incorporate some of these autoantibodies (Chen et al., 2008; Rafei et al., 2011), their role in pemphigus pathogenesis is still unclear (Spindler et al., 2018) and more complex mouse model need to be designed.

\section{T Cells}

While autoantibodies produced by B cells are the key and direct pathogenic mediators of pemphigus, recent studies are beginning to illuminate the broader autoimmune picture, with an emphasis on the role of $\mathrm{T}$ cell subsets. The disruption of peripheral $\mathrm{T}$ cellmediated tolerance to self-antigens can be a critical event leading to autoantibody generation, inflammation, and tissue infiltration by immune cells: thus, a role for autoreactive helper $\mathrm{T}$ cells in driving pemphigus has long been postulated. Patients with pemphigus possess Dsg3-reactive Th1 and Th2 cells (Lin et al., 1997; Rizzo et al., 2005), with some studies finding comparable frequencies of the two subsets (Eming et al., 2000), and others detecting greater numbers of autoreactive Th1 compared to Th2 cells (Veldman et al., 2003). Studies in a humanized HLADRB ${ }^{\star} 04: 02$ transgenic mouse model showed that T-lymphocytes recognize human desmoglein 3 epitopes in the context of HLA-DRB1 ${ }^{\star} 04: 02$ (Eming et al., 2014). This recognition was associated with a CD40-CD40L-dependent T-cell-B-cell interaction that lead to the induction of pathogenic IgG autoantibodies, which in turn triggered intraepidermal blister formation. Although it seems likely that both Dsg3-reactive Th1 and Th2 cell are important for pemphigus development, most studies have focused on the role of Th2 cells and shown them be critical for the development of the disease. Frequencies of Dsg3-reactive Th2 cells are significantly higher in patients than controls, and their levels are positively correlated with disease activity (Rizzo et al., 2005). In addition to Th2 cells, Th2 cytokine levels are significantly higher in the serum of patients with PV than 
controls, suggesting an imbalance between Dsg3-reactive Th2 and Th1 cells in the pathogenesis of PV (Satyam et al., 2009; Lee et al., 2017). However, the role of other $\mathrm{T}$ cell subsets in pemphigus pathogenesis remained unclear.

Th17 cells are identified by their specific expression of the transcription factor ROR $\gamma \mathrm{t}$ and have been implicated in the autoimmune pathology of a range of conditions including psoriasis (Fitch et al., 2007), ankylosing spondylitis (Taams et al., 2018) and, more recently, pemphigus (Xu et al., 2013; Timoteo et al., 2017; Jmaa et al., 2018). In patients with PV, the frequency of Th17 cells in the peripheral blood is significantly higher than in healthy controls, especially during the acute onset and active chronic stages (Holstein et al., 2021). Moreover, the levels of Th17-associated molecules (IL-17A and CCL20) in the serum, and the relative expression levels of ROR $\gamma \mathrm{t}$, CCR6 and CCL20 is also relatively higher in patients with PV than in controls (Asothai et al., 2015). Th17 cells are also present in lesional skin (Arakawa et al., 2009): accordingly, a comparison of the expression profiles of lesional versus perilesional and healthy skin from a patient with pemphigus identified an IL-17Adominated immune signature, with high expression of genes involved in the IL-17A signalling pathway (Holstein et al., 2021).

Alongside Th1, Th2 and Th17 cells are T follicular helper cells (Tfh): these are a subset of $\mathrm{CD}^{+} \mathrm{T}$ lymphocytes expressing the transcription factor BCL6, and CXCR5, which enable them to migrate into germinal centres where they are required for the selection of high-affinity antibody-producing $\mathrm{B}$ cells and the development of memory B cells (Morita et al., 2011; Craft, 2012). Tfh cells also express the surface receptors programmed cell death protein-1 (PD-1), inducible $\mathrm{T}$ cell costimulator, and CD40L, and secrete IL-21 to promote B cell growth, activation, immunoglobulin class-switching and differentiation into memory B cells and plasmablasts (Zotos et al., 2010). Early indications of a role for $\mathrm{Tfh}$ cells in pemphigus came from studies showing that the frequency of circulating Tfh cells (defined as $\mathrm{CD}^{+} \mathrm{CXCR}^{+} \mathrm{T}$ cells) and plasma concentrations of IL-21 were both significantly higher in patients with PV compared to controls (Holstein et al., 2021); and identified autoreactive IL-21-secreting cells in $50 \%$ of patients with PV (Hennerici et al., 2016). In addition, frequencies of Th17 and Tfh17 cells in the blood of patients with pemphigus correlate with levels of Dsg-specific CD $19^{+} \mathrm{CD} 27^{+}$memory B cells (MahoVaillant et al., 2021), while patients with acute pemphigus exhibit higher levels of Dsg3-autoreactive Tfh17 cells (Hennerici et al., 2016). Moreover, in vitro coculture experiments revealed that Tfh 17 cells are primarily responsible for inducing Dsg-specific autoantibody production by B cells (Holstein et al., 2021). Leading on from this, targeting the inducible co-stimulator expressed on $\mathrm{CXCR} 5^{+} \mathrm{PD}-1^{+} \mathrm{Tfh}$ cells suppressed the progression of PV in a murine model (Kim et al., 2020). All these findings show that Tfh17 cells are critically involved in the pathogenesis of pemphigus and offer novel targets for therapeutic intervention.

A major cell type tasked with preventing autoimmunity in the body is regulatory $\mathrm{T}$ cells (Treg), which exhibit a TCR $\alpha \beta^{+}$Foxp $3^{+} \mathrm{CD}^{+}$phenotype and develop in the thymus (Sakaguchi et al., 1995; Peterson, 2012). Treg cells possess potent immune-suppressive activity and their main role is to control inflammation and immune responses to self-antigens. Various studies have demonstrated that the proportion of Treg cells in the blood of patients with PV is markedly lower than in healthy donors (Veldman et al., 2004). Similar trends are observed in patients with PV in the acute onset and remittent stages: frequencies of Th17 and Treg cell populations are inversely correlated, indicating that the balance of Th17/Treg cells is disrupted in PV (Xu et al., 2013; Asothai et al., 2015, 4). Similarly, a lower ratio of Dsg3-specific type 1 regulatory T cells (Tr1) to Th2 cells in patients with $\mathrm{PV}$ has been described (Veldman et al., 2006). In vivo, mouse models of PV have demonstrated that Tregs control anti-Dsg3 antibody production, and that adoptive transfer of Tregs or the depletion of endogenous Tregs suppresses and increases antiDsg3 antibody production, respectively (Yokoyama et al., 2011). Alongside, in vitro studies have shown that Dsg3-specific Tr1 cells secrete IL-10, TGF- $\beta$, and IL-5 upon autoantigen stimulation and inhibit the proliferation of Dsg3-responsive, auto-reactive helper $\mathrm{T}$ clones in an autoantigen- and cell-number- dependent manner (Veldman et al., 2004). This study suggests that Treg cells are involved in the maintenance and restoration of tolerance against autoantigens in PV. Recent work also suggests that Treg cells from patients with PV may have defective CCR4-CCL22 ligand interactions (Asothai et al., 2015), which could lead to reduced homing to the sites of skin lesions.

The skin also provides a niche for long term tissue-resident memory T (TRM) cells to accumulate, where they can mediate durable protective immunity but may also be involved in driving inflammatory diseases (Ho and Kupper, 2019). Recently, a study reported the over-representation of $\mathrm{CD}^{+}{ }^{+} \mathrm{TRM}$ in the lesional skin of patients with pemphigus (Zou et al., 2021). These $\mathrm{T}$ follicular helper-like CD $4^{+}$TRM cells were thought to promote local autoantibody production, which could result in the formation and recurrence of lesions. Another study suggested that the long-lasting response to rituximab in pemphigus could rely on the decrease of Dsg-specific circulating T follicular helper cells, which correlates with a sustained depletion of IgG-switched memory autoreactive B cells, leading to the disappearance of antiDsg antibody-secreting cells (Maho-Vaillant et al., 2021). These results support the therapeutic targeting of Tfh-like TRM cells in pemphigus treatment, perhaps via IRF4 which might serve as potential therapeutic target (Zou et al., 2021). Understanding the changes in phenotype, functions, and interactions of these, and other, $\mathrm{T}$ cell subsets is key to understanding the pathogenesis of pemphigus and for the development of new targeted therapeutics.

\section{Myeloid Cells}

The myeloid cell population represents a major compartment of the immune system and includes dendritic cells, macrophages, monocytes and neutrophils (Bassler et al., 2019). Dermal dendritic cells (cDC1, cDC2) and epidermal Langerhans cells (LCs) represent the specialized antigen presenting cells of the skin and the functional "bridge" between innate and adaptive immunity. They are considered as sentinels of the skin that defend against pathogens by controlling the innate immune cell wave infiltrating the area during infection (Del Fresno 
et al., 2018; Janela et al., 2019) as well as by shaping the B and $\mathrm{T}$ cell mediated immune response: accordingly, they are key players in the maintenance of tolerance. Despite this, little is known of the role of the myeloid compartment in PV pathogenesis.

The frequency of myeloid DCs in the blood of patients with pemphigus is increased, and these cells exhibit altered expression of DC-associated stimulatory (CD40 and CD80) and inhibitory (PSGL1 and ILT3) markers compared to healthy donors (Das et al., 2020). These observations suggest a potential role of DC dysregulation in the immunopathogenesis of pemphigus. A recent study demonstrated that high numbers of LCs are present in perilesional skin from patients with pemphigus (Das et al., 2020); while in vitro work showed that LCs were able to capture the epidermal antigen Dsg3 via langerin and to present this antigen to $\mathrm{T}$ cells (Kitashima et al., 2018). Interestingly, LCs express the IL-2 receptor complex, and disruption of IL-2 signalling in LCs inhibits LC-mediated regulatory $\mathrm{T}$ cell expansion in vitro (Kitashima et al., 2018). Therefore, LCs may be important mediators of peripheral tolerance against epidermal autoantigens via IL-2 signalling, though this has yet to be directly demonstrated in pemphigus.

Another population of cells that exhibits potentially significant changes in pemphigus is myeloid-derived suppressor cells (MDSCs). This heterogeneous group of immature myeloid cells incorporates granulocytic or polymorphonuclear-like MDSCs (PMN-MDSCs) and monocytic MDSCs (M-MDSCs) (Gabrilovich and Nagaraj, 2009), which inhibit T cell activity via several mechanisms (Nagaraj et al., 2010). A population of $\mathrm{CD} 66 \mathrm{~b}+\mathrm{CD} 11 \mathrm{~b}+\mathrm{PMN}-\mathrm{MDSC}$ is expanded in the peripheral blood of patients with active pemphigus (Oktem et al., 2021), but not those in remission (Neri et al., 2021). In vitro, these PMNMDSCs can suppress allogeneic T-cell proliferation and exhibit high levels of expression of characteristic effector molecules such as arginase I and interleukin-10 (Neri et al., 2021). In addition, a correlation between MDSC frequency and Th2/Th1 cell ratio has been highlighted, which suggests a possible role of these cells as regulators of Th cell responses in pemphigus (Neri et al., 2021).

Plasmacytoid DCs (pDCs), which were long-thought to be part of myeloid lineage but in fact come from a lymphoid progenitor (Dress et al., 2019), could also have a possible role in pemphigus pathogenesis. pDCs seems to be recruited at very high level into the lesional skin of pemphigus patients (Ramadan et al., 2019). It is thus possible that pDCs might be involved in the initial mechanisms leading to autoantibody production, but this has yet to be formally investigated.

It has been demonstrated in autoimmune diseases such as lupus, rheumatoid arthritis and small vessel vasculitis that neutrophil extracellular traps (NETs) are linked with immune complexes and responsible for tissue inflammation and polyclonal activation of B-cell as well as memory B-cell activation (Yu and Su, 2013; Delgado-Rizo et al., 2017; Apel et al., 2018; O'Neil et al., 2019). As neutrophil can be found in the skin of pemphigus, a clinical trial aims to assess the effects on $\mathrm{B}$-cell activation and the phenotypic changes in B-cell population from pemphigus patients after stimulation by NETs (NCT04117529). The understanding of the link between innate and adaptive immunity is essential for a direct targeting of the different actors of the diseases.

\section{COMPREHENSION OF THE PEMPHIGUS BY USING IN VIVO MODEL OF THE DISEASE}

As discussed above, there are many aspects of the aetiology, pathogenesis and treatment of pemphigus that we have yet to fully understand: these diseases are rare-very rare in the case of some variants and sub-variants-which limits opportunities for clinical studies, and robust insights can be hard to glean from the type of mechanistic experiments that are possible using human cells in vitro. In the past three decades, experiments using different mouse models of pemphigus have led directly or indirectly to the identification of the dominant autoantigens, the discovery of autoreactive T cells and B cells and their roles in the production of pathogenic IgG autoantibodies. These findings represent the sum of multiple studies employing different in vivo models, each focused on specific aspects of the autoimmune cascade, from loss of immunological tolerance on the level of $\mathrm{T}$ and $\mathrm{B}$ cells to the pathogenic effects of autoantibodies upon binding to their target autoantigen.

The first mouse model of pemphigus was the passive transfer model, in which IgG from the sera of patients with PV is injected intraperitoneally into neonatal mice, resulting in the formation of cutaneous blisters and erosions and reproducing the clinical, histologic, ultrastructural and immunologic features of the disease (Anhalt et al., 1982). Studies in these mice provided the first evidence that PV IgG alone are pathogenic in vivo, and facilitated the dissection of the mechanism of blister formation (Schulze et al., 2012). Later, the need to study the mechanisms leading to the generation of pathogenic autoantibodies in PV drove the development of an active disease model: $\mathrm{Dsg} 3^{-1-}$ mice, lacking self-tolerance against naturally expressed Dsg3 (Koch et al., 1997), were immunized against Dsg-3 to generate a source of Dsg3-reactive T and B cells, which were then isolated and injected into immune-deficient $\left(\mathrm{Rag}^{-/-}\right.$) but $\mathrm{Dsg}^{+/+}$recipients to induce a Dsg3-specific autoimmune response in vivo (Amagai et al., 2000; Tsunoda et al., 2003; Aoki-Ota et al., 2004). The recipient mice developed oral erosions with suprabasal acantholysis that was induced by the stable production of a panel of Dsg3-specific autoantibodies (Ohyama et al., 2002). A deeper analysis of the active pemphigus mouse model revealed that, in these mice, a single Dsg3-specific $\mathrm{CD}^{+} \mathrm{T}$-cell clone was able to induce a clinical phenotype in recipient mice by activating Dsg3-reactive $\mathrm{B}$ cells (Takahashi et al., 2008).

A major criticism of the passive-transfer and active pemphigus mouse models is that they cannot take account of the genetic components of pemphigus predisposition, which are known from human studies to be significant determinants of disease. In response, a humanized HLA-class II transgenic mouse model of PV was developed (Eming et al., 2014). In this mouse, antigen presentation to $\mathrm{CD} 4^{+} \mathrm{T}$ cells is restricted to human HLA alleles, which allows the characterization of the loss of self-tolerance 
against human Dsg3 in an HLA-restricted in vivo model system (Eming et al., 2014). The immunization of HLA-DRB1*04:02transgenic mice with immunodominant Dsg3 peptides generates a $\mathrm{CD}^{+}{ }^{+} \mathrm{T}$ cell-dependent immune response against human Dsg3 along with the production of pathogenic Dsg3 reactive IgG antibodies (Eming et al., 2014). This model therefore allows investigation of the communication between $\mathrm{B}$ cells and $\mathrm{T}$ cells that underpins the production of anti-Dsg3 IgG, leading to the discovery that the use of anti-CD40L or the depletion of $\mathrm{CD}^{+} \mathrm{T}$ cells abolishes the induction of pathogenic anti-Dsg3 IgG. Furthermore, when Treg were induced in these mice by injection with anti-CD28 antibodies, researchers observed a reduced humoral Dsg3-specific immune response, which supports the hypothesis that the Dsg3-specific $\mathrm{CD} 4^{+} \mathrm{T}$-cell dependent immune pathogenesis of $\mathrm{PV}$ is modulated by Treg (Schmidt et al., 2016).

Whilst these studies, in conjunction with clinical data, have supported major steps forward in our understanding and treatment of pemphigus in recent years, significant challenges remain. For example, our knowledge of the initiation of pemphigus is severely limited as we lack a spontaneous model of the disease. Similarly, our understanding of immunepathogenesis is almost completely restricted to Dsg3 as the target autoantigen, despite knowledge from human patients that this is only one part of the pemphigus picture. A pressing need in the field is the development of a model that reproduces the full complexity of the disease, including multi-pathogenic mechanisms that target different autoantigens. The impact of the lack of such a model is nowhere clearer than in the development of novel therapeutics to treat pemphigus disease.

\section{PEMPHIGUS TREATMENT}

Prior to the era of systemic corticosteroids, $75 \%$ of patients with pemphigus were dying within the first year of the disease (Bystryn, 1996). Complications such as infections or nutritional deficiency contributed significantly towards this high mortality. The introduction of systemic corticosteroids and subsequent use of other immunomodulatory or immunosuppressive agents has brought a marked improvement in survival (Bystryn, 1996), however the level of immunosuppression required to ameliorate symptoms has created its own problems. More recently, advances in our understanding of the pathogenesis of pemphigus and the biological mechanisms of therapeutics have led to a paradigm shift in the treatment of this disease, from blanket immunosuppression towards a more targeted restriction of autoimmunity.

\section{Conventional Systemic Immunosuppressants/Immunomodulators}

Immunosuppression with systemic corticosteroids in the form of oral prednisone or prednisolone frequently remain either the initial or mainstay of treatment for pemphigus. Different dosing schedules are employed depending on the severity of the disease: they are typically initiated at a dose of 0.5 to $1.5 \mathrm{mg} / \mathrm{kg} /$ day to achieve initial control of the disease (Hertl et al., 2015; Harman et al., 2017); while more extreme cases may be treated with either intravenous pulse methylprednisolone (500-1,000 mg daily for three to five consecutive days) or dexamethasone $100 \mathrm{mg}$ daily for three consecutive days, with or without concomitant cyclophosphamide (Pasricha et al., 1995; Werth, 1996; Saha et al., 2009). Corticosteroids are effective in autoimmune diseases as they exert strong anti-inflammatory effects and induce apoptosis of lymphocytes (Shimba and Ikuta, 2020). However, as morbidity and mortality from cumulative longterm corticosteroid use is significant (Razzaque Ahmed and Moy, 1982), various non-steroid immunosuppressive agents have been trialled in a bid to improve outcomes in these patients.

Initial attempts to treat pemphigus with non-steroid immunosuppressive agents such as azathioprine, mycophenolate mofetil and cyclophosphamide achieved mixed results: when analysed together, they seemed to reduce the risk of relapse in pemphigus (Atzmony et al., 2015). However, these medications individually were not shown to be better in achieving remission, reducing deaths or reducing relapse compared to corticosteroids alone (Martin et al., 2009). Nonetheless, both azathioprine and cyclophosphamide showed steroid-sparing effects and mycophenolate demonstrated a significant effect on disease control (Martin et al., 2009). Azathioprine is often used at a dose of $2-3 \mathrm{mg} / \mathrm{kg} /$ day, mycophenolate mofetil at a dose of $2-3 \mathrm{~g} /$ day and cyclophosphamide at $75-150 \mathrm{mg} /$ day orally or $500-1,000 \mathrm{mg}$ monthly intravenously. Due to its toxicity, cyclophosphamide is not widely used and is usually only considered in severe recalcitrant cases where other therapeutic options are not available or are contraindicated (Atzmony et al., 2015).

Methotrexate, a dihydrofolate reductase inhibitor, is the earliest steroid-sparing agent used in the treatment of pemphigus. It fell out of favour due to its associated toxicities when used at higher dose. It was not until later, when low to moderate doses (ranging 15-20 mg/week) were employed that it re-emerged as a safe and effective adjunct therapy in pemphigus (Gürcan and Razzaque Ahmed, 2009). Dapsone, with its ability to interfere with neutrophil chemo-attractants, is often used in the treatment of pemphigus with a predominantly neutrophilic infiltrate, such as pemphigus foliaceus, IgA pemphigus and pemphigus herpetiformis (Kasperkiewicz et al., 2014; Porro et al., 2019; Kridin et al., 2020). Dapsone is also an appropriate adjunctive steroid-sparing agent for the treatment of patients with PV whose disease was initially controlled with corticosteroids (Werth et al., 2008).

\section{Anti-CD20 Antibody Therapy}

The latest game changer in the treatment of pemphigus is rituximab, a murine-human chimeric anti-CD20 monoclonal antibody (human Fc portion associated with a murine variable region) which targets $B$ cells expressing CD20, and was initially developed and used to treat B cell malignancies (Grillo-López, 2000). First trialled in PNP in 2001 (Heizmann et al., 2001) and in PV in 2002 (Salopek et al., 2002), rituximab is now considered by many to be the primary therapeutic option in pemphigus. 
Injection of rituximab induces rapid depletion of $\mathrm{B}$ cells, including autoreactive B cells, from the peripheral blood of patients, with the $\mathrm{B}$ cell pool being reconstituted over the next 6-12 months from non-depleted progenitors (Mouquet et al., 2008). CD20 is expressed on the surface of B cells from the late pre-B-cell stage in the bone marrow, through naive follicular $\mathrm{B}$ cells and into the memory B cell population; but the long-lived plasma cells do not express this molecule and survive in specific niches including the bone marrow, gut-associated lymphoid tissue (GALT) and skin-associated lymphoid tissue (iSALT) (Lightman et al., 2019; Zhou et al., 2020). Thus, depletion of mature B cells and short-lived plasma cells in patients with PV leads to lowering of autoreactive anti-Dsg antibodies in the serum, while antibodies produced by long-lived plasma cells, such as those directed against tetanus and pneumococcus, remain unchanged (Mouquet et al., 2008). Although rituximab is more expensive than broad spectrum immunosuppressants, a recent study showed that the initially higher cost of rituximab was almost completely off-set by costs related to management of flares and relapses in patients treated with the standard corticosteroid regimen (Hébert et al., 2020).

The therapeutic efficacy of rituximab treatment in patients with pemphigus seems to operate on multiple levels. Prolonged and continuous repopulation of naïve $B$ cells bearing a new repertoire and a markedly delayed reappearance of memory $B$ cells are seen after rituximab treatment: numbers of $\mathrm{CD} 19^{+}$ B-lymphocytes even 6 years after treatment are much lower than at baseline (Colliou et al., 2013). This prolonged blockage of B cell maturation also inhibits the IgM to IgG class switching process, thereby reducing levels of autoimmune $\operatorname{IgG}^{+}$circulating $\mathrm{B}$ lymphocytes and autoantibodies (Colliou et al., 2013): such long-lasting modification of the naive/memory-B-cell ratio accounts for the prolonged therapeutic effect of rituximab in patients with pemphigus. In addition, transitional B-cell and IL10 -secreting regulatory $\mathrm{B}$ cell (B reg) populations seem to expand during the B cell repopulation (Colliou et al., 2013); this could be significant because $B$ reg cells can down-regulate inflammation and may be involved in the maintenance of long term immune tolerance (Lund and Randall, 2010; Mauri and Menon, 2017; Cao et al., 2019).

However, post-rituximab relapses do occur, and are thought to be linked to the re-emergence of anti-Dsg B cell clones that have lost self-tolerance (Hammers et al., 2015). Relapse occurs in more than $80 \%$ of PV patients over a median period of 79 months (Colliou et al., 2013), and is more likely when patients have severe disease at treatment outset and/or persistently high anti-Dsg1/3 antibody levels 3 months after treatment (Mignard et al., 2020): conversely, older patients and those given higher doses of the drug are less likely to experience early relapse (Kushner et al., 2019). It is plausible that higher doses of rituximab achieve a deeper B cell depletion and that the weaker immune systems of the elderly make the re-emergence of anti-Dsg B cell clones less likely. Alongside, long-term follow-up of auto-reactive B cells and antibodies in rituximab-treated patients with pemphigus demonstrated a complex regulatory process: in patients in remission, there were fewer autoreactive $B$ cells than in patients with active pemphigus, and within that $\mathrm{B}$ cell population there was a higher proportion of $\operatorname{IgM} \mathrm{Dsg}^{+}$cells than IgG Dsg $3^{+}$cells, in association with a rearrangement in Ig repertoire which had switched from an oligoclonal to polyclonal profile (Colliou et al., 2013; Hébert et al., 2019). In addition, the remaining autoreactive anti-Dsg antibodies detected in patients in remission seem to target non-pathogenic epitopes of Dsg (Müller et al., 2010).

It may be possible to reduce relapse rates, or lengthen the time to relapse, by modifying the approach to the use of rituximab in pemphigus patients. In a recent randomised control trial, $89 \%$ of patients treated with two infusions of $1 \mathrm{~g}$ of rituximab given a fortnight apart at baseline, and with $0.5 \mathrm{~g}$ at 12 and 18 months, combined with short-term prednisolone $(0.5-1.0 \mathrm{mg} / \mathrm{kg} / \mathrm{day}$ for 3-6 months) were in complete remission off therapy at 2 years, compared with only $34 \%$ of those given prednisone alone (1.0-1.5 mg/kg/day) (Joly et al., 2017). Importantly, the cumulative prednisolone dose used, and the number of severe adverse events in the rituximab-treated group, was three times and two times lower respectively, when compared to the prednisone-only group.

Alongside the relapse-rate, unfortunately, $10-20 \%$ of patients with pemphigus seem to be resistant to rituximab therapy (Joly et al., 2017). Trying to understand this phenomenon, a recent study showed that memory and germinal autoreactive B cells may persist in lymphoid tissues or ectopic lymphoid-like structures in PV lesions in cases of rituximab resistance (Zhou et al., 2020). Furthermore, the authors showed similar persistence of autoreactive $\mathrm{CD}^{+}$Th cells, which provide a crucial help to $\mathrm{B}$ cells for the secretion of autoantibodies. Post rituximab treatment, the disruption of immune tolerance could lead to the appearance of new autoreactive B cells, and the non-depletion of the long-lived autoreactive plasma cells with persistent production of anti-Dsg 3 antibodies could similarly explain the resistance to treatment in some patients (Hammers et al., 2015). There may also be a link between the production of human antichimeric antibodies (HACA) to the murine fragments of rituximab which may hamper the effectiveness of subsequent doses and contribute to a lack of therapeutic response (Lunardon and Payne, 2012). In addition, a downregulation of CD20 in some $\mathrm{CD} 27^{+}$memory $\mathrm{B}$ cells and the presence of an alternative transcript of the CD20 (D393-CD20), which was described in lymphoma and pemphigus could explain an impairment of the rituximab binding and the resultant lack of $\mathrm{B}$ cell depletion (Gamonet et al., 2014). Taken together, multiple pathways of incomplete/non-responsiveness to rituximab treatment have been suggested, and ways of overcoming these limitations and/ or new therapies remain urgently needed.

Rituximab's targeting of B-cells also has the side-effect of leaving patients highly susceptible to bacterial infections, particularly those of the respiratory tract and skin (Goh et al., 2007; Kamran et al., 2013). Similarly, viral infections or reactivation of latent viruses such as herpes simplex (HSV), cytomegalovirus (CMV), hepatitis $\mathrm{B}(\mathrm{HBV})$ and hepatitis $\mathrm{C}$ $(\mathrm{HCV})$ viruses have been described in lymphoma or pemphigus patients who received rituximab (Suzan et al., 2001; Goh et al., 2007; Yeo et al., 2009; Nooka et al., 2011). Screening or prophylaxis for HSV and CMV infections is 
generally not regarded as necessary, but pre-treatment screening for HBV and HCV is (Sagnelli et al., 2012; Pattullo, 2015; Reddy et al., 2015). However, establishing a direct causal link between infections and rituximab therapy is often confounded by the concomitant use of other immunosuppressive agents and generalised immune dysfunction induced by the underlying diseases for which rituximab is used as therapy. As rituximab does not affect $\mathrm{CD}^{+} / \mathrm{CD}^{+}$T-cell circulating numbers, susceptibility to bacterial infection and opportunistic infections after rituximab therapy may then be partly explained by the disruption of B cell's role in T-cell activation and optimal CD4 ${ }^{+}$ memory response. Hypogammaglobulinemia, which has been associated with multiple infusions of rituximab for rheumatic autoimmune diseases and lymphoma, is a risk factor for serious infections (Casulo et al., 2013; Yusof et al., 2019). However, hypogammaglobulinaemia has not been reported in pemphigus patients and it remains to be seen with longer term follow up of pemphigus patients undergoing multiple rituximab infusions. Concerns of progressive multifocal leukoencephalopathy has largely been reassured by the findings of post-marketing surveillance that this rare opportunistic infection is mainly seen in oncology (lymphoma) patients (Focosi et al., 2019).

The use of rituximab has undeniably revolutionised the treatment of pemphigus for many patients but its high initial cost, the high rate of relapse (Colliou et al., 2013) lowered resistance to infection and further lower immunogenicity to several vaccines remain significant drawbacks. These factors have driven more research aiming to discover and develop more targeted therapeutics with improved safety and efficacy profiles.

\section{Adjunct Therapies}

In the absence of a single therapy that works across all patients with pemphigus, different treatments have been trialled in combination with more conventional therapies, aiming to enhance the overall effect. One such adjunct therapy for severe recalcitrant pemphigus is high dose intravenous immunoglobulins (IVIG), given at $2 \mathrm{~g} / \mathrm{kg}$ across five daily doses per month (Amagai et al., 2009) in addition to conventional immunosuppressive agents or rituximab (see below) (Jolles, 2001; Grando, 2019). Initial IVIG therapy rapidly elevates total circulating Ig levels, which is thought to stimulate homeostatic antibody-catabolic mechanisms, leading to lowering of serum levels of IgG1 and IgG4 anti-Dsg 1 and Dsg 3 antibodies (Green and Bystryn, 2008) while normal antibodies are replaced by those in subsequent IVIG doses: this is a particularly useful treatment when fast onset of therapy and lower risk of infection is needed. Combining rituximab and IVIG can be effective for the treatment of refractory pemphigus cases and may even induce long-term complete remission with lower risk of infection (Hamadah et al., 2019): accordingly, a clinical trial was started in June 2020 to evaluate the efficacy and safety of early use of rituximab with or without IVIGs in patients with moderate to severe pemphigus (NCT04400994). Immunoadsorption, which also rapidly removes anti-Dsg IgG from the circulation, has also been trialled in conjunction with conventional immunosuppressive treatment and intravenous rituximab (Eming and Hertl, 2006; Behzad et al., 2012). In its current form, immunoglobulins are non-specifically adsorbed and removed, but studies are underway to develop anti-Dsg immunoglobulin-specific adsorption (Langenhan et al., 2014); it is, however, not easily available in many parts of the world, limiting its potential for widespread use.

Complementary to systemic therapeutic options, local treatment of mucosal - especially oral - lesions of pemphigus should not be overlooked. Poor oral hygiene can be a contributory factor for persistent oral erosions in pemphigus (Gambino et al., 2014), and topical analgesics or anaesthetics (e.g., lidocaine $2 \%$ gel) can be used prior to eating or brushing of teeth. Topical medium or high potency corticosteroids (e.g., clobetasol propionate $0.05 \%$ in adhesive paste) can also be applied directly to the lesions (Lozada-Nur et al., 1994) or used as mouth gargle. Alongside, the use of topical calcineurin inhibitors and cyclosporine mouthwash may be also beneficial (Gooptu and Staughton, 1998; Hodgson et al., 2003). Candida infection is a common occurrence in patients with mucosal pemphigus who are treated with topical or systemic glucocorticoids (Lozada-Nur et al., 1994): oral nystatin swishand-swallow or mouthwash can be used as prophylaxis. Dietary advice in favour of a soft diet and the avoidance of spicy or very hot foods can also be helpful for patients.

\section{NOVEL TREATMENT IN THE PIPELINE}

As we learn more about the pathogenesis of pemphigus, the development of more targeted therapeutic approaches with improved safety and efficacy profiles is gradually becoming possible.

Recent studies characterising the immune features of pemphigus lesions themselves have paved the way for innovative local treatment strategies. For example, intralesional delivery of rituximab, which has already been used in the treatment of lymphoma (Davies et al., 2017), has been proposed as a way of targeting the diffuse ectopic lymphoidlike structures that are commonly seen in lesions of both PV and $\mathrm{PF}$ and to treat refractory oral pemphigus vulgaris (Vinay et al., 2015; Zhou et al., 2020). Disruption of these lymphoid-like structures, which are composed of $\mathrm{T}$ cells, dendritic cells, centroblasts, plasmablasts and plasma cells might therefore disrupt the niche that supports the in situ B cell differentiation, clonal expansion and production of autoreactive antibody in the skin of patients with pemphigus. Identification of the cell composition and exploration of the impact of the injection of steroids into lesions of patients with pemphigus that harbour ectopic lymph node-like structures is ongoing (NCT04509570).

Some novel approaches target specific obstacles within current therapeutic settings. Aiming to restore the efficacy of anti-CD20 therapy in rituximab patients with HACA, subcutaneous injection of Ofatumumab, a fully human anti-CD20 IgG antibody with increased binding affinity for CD20, has been successfully trialled in a single patient (Rapp et al., 2018), but 
has yet to be assessed in a larger cohort. Similarly, veltuzumab, a second generation humanized anti-CD20 antibody, has been successfully used in a case of rituximab-refractory PV (Ellebrecht et al., 2014). The development of these second and third generation anti-CD20 antibodies, which possess superior B cell-depleting qualities and higher binding affinities compared to rituximab, might represent an important step forward in the treatment of pemphigus and other autoimmune B cell diseases.

A different type of treatment obstacle can be simply a practical limitation, as in the case of IVIG: these products are generally considered safe and effective, but their production requires an abundant supply of human plasma in order to generate the large doses of product (up to $2 \mathrm{~g} / \mathrm{kg}$ body weight) needed for therapy.

To overcome this supply limitation, antibodies with high affinity for the neonatal $F c$ receptor (FcRn) have been developed. These antibodies represent a key determinant actor for IgG levels and functions (Pyzik et al., 2019). FcRn-targeting therapeutics aim to block the binding of IgG and IgG immune complexes to the FcRn, thereby accelerating their breakdown and inducing a reduction in overall plasma IgG levels, including the levels of pathogenic autoantibodies (Blumberg et al., 2019).

Data from a phase $1 \mathrm{~b} / 2 \mathrm{a}$ study using ALXN1830 (NCT03075904), a humanized affinity-matured IgG4-kappa monoclonal antibody with high affinity for the neonatal Fc receptor, has shown major improvements in both cutaneous and mucosal disease, and an overall acceptable safety and tolerability profile (Werth et al., 2021). In this trial, ALXN1830-associated clinical improvement was accompanied by a similarly rapid and significant decrease in levels of total IgG, all individual IgG subclasses, and IgG immune complexes. In addition, this study thereby provides evidence that IgG circulating immune complexes may be involved in the pathogenesis of pemphigus. Another promising anti-FcRn therapeutic is also being trialled in pemphigus. Efgartigimod is a human IgG1 antibody Fc-fragment, a natural ligand of FcRn, that has been engineered for increased affinity to FcRn compared with endogenous IgG (Zuercher et al., 2019). Proven safe and effective in patients with myasthenia gravis (Howard et al., 2021), results from a completed phase two trial of efgartigimod in patients with PV (NCT03334058) have shown that it is welltolerated and exhibited an early effect on disease activity and outcome parameters, providing support for further evaluation as a therapy for pemphigus (Goebeler et al., 2021). Two phase 3 clinical trials assessing the early and long-term efficacy and safety of a subcutaneous formulation of efgartigimod in adults with pemphigus is on-going (NCT04598451 and NCT04598477).

Focussing on the immune-associated SNPs that have been linked with pemphigus, Assaf $\mathrm{S}$ et al. recently demonstrated through a series of experiments on how ST18 contributed to destabilization of cell-cell adhesion in a tumour necrosis factor (TNF)- $\alpha$-dependent manner, potentially opening up new therapeutic option of using TNF- $\alpha$ inhibitors in the treatment of pemphigus (Assaf et al., 2021).

Targeting another aspect of the biology of B cells, such as their survival or their differentiation into plasma cells, is a useful approach that has been tested in SLE and could be applied to the treatment of pemphigus. The use of belimumab, a monoclonal human IgG1 antibody that binds to soluble B lymphocyte stimulator (BLyS) or B cell activating factor belonging to the TNF family (BAFF) (Möckel et al., 2021), or atacicept, a fully human recombinant fusion protein that blocks BLyS and the proliferation-inducing ligand (APRIL) (Kaegi et al., 2020), might be a promising treatment of pemphigus. This is further supported by the recent finding that a modification of the BAFF/BAFF receptor axis in patients with pemphigus could explain the high number of relapses following standard corticosteroid treatment alone versus with rituximab (Hébert et al., 2021). New therapies such as Bruton's tyrosine kinase (BTK) inhibitors have also emerged as a potential treatment option: BTK inhibitors seem to be able to neutralize pathogenic autoantibodies, to inhibit new autoantibody production and to possess anti-inflammatory effects (Weber et al., 2017). A trial involving the use of a BTK inhibitor, PRN 1008, in patients with PV (NCT02704429) has been completed and recently published (Murrell et al., 2021). The study suggests that BTK inhibition may be a promising treatment strategy and supports further investigation of such inhibitor for the treatment of pemphigus.

Recently, chimeric antigen receptor (CAR) $\mathrm{T}$ cell technology has revolutionized cancer immunotherapy (reviewed in Mohanty et al. (2019)). This approach uses $\mathrm{T}$ cells from the patient's own blood that are genetically manipulated in research laboratories to express a CAR capable of recognizing a specific cell type uniquely expressing the target antigen. In the case of pemphigus, researchers have engineered a chimeric autoantibody receptor (CAAR), with Dsg3 as the extracellular domain in order to generate CAAR-T cells that recognize the Dsg3specific BCR on autoreactive $B$ cells and induce their elimination (Ellebrecht et al., 2016). Preclinical study has demonstrated that DSG3-CAART could be a precise therapy for PV (Lee et al., 2020). A phase one clinical trial to determine the maximum tolerated dose of Dsg3-CAART in mucosal dominant PV patients is ongoing (NCT04422912). Whilst this is potentially a promising step forwards, the efficacy of Dsg3-CAAR-T cell therapies in pemphigus may be limited by the single antigen focus, and so the repertoire of recognition might need to be expanded in future trials if this approach is found to be safe and well-tolerated.

\section{VACCINATION AND PEMPHIGUS}

Vaccination strategy and Pemphigus treatment are in need of more studies especially in this time of COVID-19 pandemic. The effect of rituximab and other anti-CD20 monoclonal antibodies on vaccine response has been studied for inactivated vaccines (Baker et al., 2020). These studies have suggested that rituximab recipients mount attenuated yet meaningful vaccine responses. Concerning live attenuated vaccines, no study addressing their immunogenicity has been started due to the safety concerns regarding the use of these vaccines in rituximab recipients. In addition, no studies have evaluated yet the safety and immunogenicity of messenger RNA vaccines or viral vector vaccines, which are among the leading COVID-19 vaccine 
candidates. To gain knowledge on COVID-19 vaccine and pemphigus, a clinical trial has been started recently in august 2021 to compare the immune response to different COVID-19 vaccine booster doses (Moderna COVID-19 vaccine, PfizerBioNTech COVID-19 vaccine, or Janssen COVID-19 vaccine) in participants with autoimmune disease requiring immunosuppressive medications, including pemphigus patients (NCT05000216).

\section{CONCLUSION}

Alongside advances in our understanding of pemphigus pathogenicity, the number of therapeutic options to treat pemphigus has increased over the last decade, with more targeted therapies and refined diagnostic techniques beginning to emerge. However, with better definition of the clinical subtypes of pemphigus, the aetiology and immune pathogenesis of these diseases is revealed to be more and more complex, and still

\section{REFERENCES}

Abasq, C., Mouquet, H., Gilbert, D., Tron, F., Grassi, V., Musette, P., et al. (2009). ELISA Testing of Anti-desmoglein 1 and 3 Antibodies in the Management of Pemphigus. Arch. Dermatol. 145, 529-535. doi:10.1001/archdermatol.2009.9

Abida, O., Masmoudi, A., Rebaï, A., Ben Ayed, M., Mahfoudh, N., Kallel-Sellami, M., et al. (2009). The Familial Feature of Tunisian Endemic Pemphigus Foliaceus. Br. J. Dermatol. 161, 951-953. doi:10.1111/j.1365-2133.2009.09386.x

Abrèu-Velez, A. M., Beutner, E. H., Montoya, F., Bollag, W. B., and Hashimoto, T. (2003a). Analyses of Autoantigens in a New Form of Endemic Pemphigus Foliaceus in Colombia. J. Am. Acad. Dermatol. 49, 609-614. doi:10.1067/s0190-9622(03)00852-1

Abrèu-Velez, A. M., Hashimoto, T., Bollag, W. B., Tobón Arroyave, S., AbrèuVelez, C. E., Londoño, M. L., et al. (2003b). A Unique Form of Endemic Pemphigus in Northern Colombia. J. Am. Acad. Dermatol. 49, 599-608. doi:10.1067/s0190-9622(03)00851-x

Aghassi, D. (1998). Pemphigus Foliaceus Induced by Psoralen-UV-A. Arch. Dermatol. 134, 1300. doi:10.1001/archderm.134.10.1300-a

Razzaque Ahmed, A., and Blose, D. A. (1984). Pemphigus Vegetans. Int. J. Dermatol. 23, 135-141. doi:10.1111/j.1365-4362.1984.tb05688.x

Ahmed, A. R., Wagner, R., Khatri, K., Notani, G., Awdeh, Z., Alper, C. A., et al. (1991). Major Histocompatibility Complex Haplotypes and Class II Genes in Non-jewish Patients with Pemphigus Vulgaris. Proc. Natl. Acad. Sci. 88, 5056-5060. doi:10.1073/pnas.88.11.5056

Ahmed, A. R., Carrozzo, M., Caux, F., Cirillo, N., Dmochowski, M., Alonso, A. E., et al. (2016). Monopathogenic vs Multipathogenic Explanations of Pemphigus Pathophysiology. Exp. Dermatol. 25, 839-846. doi:10.1111/exd.13106

Allen, E. M., Giudice, G. J., and Diaz, L. A. (1993). Subclass Reactivity of Pemphigus Foliaceus Autoantibodies with Recombinant Human Desmoglein. J. Invest. Dermatol. 100, 685-691. doi:10.1111/1523-1747.ep12472348

Amagai, M., and Stanley, J. R. (2012). Desmoglein as a Target in Skin Disease and beyond. J. Invest. Dermatol. 132, 776-784. doi:10.1038/jid.2011.390

Amagai, M., Klaus-Kovtun, V., and Stanley, J. R. (1991). Autoantibodies against a Novel Epithelial Cadherin in Pemphigus Vulgaris, a Disease of Cell Adhesion. Cell 67, 869-877. doi:10.1016/0092-8674(91)90360-B

Amagai, M., Karpati, S., Prussick, R., Klaus-Kovtun, V., and Stanley, J. R. (1992). Autoantibodies against the Amino-Terminal Cadherin-like Binding Domain of Pemphigus Vulgaris Antigen Are Pathogenic. J. Clin. Invest. 90, 919-926. doi:10.1172/JCI115968

Amagai, M., Hashimoto, T., Green, K. J., Shimizu, N., and Nishikawa, T. (1995). Antigen-Specific Immunoadsorption of Pathogenic Autoantibodies in Pemphigus Foliaceus. J. Invest. Dermatol. 104, 895-901. doi:10.1111/15231747.ep12606168 requires further investigation. Better comprehension of the early stages of pemphigus, the role of innate and adaptive immune cells most notably dendritic cells and full analysis of the involved B cells' biology will be required. To support this, the field should develop new mouse models that incorporate all the immune players necessary for the emergence of pemphigus variants, and that can be used to test new and innovative therapies.

\section{AUTHOR CONTRIBUTIONS}

All authors listed have made a substantial, direct, and intellectual contribution to the work and approved it for publication.

\section{ACKNOWLEDGMENTS}

We would like to acknowledge Dr Christelle Leroux for sharing photos of different Pemphigus variants.

Amagai, M., Nishikawa, T., Nousari, H. C., Anhalt, G. J., and Hashimoto, T. (1998). Antibodies against Desmoglein 3 (Pemphigus Vulgaris Antigen) Are Present in Sera from Patients with Paraneoplastic Pemphigus and Cause Acantholysis In Vivo in Neonatal Mice. J. Clin. Invest. 102, 775-782. doi:10.1172/JCI3647

Amagai, M., Komai, A., Hashimoto, T., Shirakata, Y., Hashimoto, K., Yamada, T., et al. (1999). Usefulness of Enzyme-Linked Immunosorbent Assay Using Recombinant Desmogleins 1 and 3 for Serodiagnosis of Pemphigus. Br. J. Dermatol. 140, 351-357. doi:10.1046/j.1365-2133.1999.02752.x

Amagai, M., Tsunoda, K., Suzuki, H., Nishifuji, K., Koyasu, S., and Nishikawa, T. (2000). Use of Autoantigen-Knockout Mice in Developing an Active Autoimmune Disease Model for Pemphigus. J. Clin. Invest. 105, 625-631. doi:10.1172/JCI8748

Amagai, M., Ikeda, S., Shimizu, H., Iizuka, H., Hanada, K., Aiba, S., et al. (2009). A Randomized Double-Blind Trial of Intravenous Immunoglobulin for Pemphigus. J. Am. Acad. Dermatol. 60, 595-603. doi:10.1016/j.jaad.2008.09.052

Amagai, M. (2009). The Molecular Logic of Pemphigus and Impetigo: the Desmoglein story. Vet. Dermatol. 20, 308-312. doi:10.1111/j.1365-3164.2009.00831.x

Amber, K. T., Valdebran, M., and Grando, S. A. (2018). Non-Desmoglein Antibodies in Patients with Pemphigus Vulgaris. Front. Immunol. 9, 1190. doi:10.3389/fimmu.2018.01190

Amerian, M. L., and Ahmed, A. R. (1985). Pemphigus Erythematosus. Int. J. Dermatol. 24, 16-25. doi:10.1111/j.1365-4362.1985.tb05349.x

Anhalt, G. J., Labib, R. S., Voorhees, J. J., Beals, T. F., and Diaz, L. A. (1982). Induction of Pemphigus in Neonatal Mice by Passive Transfer of IgG from Patients with the Disease. N. Engl. J. Med. 306, 1189-1196. doi:10.1056/NEJM198205203062001

Anhalt, G. J., Kim, S., Stanley, J. R., Korman, N. J., Jabs, D. A., Kory, M., et al. (1990). Paraneoplastic Pemphigus. N. Engl. J. Med. 323, 1729-1735. doi:10.1056/NEJM199012203232503

Anhalt, G. J. (2004). Paraneoplastic Pemphigus. J. Invest. Dermatol. Symp. Proc. 9, 29-33. doi:10.1111/j.1087-0024.2004.00832.x

Aoki, V., Rivitti, E. A., and Diaz, L. A. (2015). Cooperative Group on Fogo Selvagem ResearchUpdate on Fogo Selvagem, an Endemic Form of Pemphigus Foliaceus. J. Dermatol. 42, 18-26. doi:10.1111/1346-8138.12675

Aoki-Ota, M., Tsunoda, K., Ota, T., Iwasaki, T., Koyasu, S., Amagai, M., et al. (2004). A Mouse Model of Pemphigus Vulgaris by Adoptive Transfer of Naive Splenocytes from Desmoglein 3 Knockout Mice. Br. J. Dermatol. 151, 346-354. doi:10.1111/j.1365-2133.2004.06056.x

Apel, F., Zychlinsky, A., and Kenny, E. F. (2018). The Role of Neutrophil Extracellular Traps in Rheumatic Diseases. Nat. Rev. Rheumatol. 14, 467-475. doi:10.1038/s41584-018-0039-z

Arakawa, M., Dainichi, T., Yasumoto, S., and Hashimoto, T. (2009). Lesional Th17 Cells in Pemphigus Vulgaris and Pemphigus Foliaceus. J. Dermatol. Sci. 53, 228-231. doi:10.1016/j.jdermsci.2008.09.008 
Asothai, R., Anand, V., Das, D., Antil, P. S., Khandpur, S., Sharma, V. K., et al. (2015). Distinctive Treg Associated CCR4-CCL22 Expression Profile with Altered Frequency of Th17/Treg Cell in the Immunopathogenesis of Pemphigus Vulgaris. Immunobiology 220, 1129-1135. doi:10.1016/ j.imbio.2015.06.008

Assaf, S., Malki, L., Mayer, T., Mohamad, J., Peled, A., Pavlovsky, M., et al. (2021). ST18 Affects Cell-Cell Adhesion in Pemphigus Vulgaris in a Tumour Necrosis Factor- $\alpha$-dependent Fashion*. Br. J. Dermatol. 184, 1153-1160. doi:10.1111/ bjd. 19679

Atzmony, L., Hodak, E., Leshem, Y. A., Rosenbaum, O., Gdalevich, M., Anhalt, G. J., et al. (2015). The Role of Adjuvant Therapy in Pemphigus: A Systematic Review and Meta-Analysis. J. Am. Acad. Dermatol. 73, 264-271. doi:10.1016/ j.jaad.2015.04.038

Baker, D., Roberts, C. A. K., Pryce, G., Kang, A. S., Marta, M., Reyes, S., et al. (2020). COVID-19 Vaccine-Readiness for Anti-CD20-depleting Therapy in Autoimmune Diseases. Clin. Exp. Immunol. 202, 149-161. doi:10.1111/ cei. 13495

Bassler, K., Schulte-Schrepping, J., Warnat-Herresthal, S., Aschenbrenner, A. C., and Schultze, J. L. (2019). The Myeloid Cell Compartment-Cell by Cell. Annu. Rev. Immunol. 37, 269-293. doi:10.1146/annurev-immunol-042718-041728

Bastuji-Garin, S., Souissi, R., Blum, L., Turki, H., Nouira, R., Jomaa, B., et al. (1995). Comparative Epidemiology of Pemphigus in Tunisia and France: Unusual Incidence of Pemphigus Foliaceus in Young Tunisian Women. J. Invest. Dermatol. 104, 302-305. doi:10.1111/1523-1747.ep12612836

Bastuji-Garin, S., Souissi, R., Blum, L., Turki, H., Nouira, R., Jomaa, B., et al. (1996). Comparative Epidemiology of Pemphigus in Tunisia and France. Incidence of Foliaceus Pemphigus in Young Tunisian Women. Ann. Dermatol. Venereol. 123, 337-342.

Behzad, M., Möbs, C., Kneisel, A., Möller, M., Hoyer, J., Hertl, M., et al. (2012). Combined Treatment with Immunoadsorption and Rituximab Leads to Fast and Prolonged Clinical Remission in Difficult-To-Treat Pemphigus Vulgaris. Br. J. Dermatol. 166, 844-852. doi:10.1111/j.13652133.2011.10732.x

Belloni-Fortina, A., Faggion, D., Pigozzi, B., Peserico, A., Bordignon, M., Baldo, V., et al. (20092009). Detection of Autoantibodies against Recombinant Desmoglein 1 and 3 Molecules in Patients with Pemphigus Vulgaris: Correlation with Disease Extent at the Time of Diagnosis and during Follow-Up. Clin. Develop. Immunol. 2009, 1-6. doi:10.1155/2009/187864

Berkowitz, P., Hu, P., Liu, Z., Diaz, L. A., Enghild, J. J., Chua, M. P., et al. (2005). Desmosome Signaling. J. Biol. Chem. 280, 23778-23784. doi:10.1074/ jbc.M501365200

Berkowitz, P., Hu, P., Warren, S., Liu, Z., Diaz, L. A., and Rubenstein, D. S. (2006). p38MAPK Inhibition Prevents Disease in Pemphigus Vulgaris Mice. Proc. Natl. Acad. Sci. 103, 12855-12860. doi:10.1073/pnas.0602973103

Berkowitz, P., Diaz, L. A., Hall, R. P., and Rubenstein, D. S. (2008). Induction of p38MAPK and HSP27 Phosphorylation in Pemphigus Patient Skin. J. Invest. Dermatol. 128, 738-740. doi:10.1038/sj.jid.5701080

Berkun, Y., Mimouni, D., and Shoenfeld, Y. (2005). Pemphigus Following Hepatitis B Vaccination-Coincidence or Causality? Autoimmunity 38, 117-119. doi:10.1080/08916930400027078

Bhol, K. C., and Razzaque Ahmed, A. (2002). Production of Non-pathogenic Human Monoclonal Antibodies to Desmoglein 3 from Pemphigus Vulgaris Patient. Autoimmunity 35, 87-91. doi:10.1080/08916930290016655

Blumberg, L. J., Humphries, J. E., Jones, S. D., Pearce, L. B., Holgate, R., Hearn, A., et al. (2019). Blocking FcRn in Humans Reduces Circulating IgG Levels and Inhibits IgG Immune Complex-Mediated Immune Responses. Sci. Adv. 5, eaax9586. doi:10.1126/sciadv.aax9586

Brandt, O., Rafei, D., Podstawa, E., Niedermeier, A., Jonkman, M. F., Terra, J. B., et al. (2012). Differential IgG Recognition of Desmoglein 3 by Paraneoplastic Pemphigus and Pemphigus Vulgaris Sera. J. Invest. Dermatol. 132, 1738-1741. doi:10.1038/jid.2012.1

Brenner, S., Sasson, A., and Sharon, O. (2002). Pemphigus and Infections. Clin. Dermatol. 20, 114-118. doi:10.1016/s0738-081x(01)00254-1

Brochado, M. J. F., Nascimento, D. F., Campos, W., Deghaide, N. H. S., Donadi, E. A., and Roselino, A. M. (2016). Differential HLA Class I and Class II Associations in Pemphigus Foliaceus and Pemphigus Vulgaris Patients from a Prevalent Southeastern Brazilian Region. J. Autoimmun. 72, 19-24. doi:10.1016/j.jaut.2016.04.007
Bystryn, J.-C., and Rudolph, J. L. (2005). Pemphigus. The Lancet 366, 61-73. doi:10.1016/S0140-6736(05)66829-8

Bystryn, J.-C. (1996). The Adjuvant Therapy of Pemphigus. Arch. Dermatol. 132, 203. doi:10.1001/archderm.1996.03890260105016

Cao, T., Shao, S., Fang, H., Li, B., and Wang, G. (2019). Role of Regulatory Immune Cells and Molecules in Autoimmune Bullous Dermatoses. Front. Immunol. 10, 1746. doi:10.3389/fimmu.2019.01746

Capon, F., Bharkhada, J., Cochrane, N. E., Mortimer, N. J., Setterfield, J. F., Reynaert, S., et al. (2006). Evidence of an Association between Desmoglein 3 Haplotypes and Pemphigus Vulgaris. Br. J. Dermatol. 154, 67-71. doi:10.1111/ j.1365-2133.2005.06882.x

Carcassi, C., Cottoni, F., Floris, L., Vacca, A., Mulargia, M., Arras, M., et al. (1996). HLA Haplotypes and Class II Molecular Alleles in Sardinian and Italian Patients with Pemphigus Vulgaris. Tissue Antigens 48, 662-667. doi:10.1111/ j.1399-0039.1996.tb02689.x

Carew, B., and Wagner, G. (2014). Cutaneous Pemphigus Vulgaris with Absence of Desmoglein 1 Autoantibodies. An Example of the Extended Desmoglein Compensation Theory. Australas. J. Dermatol. 55, 292-295. doi:10.1111/ ajd.12154

Carvalho, A. A., Santos Neto, D. A. D., Carvalho, M. A. D. R., Eleutério, S. J. P., and Xavier, A. R. E. D. O. (2019). Pênfigo Neonatal Em Filho De Mãe Com Pênfigo Vulgar: Relato De Caso. Rev. Paul. Pediatr. 37, 130-134. doi:10.1590/19840462/;2019;37;1;00004

Casulo, C., Maragulia, J., and Zelenetz, A. D. (2013). Incidence of Hypogammaglobulinemia in Patients Receiving Rituximab and the Use of Intravenous Immunoglobulin for Recurrent Infections. Clin. Lymphoma Myeloma Leuk. 13, 106-111. doi:10.1016/j.clml.2012.11.011

Chan, P. T., Ohyama, B., Nishifuji, K., Yoshida, K., Ishii, K., Hashimoto, T., et al. (2010). Immune Response towards the Amino-Terminus of Desmoglein 1 Prevails across Different Activity Stages in Nonendemic Pemphigus Foliaceus. Br. J. Dermatol. 162, 1242-1250. doi:10.1111/j.1365-2133.2010.09696.x

Chapman, M. S., Dinulos, J. G. H., Habif, T. P., and Zug, K. A. (2018). Skin Disease: Diagnosis and Treatment. New York: Elsevier.

Chen, J., Den, Z., and Koch, P. J. (2008). Loss of Desmocollin 3 in Mice Leads to Epidermal Blistering. J. Cel. Sci. 121, 2844-2849. doi:10.1242/jcs.031518

Chernyavsky, A., Chen, Y., Wang, P. H., and Grando, S. A. (2015). Pemphigus Vulgaris Antibodies Target the Mitochondrial Nicotinic Acetylcholine Receptors that Protect Keratinocytes from Apoptolysis. Int. Immunopharmacology 29, 76-80. doi:10.1016/j.intimp.2015.04.046

Chernyavsky, A., Amber, K. T., Agnoletti, A. F., Wang, C., and Grando, S. A. (2019). Synergy Among Non-desmoglein Antibodies Contributes to the Immunopathology of Desmoglein Antibody-Negative Pemphigus Vulgaris. J. Biol. Chem. 294, 4520-4528. doi:10.1074/jbc.RA118.006743

Cho, A., Caldara, A. L., Ran, N. A., Menne, Z., Kauffman, R. C., Affer, M., et al. (2019). Single-Cell Analysis Suggests that Ongoing Affinity Maturation Drives the Emergence of Pemphigus Vulgaris Autoimmune Disease. Cel Rep. 28, 909-922. e6. doi:10.1016/j.celrep.2019.06.066

Cirillo, N., Lanza, A., and Prime, S. S. (2010). Induction of Hyper-Adhesion Attenuates Autoimmune-Induced Keratinocyte Cell-Cell Detachment and Processing of Adhesion Molecules via Mechanisms that Involve PKC. Exp. Cel Res. 316, 580-592. doi:10.1016/j.yexcr.2009.10.005

Colliou, N., Picard, D., Caillot, F., Calbo, S., Le Corre, S., Lim, A., et al. (2013). Long-Term Remissions of Severe Pemphigus after Rituximab Therapy Are Associated with Prolonged Failure of Desmoglein B Cell Response. Sci. Transl. Med. 5, 175ra30. doi:10.1126/scitranslmed.3005166

Costa, L. M. C., Cappel, M. A., and Keeling, J. H. (2019). Clinical, Pathologic, and Immunologic Features of Pemphigus Herpetiformis: a Literature Review and Proposed Diagnostic Criteria. Int. J. Dermatol. 58, 997-1007. doi:10.1111/ijd.14395

Cozzani, E., Cacciapuoti, M., .Parodi, A., and Rebora, A. (2002). Pemphigus Following Tetanus and Diphtheria Vaccination. Br. J. Dermatol. 147, 180-195. doi:10.1046/j.1365-2133.2002.47958.x

Cozzani, E., Christana, K., Mastrogiacomo, A., Rampini, P., Drosera, M., Casu, M., et al. (2007). Pemphigus Vegetans Neumann Type with Anti-desmoglein and Anti-periplakin Autoantibodies. Eur. J. Dermatol. 17, 530-533. doi:10.1684/ ejd.2007.0270

Craft, J. E. (2012). Follicular Helper T Cells in Immunity and Systemic Autoimmunity. Nat. Rev. Rheumatol. 8, 337-347. doi:10.1038/ nrrheum. 2012.58 
Cremniter, D., Baudin, M., Roujeau, J. C., Prost, C., Consoli, S. G., Francés, C., et al. (1998). Stressful Life Events as Potential Triggers of Pemphigus. Arch. Dermatol. 134, 1486-1487. doi:10.1001/archderm.134.11.1486

Cuellar, I., Mejia, M., Castellanos-Angarita, A., and Casas-Barrera, M. A. (2020). Hallopeau Type of Pemphigus Vegetans, an Unusual Clinical Presentation of an Infrequent Disease. Dermatol. Online J. 26, 13030/qt91q8q1f1. doi:10.5070/ d 32610050470

Culton, D. A., Qian, Y., Li, N., Rubenstein, D., Aoki, V., Filhio, G. H., et al. (2008). Advances in Pemphigus and its Endemic Pemphigus Foliaceus (Fogo Selvagem) Phenotype: a Paradigm of Human Autoimmunity. J. Autoimmun. 31, 311-324. doi:10.1016/j.jaut.2008.08.003

Dalla-Costa, R., Pincerati, M. R., Beltrame, M. H., Malheiros, D., and Petzl-Erler, M. L. (2010). Polymorphisms in the 2q33 and 3q21 Chromosome Regions Including T-Cell Coreceptor and Ligand Genes May Influence Susceptibility to Pemphigus Foliaceus. Hum. Immunol. 71, 809-817. doi:10.1016/ j.humimm.2010.04.001

Damiani, G., Pacifico, A., Pelloni, F., and Iorizzo, M. (2021). The First Dose of COVID-19 Vaccine May Trigger Pemphigus and Bullous Pemphigoid Flares: Is the Second Dose Therefore Contraindicated? J. Eur. Acad. Dermatol. Venereol. 35, e645-e647. doi:10.1111/jdv.17472

Daneshpazhooh, M., Chams-Davatchi, C., Khamesipour, A., Mansoori, P., Taheri, A., Firooz, A., et al. (2007). Desmoglein 1 and 3 Enzyme-Linked Immunosorbent Assay in Iranian Patients with Pemphigus Vulgaris: Correlation with Phenotype, Severity, and Disease Activity. J. Eur. Acad. Dermatol. Venerol 21, 1319-1324. doi:10.1111/j.1468-3083.2007.02254.x

Daneshpazhooh, M., Fatehnejad, M., Rahbar, Z., Balighi, K., Ghandi, N., Ghiasi, M., et al. (2016). Trauma-induced Pemphigus: a Case Series of 36 Patients. JDDG: J. der Deutschen Dermatologischen Gesellschaft 14, 166-171. doi:10.1111/ ddg. 12738

Dar, S. A., Akhter, N., Haque, S., Singh, T., Mandal, R. K., Ramachandran, V. G., et al. (2016). Tumor Necrosis Factor (TNF)-a-308G/A (Rs1800629) Polymorphism Distribution in North India and its Association with Pemphigus: Case-Control Study and Meta-Analysis. Autoimmunity 49, 179-187. doi:10.3109/08916934.2015.1134512

Das, D., Singh, A., Antil, P. S., Sharma, D., Arava, S., Khandpur, S., et al. (2020). Distorted Frequency of Dendritic Cells and Their Associated Stimulatory and Inhibitory Markers Augment the Pathogenesis of Pemphigus Vulgaris. Immunol. Res. 68, 353-362. doi:10.1007/s12026-020-09166-0

Davies, A., Merli, F., Mihaljević, B., Mercadal, S., Siritanaratkul, N., Solal-Céligny, P., et al. (2017). Efficacy and Safety of Subcutaneous Rituximab versus Intravenous Rituximab for First-Line Treatment of Follicular Lymphoma (SABRINA): a Randomised, Open-Label, Phase 3 Trial. Lancet Haematol. 4, e272-e282. doi:10.1016/S2352-3026(17)30078-9

De Bonis, M., De Paolis, E., Scaglione, G. L., Fania, L., Lavieri, M. M., Mazzanti, C., et al. (2019). High-resolution Melting Analysis to Screen the ST18 Gene Functional Risk Variant for Pemphigus Vulgaris: The Occasion to Open a Debate on its Usefulness in Clinical Setting. Exp. Mol. Pathol. 108, 57-63. doi:10.1016/j.yexmp.2019.03.009

De, D., Kumar, S., Handa, S., and Mahajan, R. (2019). Fingernail Involvement in Pemphigus and its Correlation with Disease Severity and Other Clinicodemographic Parameters. Br. J. Dermatol. 180, 662-663. doi:10.1111/ bjd.17136

De Simone, C., Caldarola, G., D'agostino, M., Zampetti, A., Amerio, P., and Feliciani, C. (2008). Exacerbation of Pemphigus after Influenza Vaccination. Clin. Exp. Dermatol. 33, 718-720. doi:10.1111/j.1365-2230.2008.02835.x

Del Fresno, C., Saz-Leal, P., Enamorado, M., Wculek, S. K., Martínez-Cano, S., Blanco-Menéndez, N., et al. (2018). DNGR-1 in Dendritic Cells Limits Tissue Damage by Dampening Neutrophil Recruitment. Science 362, 351-356. doi:10.1126/science.aan8423

Delgado, J. C., Yunis, D. E., Bozón, M. V., Salazar, M., Deulofeut, R., Turbay, D., et al. (1996). MHC Class II Alleles and Haplotypes in Patients with Pemphigus Vulgaris from India. Tissue Antigens 48, 668-672. doi:10.1111/j.13990039.1996.tb02690.x

Delgado-Rizo, V., Martínez-Guzmán, M. A., Iñiguez-Gutierrez, L., García-Orozco, A., Alvarado-Navarro, A., and Fafutis-Morris, M. (2017). Neutrophil Extracellular Traps and its Implications in Inflammation: An Overview. Front. Immunol. 8, 81. doi:10.3389/fimmu.2017.00081
Dey-Rao, R., Seiffert-Sinha, K., and Sinha, A. A. (2013). Genome-wide Expression Analysis Suggests Unique Disease-Promoting and Disease-Preventing Signatures in Pemphigus Vulgaris. Genes Immun. 14, 487-499. doi:10.1038/ gene.2013.44

Di Zenzo, G., Di Lullo, G., Corti, D., Calabresi, V., Sinistro, A., Vanzetta, F., et al. (2012). Pemphigus Autoantibodies Generated through Somatic Mutations Target the Desmoglein-3 Cis-Interface. J. Clin. Invest. 122, 3781-3790. doi:10.1172/JCI64413

Diaz, L. A., Sampaio, S. A. P., Rivitti, E. A., Martins, C. R., Cunha, P. R., Lombardi, C., et al. (1989). Endemic Pemphigus Foliaceus (Fogo Selvagem): II. Current and Historic Epidemiologic Studies. J. Invest. Dermatol. 92, 4-12. doi:10.1111/ 1523-1747.ep13070394

Didona, D., Maglie, R., Eming, R., and Hertl, M. (2019). Pemphigus: Current and Future Therapeutic Strategies. Front. Immunol. 10, 1418. doi:10.3389/ fimmu.2019.01418

Dmochowski, M., Hashimoto, T., and Nishikawa, T. (1992). The Analysis of IgG Subclasses of Anti-intercellular Antibodies in Pemphigus by an Immunoblot Technique. Arch. Dermatol. Res. 284, 309-311. doi:10.1007/bf00372587

Dmochowski, M., Hashimoto, T., Garrod, D. R., and Nishikawa, T. (1993). Desmocollins I and II Are Recognized by Certain Sera from Patients with Various Types of Pemphigus, Particularly Brazilian Pemphigues Foliaceus. J. Invest. Dermatol. 100, 380-384. doi:10.1111/1523-1747.ep12471934

Dress, R. J., Dutertre, C.-A., Giladi, A., Schlitzer, A., Low, I., Shadan, N. B., et al. (2019). Plasmacytoid Dendritic Cells Develop from Ly6D+ Lymphoid Progenitors Distinct from the Myeloid Lineage. Nat. Immunol. 20, 852-864. doi:10.1038/s41590-019-0420-3

Eberhard, Y., Burgos, E., Gagliardi, J., Vullo, C. M., Borosky, A., Pesoa, S., et al. (2005). Cytokine Polymorphisms in Patients with Pemphigus. Arch. Dermatol. Res. 296, 309-313. doi:10.1007/s00403-004-0528-6

Ellebrecht, C. T., Choi, E. J., Allman, D. M., Tsai, D. E., Wegener, W. A., Goldenberg, D. M., et al. (2014). Subcutaneous Veltuzumab, a Humanized Anti-CD20 Antibody, in the Treatment of Refractory Pemphigus Vulgaris. JAMA Dermatol. 150, 1331. doi:10.1001/jamadermatol.2014.1939

Ellebrecht, C. T., Bhoj, V. G., Nace, A., Choi, E. J., Mao, X., Cho, M. J., et al. (2016). Reengineering Chimeric Antigen Receptor T Cells for Targeted Therapy of Autoimmune Disease. Science 353, 179-184. doi:10.1126/science.aaf6756

Eming, R., and Hertl, M. (2006). Immunoadsorption in Pemphigus. Autoimmunity 39, 609-616. doi:10.1080/08916930600972040

Eming, R., Büdinger, L., Riechers, R., Christensen, O., Bohlen, H., Kalish, R., et al. (2000). Frequency Analysis of Autoreactive T-helper 1 and 2 Cells in Bullous Pemphigoid and Pemphigus Vulgaris by Enzyme-linked Immunospot Assay. Br. J. Dermatol. 143, 1279-1282. doi:10.1046/j.1365-2133.2000.03901.x

Eming, R., Hennerici, T., Bäcklund, J., Feliciani, C., Visconti, K. C., Willenborg, S., et al. (2014). Pathogenic IgG Antibodies against Desmoglein 3 in Pemphigus Vulgaris Are Regulated by HLA-Drb1 ${ }^{\star} 04: 02$-Restricted T Cells. J.I. 193, 4391-4399. doi:10.4049/jimmunol.1401081

Etesami, I., Seirafi, H., Ghandi, N., Salmani, H., Arabpour, M., Nasrollahzadeh, A., et al. (2018). The Association between ST 18 Gene Polymorphism and Severe Pemphigus Disease Among Iranian Population. Exp. Dermatol. 27, 1395-1398. doi:10.1111/exd.13778

Evangelista, F., Dasher, D. A., Diaz, L. A., Prisayanh, P. S., and Li, N. (2008). E-cadherin Is an Additional Immunological Target for Pemphigus Autoantibodies. J. Invest. Dermatol. 128, 1710-1718. doi:10.1038/sj.jid. 5701260

Eyre, R. W., and Stanley, J. R. (1987). Human Autoantibodies against a Desmosomal Protein Complex with a Calcium-Sensitive Epitope Are Characteristic of Pemphigus Foliaceus Patients. J. Exp. Med. 165, 1719-1724. doi:10.1084/jem.165.6.1719

Eyre, R. W., and Stanley, J. R. (1988). Identification of Pemphigus Vulgaris Antigen Extracted from normal Human Epidermis and Comparison with Pemphigus Foliaceus Antigen. J. Clin. Invest. 81, 807-812. doi:10.1172/JCI113387

Fenner, J., Min, M. S., Liu, S., and Silverberg, N. (2020). A Case of Neonatal Pemphigus Vulgaris with Co-existing BP180 Autoantibodies. Pediatr. Dermatol. 37, 241-243. doi:10.1111/pde.14059

Fenniche, S., Benmously, R., Marrak, H., Dhaoui, A., Ammar, F. B., and Mokhtar, I. (2006). Neonatal Pemphigus Vulgaris in an Infant Born to a Mother with Pemphigus Vulgaris in Remission. Pediatr. Dermatol. 23, 124-127. doi:10.1111/ j.1525-1470.2006.00195.x 
Fiebiger, E., Hammerschmid, F., Stingl, G., and Maurer, D. (1998). AntiFcepsilonRIalpha Autoantibodies in Autoimmune-Mediated Disorders. Identification of a Structure-Function Relationship. J. Clin. Invest. 101, 243-251. doi:10.1172/JCI511

Fitch, E., Harper, E., Skorcheva, I., Kurtz, S. E., and Blauvelt, A. (2007). Pathophysiology of Psoriasis: Recent Advances on IL-23 and Th17 Cytokines. Curr. Rheumatol. Rep. 9, 461-467. doi:10.1007/s11926-007-0075-1

Focosi, D., Tuccori, M., and Maggi, F. (2019). Progressive Multifocal Leukoencephalopathy and anti-CD20 Monoclonal Antibodies: What Do We Know after 20 Years of Rituximab. Rev. Med. Virol. 29. doi:10.1002/ rmv.2077

Foster, M. L., Spaulding, R. T., and Schadt, C. R. (2021). Neonatal Pemphigus Vulgaris. JAMA Dermatol. 157, 220. doi:10.1001/jamadermatol.2020.3990

Frušić-zlotkin, M., Pergamentz, R., Michel, B., David, M., Mimouni, D., Brégégère, F., et al. (2005). The Interaction of Pemphigus Autoimmunoglobulins with Epidermal Cells: Activation of the Fas Apoptotic Pathway and the Use of Caspase Activity for Pathogenicity Tests of Pemphigus Patients. Ann. N.Y Acad. Sci. 1050, 371-379. doi:10.1196/annals.1313.040

Fryer, E. J., and Lebwohl, M. (1994). Pemphigus Vulgaris after Initiation of Psoralen and UVA Therapy for Psoriasis. J. Am. Acad. Dermatol. 30, 651-653. doi:10.1016/S0190-9622(09)80116-3

Futei, Y., Amagai, M., Sekiguchi, M., Nishifuji, K., Fujii, Y., and Nishikawa, T. (2000). Use of Domain-Swapped Molecules for Conformational Epitope Mapping of Desmoglein 3 in Pemphigus Vulgaris. J. Invest. Dermatol. 115, 829-834. doi:10.1046/j.1523-1747.2000.00137.x

Gabrilovich, D. I., and Nagaraj, S. (2009). Myeloid-derived Suppressor Cells as Regulators of the Immune System. Nat. Rev. Immunol. 9, 162-174. doi:10.1038/ nri2506

Gambino, A., Carbone, M., Arduino, P. G., Carcieri, P., Carbone, L., and Broccoletti, R. (20142014). Conservative Approach in Patients with Pemphigus Gingival Vulgaris: A Pilot Study of Five Cases. Int. J. Dentistry 2014, 1-4. doi:10.1155/2014/747506

Gamonet, C., Ferrand, C., Colliou, N., Musette, P., Joly, P., Girardin, M., et al. (2014). Lack of Expression of an Alternative CD20 Transcript Variant in Circulating B Cells from Patients with Pemphigus. Exp. Dermatol. 23, 66-67. doi:10.1111/exd.12299

Gao, J., Zhu, C., Zhang, Y., Sheng, Y., Yang, F., Wang, W., et al. (2018). Association Study and Fine-Mapping Major Histocompatibility Complex Analysis of Pemphigus Vulgaris in a Han Chinese Population. J. Invest. Dermatol. 138, 2307-2314. doi:10.1016/j.jid.2018.05.011

Gazit, E., and Loewenthal, R. (2005). The Immunogenetics of Pemphigus Vulgaris. Autoimmun. Rev. 4, 16-20. doi:10.1016/j.autrev.2004.05.002

Geller, S., Gat, A., Zeeli, T., Hafner, A., Eming, R., Hertl, M., et al. (2014). The Expanding Spectrum ofIgApemphigus: a Case Report and Review of the Literature. Br. J. Dermatol. 171, 650-656. doi:10.1111/bjd.12940

Geng, L., Wang, Y., Zhai, N., Lu, Y. N., Song, F. J., and Chen, H. D. (2005). Association between Pemphigus Vulgaris and Human Leukocyte Antigen in Han Nation of Northeast China. Chin. Med. Sci. J. 20, 166-170.

Ghaedi, F., Etesami, I., Aryanian, Z., Kalantari, Y., Goodarzi, A., Teymourpour, A., et al. (2021). Drug-induced Pemphigus: A Systematic Review of 170 Patients. Int. Immunopharmacology 92, 107299. doi:10.1016/j.intimp.2020.107299

Goebeler, M., Bata-Csörgö, Z., De Simone, C., Didona, B., Remenyik, E., Reznichenko, N., et al. (2021). Treatment of Pemphigus Vulgaris and Foliaceus with Efgartigimod, a Neonatal Fc Receptor Inhibitor: a Phase II Multicentre, Open-label Feasibility Trial. Br. J. Dermatol., 20782. doi:10.1111/ bjd. 20782

Goh, M. S. Y., McCormack, C., Dinh, H. V., Welsh, B., Foley, P., and Prince, H. M. (2007). Rituximab in the Adjuvant Treatment of Pemphigus Vulgaris: a Prospective Open-Label Pilot Study in Five Patients. Br. J. Dermatol. 156, 990-996. doi:10.1111/j.1365-2133.2007.07800.x

Gonçalves, G. A., Brito, M. M., Salathiel, A. M., Ferraz, T. S., Alves, D., and Roselino, A. M. (2011). Incidence of Pemphigus Vulgaris Exceeds that of Pemphigus Foliaceus in a Region where Pemphigus Foliaceus Is Endemic: Analysis of a 21-year Historical Series. Bras Dermatol. 86, 1109-1112. doi:10.1590/s0365-05962011000600007

Gooptu, C., and Staughton, R. C. D. (1998). Use of Topical Cyclosporin in Oral Pemphigus. J. Am. Acad. Dermatol. 38, 860-861. doi:10.1016/S0190-9622(98) 70476-1
Grando, S. A., and Dahl, M. V. (2000). Nicotine and Pemphigus. Arch. Dermatol. 136, 1269. doi:10.1001/archderm.136.10.1269

Grando, S. A. (2000). Autoimmunity to Keratinocyte Acetylcholine Receptors in Pemphigus. Dermatology 201, 290-295. doi:10.1159/000051540

Grando, S. A. (2019). Retrospective Analysis of a Single-center Clinical Experience toward Development of Curative Treatment of 123 Pemphigus Patients with a Long-term Follow-up: Efficacy and Safety of the Multidrug Protocol Combining Intravenous Immunoglobulin with the Cytotoxic Immunosuppressor and Mitochondrion-protecting Drugs. Int. J. Dermatol. 58, 114-125. doi:10.1111/ijd.14143

Green, M. G., and Bystryn, J.-C. (2008). Effect of Intravenous Immunoglobulin Therapy on Serum Levels of IgG1 and IgG4 Antidesmoglein 1 and Antidesmoglein 3 Antibodies in Pemphigus Vulgaris. Arch. Dermatol. 144, 1621-1624. doi:10.1001/archdermatol.2008.503

Grillo-López, A. J. (2000). Rituximab: an Insider's Historical Perspective. Semin. Oncol. 27 (6 Suppl 12), 9-16.

Gürcan, H. M., and Razzaque Ahmed, A. (2009). Analysis of Current Data on the Use of Methotrexate in the Treatment of Pemphigus and Pemphigoid. $\mathrm{Br}$. J. Dermatol. 161, 723-731. doi:10.1111/j.1365-2133.2009.09246.x

Gushi, M., Yamamoto, Y.-I., Mine, Y., Awazawa, R., Nonaka, K., Taira, K., et al. (2008). Neonatal Pemphigus Vulgaris. J. Dermatol. 35, 529-535. doi:10.1111/ j.1346-8138.2008.00515.x

Hamadah, I., Chisti, M. A., Haider, M., Binamer, Y., Alajlan, S., Aleyouni, Y., et al. (2019). Rituximab/IVIG in Pemphigus - a 10-year Study with a Long FollowUp. J. Dermatol. Treat. 30, 170-175. doi:10.1080/09546634.2018.1484873

Hammers, C. M., and Stanley, J. R. (2016). Mechanisms of Disease: Pemphigus and Bullous Pemphigoid. Annu. Rev. Pathol. Mech. Dis. 11, 175-197. doi:10.1146/ annurev-pathol-012615-044313

Hammers, C. M., Chen, J., Lin, C., Kacir, S., Siegel, D. L., Payne, A. S., et al. (2015). Persistence of Anti-desmoglein $3 \mathrm{IgG}+\mathrm{B}$-Cell Clones in Pemphigus Patients over Years. J. Invest. Dermatol. 135, 742-749. doi:10.1038/jid.2014.291

Harman, K. E., Brown, D., Exton, L. S., Groves, R. W., Hampton, P. J., Mohd Mustapa, M. F., et al. (2017). British Association of Dermatologists' Guidelines for the Management of Pemphigus Vulgaris 2017. Br. J. Dermatol. 177, 1170-1201. doi:10.1111/bjd.15930

Hashimoto, K., Miki, Y., Nakata, S., and Matsuyama, M. (1977). HLA-A10 in Pemphigus Among Japanese. Arch. Dermatol. 113, 1518-1519. doi:10.1001/ archderm.1977.01640110038003

Hashimoto, T., Sugiura, M., Kurihara, S., and Nishikawa, T. (1983). Atypical Pemphigus Showing Eosinophilic Spongiosis. Clin. Exp. Dermatol. 8, 37-40. doi:10.1111/j.1365-2230.1983.tb01742.x

Hashimoto, K., Singer, K., and Lazarus, G. S. (1984). Penicillamine-Induced Pemphigus. Arch. Dermatol. 120, 762-764. doi:10.1001/ archderm.1984.01650420072019

Hashimoto, K., Wun, T.-C., Baird, J., Lazarus, G. S., and Jensen, P. J. (1989). Characterization of Keratinocyte Plasminogen Activator Inhibitors and Demonstration of the Prevention of Pemphigus IgG-Induced Acantholysis by a Purified Plasminogen Activator Inhibitor. J. Invest. Dermatol. 92, 310-314. doi:10.1111/1523-1747.ep12277087

Hashimoto, T., Ogawa, M. M., Konohana, A., and Nishikawa, T. (1990). Detection of Pemphigus Vulgaris and Pemphigus Foliaceus Antigens by Immunoblot Analysis Using Different Antigen Sources. J. Invest. Dermatol. 94, 327-331. doi:10.1111/1523-1747.ep12874456

Hashimoto, K., Hashimoto, T., Higashiyama, M., Nishikawa, T., Garrod, D., and Yoshikawa, K. (1994). Detection of Anti-desmocollins I and II Autoantibodies in Two Cases of Hallopeau Type Pemphigus Vegetans by Immunoblot Analysis. J. Dermatol. Sci. 7, 100-106. doi:10.1016/0923-1811(94)90083-3

Hashimoto, T., Amagai, M., Watanabe, K., Chorzelski, T. P., Bhogal, B. S., Black, M. M., et al. (1995). Characterization of Paraneoplastic Pemphigus Autoantigens by Immunoblot Analysis. J. Invest. Dermatol. 104, 829-834. doi:10.1111/1523-1747.ep12607012

Hashimoto, T., Kiyokawa, C., Mori, O., Miyasato, M., Chidgey, M. A. J., Garrod, D. R., et al. (1997). Human Desmocollin 1 (Dscl) Is an Autoantigen for the Subcorneal Pustular Dermatosis Type of IgA Pemphigus. J. Invest. Dermatol. 109, 127-131. doi:10.1111/1523-1747.ep12319025

Hébert, V., Petit, M., Maho-Vaillant, M., Golinski, M.-L., Riou, G., Derambure, C., et al. (2019). Modifications of the Transcriptomic Profile of Autoreactive B Cells from Pemphigus Patients after Treatment with Rituximab or a Standard 
Corticosteroid Regimen. Front. Immunol. 10, 1794. doi:10.3389/ fimmu.2019.01794

Hébert, V., Vermeulin, T., Tanguy, L., Tedbirt, B., Mignard, C., Bénichou, J., et al. (2020). Comparison of Real Costs in the French Healthcare System in Newly Diagnosed Patients with Pemphigus for First-line Treatment with Rituximab vs. Standard Corticosteroid Regimen: Data from a National Multicentre Trial. Br. J. Dermatol. 183, 121-127. doi:10.1111/bjd.18563

Hébert, V., Maho-Vaillant, M., Golinski, M.-L., Petit, M., Riou, G., Boyer, O., et al. (2021). Modifications of the BAFF/BAFF-Receptor Axis in Patients with Pemphigus Treated with Rituximab versus Standard Corticosteroid Regimen. Front. Immunol. 12, 666022. doi:10.3389/fimmu.2021.666022

Heizmann, M., Itin, P., Wernli, M., Borradori, L., and Bargetzi, M. J. (2001). Successful Treatment of Paraneoplastic Pemphigus in Follicular NHL with Rituximab: Report of a Case and Review of Treatment for Paraneoplastic Pemphigus in NHL and CLL. Am. J. Hematol. 66, 142-144. doi:10.1002/10968652(200102)66:2<142::AID-AJH1032>3.0.CO;2-0

Hennerici, T., Pollmann, R., Schmidt, T., Seipelt, M., Tackenberg, B., Möbs, C., et al. (2016). Increased Frequency of T Follicular Helper Cells and Elevated Interleukin-27 Plasma Levels in Patients with Pemphigus. PLoS ONE 11, e0148919. doi:10.1371/journal.pone.0148919

Hertl, M., Jedlickova, H., Karpati, S., Marinovic, B., Uzun, S., Yayli, S., et al. (2015). Pemphigus. S2 Guideline for Diagnosis and Treatment - Guided by the European Dermatology Forum (EDF) in Cooperation with the European Academy of Dermatology and Venereology (EADV). J. Eur. Acad. Dermatol. Venereol. 29, 405-414. doi:10.1111/jdv.12772

Heupel, W.-M., Zillikens, D., Drenckhahn, D., and Waschke, J. (2008). Pemphigus Vulgaris IgG Directly Inhibit Desmoglein 3-mediated Transinteraction. J. Immunol. 181, 1825-1834. doi:10.4049/jimmunol.181.3.1825

Ho, A. W., and Kupper, T. S. (2019). T Cells and the Skin: from Protective Immunity to Inflammatory Skin Disorders. Nat. Rev. Immunol. 19, 490-502. doi:10.1038/s41577-019-0162-3

Hobbs, L. K., Noland, M. M. B., Raghavan, S. S., and Gru, A. A. (2021). Pemphigus Erythematosus: A Case Series from a Tertiary Academic center and Literature Review. J. Cutan. Pathol. 48, 1038-1050. doi:10.1111/cup.13992

Hodgson, T. A., Malik, F., Hegarty, A. M., and Porter, S. R. (2003). Topical Tacrolimus: a Novel Therapeutic Intervention for Recalcitrant Labial Pemphigus Vulgaris. Eur. J. Dermatol. 13, 142-144.

Holstein, J., Solimani, F., Baum, C., Meier, K., Pollmann, R., Didona, D., et al. (2021). Immunophenotyping in Pemphigus Reveals a TH17/TFH17 CellDominated Immune Response Promoting Desmoglein1/3-specific Autoantibody Production. J. Allergy Clin. Immunol. 147, 2358-2369. doi:10.1016/j.jaci.2020.11.008

Horwitz, M. S., and Sarvetnick, N. (1999). Viruses, Host Responses, and Autoimmunity. Immunol. Rev. 169, 241-253. doi:10.1111/j.1600065X.1999.tb01319.x

Howard, J. F., Bril, V., Vu, T., Karam, C., Peric, S., Margania, T., et al. (2021). Safety, Efficacy, and Tolerability of Efgartigimod in Patients with Generalised Myasthenia Gravis (ADAPT): a Multicentre, Randomised, PlaceboControlled, Phase 3 Trial. Lancet Neurol. 20, 526-536. doi:10.1016/S14744422(21)00159-9

Hsu, D. Y., Brieva, J., Sinha, A. A., Langan, S. M., and Silverberg, J. I. (2016). Comorbidities and Inpatient Mortality for Pemphigus in the U.S.A. $\mathrm{Br}$. J. Dermatol. 174, 1290-1298. doi:10.1111/bjd.14463

Huang, Y.-H., Wang, S.-H., Kuo, T.-T., and Chi, C.-C. (2005). Pemphigus Vegetans Occurring in a Split-Thickness Skin Graft. Dermatol. Surg. 31, 240-243. doi:10.1097/00042728-200502000-00023

Hübner, F., Recke, A., Zillikens, D., Linder, R., and Schmidt, E. (2016). Prevalence and Age Distribution of Pemphigus and Pemphigoid Diseases in Germany. J. Invest. Dermatol. 136, 2495-2498. doi:10.1016/j.jid.2016.07.013

Imchen, S., Jain, V., and Jindal, N. (2014). Localized Pemphigus Vegetans without Mucosal Involvement. Indian J. Dermatol. 59, 210. doi:10.4103/00195154.127712

Inaoki, M., Kodera, M., Fujimoto, A., Nousari, H. C., Anhalt, G. J., and Takehara, K. (2001). Paraneoplastic Pemphigus without Antidesmoglein 3 or Antidesmoglein 1 Autoantibodies. Br. J. Dermatol. 144, 610-613. doi:10.1046/j.1365-2133.2001.04095.x

Ishii, M., Izumi, J., Fujiwara, H., Ito, M., and Hamada, M. (2001). Immunoblotting Detection of Gamma-Catenin (Plakoglobin) Antibody in the Serum of a Patient with Paraneoplastic Pemphigus. Br. J. Dermatol. 144, 377-379. doi:10.1046/ j.1365-2133.2001.04031.x

Ishii, K., Lin, C., Siegel, D. L., and Stanley, J. R. (2008). Isolation of Pathogenic Monoclonal Anti-desmoglein 1 Human Antibodies by Phage Display of Pemphigus Foliaceus Autoantibodies. J. Invest. Dermatol. 128, 939-948. doi:10.1038/sj.jid.5701132

Ishii, N., Teye, K., Fukuda, S., Uehara, R., Hachiya, T., Koga, H., et al. (2015). Antidesmocollin Autoantibodies in Nonclassical Pemphigus. Br. J. Dermatol. 173, 59-68. doi:10.1111/bjd.13711

Jablonska, S., Chorzelski, T. P., Beutner, E. H., and Chorzelska, J. (1975). Herpetiform Pemphigus, a Variable Pattern of Pemphigus. Int. J. Dermatol. 14, 353-359. doi:10.1111/j.1365-4362.1975.tb00125.x

Jain, V. K., Dixit, V. B., and Mohan, H. (1989). Pemphigus Vegetans in an Unusual Site. Int. J. Dermatol. 28, 352-353. doi:10.1111/j.1365-4362.1989.tb01365.x

Janela, B., Patel, A. A., Lau, M. C., Goh, C. C., Msallam, R., Kong, W. T., et al. (2019). A Subset of Type I Conventional Dendritic Cells Controls Cutaneous Bacterial Infections through VEGFa-Mediated Recruitment of Neutrophils. Immunity 50, 1069-1083. e8. doi:10.1016/j.immuni.2019.03.001

Jelti, L., Cordel, N., Gillibert, A., Lacour, J.-P., Uthurriague, C., Doutre, M.-S., et al. (2019). Incidence and Mortality of Pemphigus in France. J. Invest. Dermatol. 139, 469-473. doi:10.1016/j.jid.2018.07.042

Jennings, J. M., Tucker, D. K., Kottke, M. D., Saito, M., Delva, E., Hanakawa, Y., et al. (2011). Desmosome Disassembly in Response to Pemphigus Vulgaris IgG Occurs in Distinct Phases and Can Be Reversed by Expression of Exogenous Dsg3. J. Invest. Dermatol. 131, 706-718. doi:10.1038/jid.2010.389

Jmaa, M. B., Abida, O., Fakhfakh, R., Bahloul, E., Sellami, K., Gaddour, L., et al. (20182018). Involvement of the IL23/Th17 Pathway in the Pathogenesis of Tunisian Pemphigus Foliaceus. Mediators Inflamm. 2018, 1-12. doi:10.1155/ $2018 / 8206983$

Jolles, S. (2001). A Review of High-Dose Intravenous Immunoglobulin (hdIVIg) in the Treatment of the Autoimmune Blistering Disorders. Clin. Exp. Dermatol. 26, 127-131. doi:10.1046/j.1365-2230.2001.00779.x

Joly, P., and Litrowski, N. (2011). Pemphigus Group (Vulgaris, Vegetans, Foliaceus, Herpetiformis, Brasiliensis). Clin. Dermatol. 29, 432-436. doi:10.1016/ j.clindermatol.2011.01.013

Joly, P., Richard, C., Gilbert, D., Courville, P., Chosidow, O., Roujeau, J. C., et al. (2000). Sensitivity and Specificity of Clinical, Histologic, and Immunologic Features in the Diagnosis of Paraneoplastic Pemphigus. J. Am. Acad. Dermatol. 43, 619-626. doi:10.1067/mjd.2000.107488

Joly, P., Maho-Vaillant, M., Prost-Squarcioni, C., Hebert, V., Houivet, E., Calbo, S., et al. (2017). First-line Rituximab Combined with Short-Term Prednisone versus Prednisone Alone for the Treatment of Pemphigus (Ritux 3): a Prospective, Multicentre, Parallel-Group, Open-Label Randomised Trial. The Lancet 389, 2031-2040. doi:10.1016/S0140-6736(17)30070-3

Joly, P., Horvath, B., Patsatsi, A., Uzun, S., Bech, R., Beissert, S., et al. (2020). Updated S2K Guidelines on the Management of Pemphigus Vulgaris and Foliaceus Initiated by the European Academy of Dermatology and Venereology (EADV). J. Eur. Acad. Dermatol. Venereol. 34, 1900-1913. doi:10.1111/jdv.16752

Kaegi, C., Steiner, U. C., Wuest, B., Crowley, C., and Boyman, O. (2020). Systematic Review of Safety and Efficacy of Atacicept in Treating Immune-Mediated Disorders. Front. Immunol. 11, 433. doi:10.3389/fimmu.2020.00433

Kalantari-Dehaghi, M., Anhalt, G. J., Camilleri, M. J., Chernyavsky, A. I., Chun, S., Felgner, P. L., et al. (2013). Pemphigus Vulgaris Autoantibody Profiling by Proteomic Technique. PLoS ONE 8, e57587. doi:10.1371/journal.pone.0057587

Kamiya, K., Aoyama, Y., Shirafuji, Y., Hamada, T., Morizane, S., Fujii, K., et al. (2012). Detection of Antibodies against the Non-calcium-dependent Epitopes of Desmoglein 3 in Pemphigus Vulgaris and Their Pathogenic Significance. Br. J. Dermatol. 167, 252-261. doi:10.1111/j.1365-2133.2012.10929.x

Kamiya, K., Aoyama, Y., Shirafuji, Y., Hamada, T., Morizane, S., Fujii, K., et al. (2013). A Higher Correlation of the Antibody Activities against the Calciumdependent Epitopes of Desmoglein 3 Quantified by Ethylenediaminetetraacetic Acid-Treated Enzyme-Linked Immunosorbent Assay with Clinical Disease Activities of Pemphigus Vulgaris. J. Dermatol. Sci. 70, 190-195. doi:10.1016/ j.jdermsci.2013.02.011

Kamran, B., Maryam, D., Somayeh, K., Mostafa, M.-n., Mahsa, H.-j., and Cheyda, C.-D. (2013). Adjuvant Rituximab in the Treatment of Pemphigus Vulgaris: a Phase II Clinical Trial. Int. J. Dermatol. 52, 862-867. doi:10.1111/j.13654632.2012.5847.x 
Kano, Y., Shimosegawa, M., Mizukawa, Y., and Shiohara, T. (2000). Pemphigus Foliaceus Induced by Exposure to Sunlight. Dermatology 201, 132-138. doi:10.1159/000018456

Kanwar, A. J., and Kaur, S. (1991). Pemphigus in Children. Int. J. Dermatol. 30, 343-346. doi:10.1111/j.1365-4362.1991.tb03872.x

Kardos, M., Levine, D., Gürcan, H. M., and Ahmed, A. R. (2009). Pemphigus Vulgaris in Pregnancy. Obstetrical Gynecol. Surv. 64, 739-749. doi:10.1097/ OGX.0b013e3181bea089

Kárpáti, S., Amagai, M., Liu, W. L., Dmochowski, M., Hashimoto, T., and Horváth, A. (2000). Identification of Desmoglein 1 as Autoantigen in a Patient with Intraepidermal Neutrophilic IgA Dermatosis Type of IgA Pemphigus. Exp. Dermatol. 9, 224-228. doi:10.1034/j.1600-0625.2000.009003224.x

Kasperkiewicz, M., Kowalewski, C., and Jabłońska, S. (2014). Pemphigus Herpetiformis: From First Description until Now. J. Am. Acad. Dermatol. 70, 780-787. doi:10.1016/j.jaad.2013.11.043

Kasperkiewicz, M., Ellebrecht, C. T., Takahashi, H., Yamagami, J., Zillikens, D., Payne, A. S., et al. (2017). Pemphigus. Nat. Rev. Dis. Primers 3, 17026. doi:10.1038/nrdp.2017.26

Kawasaki, Y., Aoyama, Y., Tsunoda, K., Amagai, M., and Kitajima, Y. (2006). Pathogenic Monoclonal Antibody against Desmoglein 3 Augments Desmoglein 3 and P38 MAPK Phosphorylation in Human Squamous Carcinoma Cell Line. Autoimmunity 39, 587-590. doi:10.1080/08916930600971943

Kazerounian, S., Mahoney, M. G., Uitto, J., and Aho, S. (2000). Envoplakin and Periplakin, the Paraneoplastic Pemphigus Antigens, Are Also Recognized by Pemphigus Foliaceus Autoantibodies. J. Invest. Dermatol. 115, 505-507. doi:10.1046/j.1523-1747.2000.00088-2.x

Khachemoune, A., Guldbakke, K. K., and Ehrsam, E. (2006). Pemphigus Foliaceus: a Case Report and Short Review. Cutis 78 (2), 105-110.

Kim, S.-C., Kwon, Y. D., Lee, I. J., Lee, I. J., Chang, S. N., and Lee, T. G. (1997). cDNA Cloning of the 210-kDa Paraneoplastic Pemphigus Antigen Reveals that Envoplakin Is a Component of the Antigen Complex. J. Invest. Dermatol. 109, 365-369. doi:10.1111/1523-1747.ep12336235

Kim, S.-C., Chung, Y. L., Kim, J., Cho, N. J., and Amagai, M. (2001). Pemphigus Vulgaris with Autoantibodies to Desmoplakin. Br. J. Dermatol. 145, 838-840. doi:10.1046/j.1365-2133.2001.04415.x

Kim, A. R., Han, D., Choi, J. Y., Seok, J., Kim, S.-E., Seo, S.-H., et al. (2020). Targeting Inducible Costimulator Expressed on CXCR5+PD-1+ TH Cells Suppresses the Progression of Pemphigus Vulgaris. J. Allergy Clin. Immunol. 146, 1070-1079. e8. doi:10.1016/j.jaci.2020.03.036

Kitashima, D. Y., Kobayashi, T., Woodring, T., Idouchi, K., Doebel, T., Voisin, B., et al. (2018). Langerhans Cells Prevent Autoimmunity via Expansion of Keratinocyte Antigen-specific Regulatory T Cells. EBioMedicine 27, 293-303. doi:10.1016/j.ebiom.2017.12.022

Kljuic, A., Bazzi, H., Sundberg, J. P., Martinez-Mir, A., O’Shaughnessy, R., Mahoney, M. G., et al. (2003). Desmoglein 4 in Hair Follicle Differentiation and Epidermal Adhesion. Cell 113, 249-260. doi:10.1016/S0092-8674(03) 00273-3

Kneisel, A., and Hertl, M. (2011a). Autoimmune Bullous Skin Diseases. Part 1: Clinical Manifestations. JDDG: J. der Deutschen Dermatologischen Gesellschaft 9, 844-857. doi:10.1111/j.1610-0387.2011.07793.x

Kneisel, A., and Hertl, M. (2011b). Autoimmune Bullous Skin Diseases. Part 2: Diagnosis and Therapy. JDDG: J. der Deutschen Dermatologischen Gesellschaft 9, 927-947. doi:10.1111/j.1610-0387.2011.07809.x

Koch, P. J., Mahoney, M. G., Ishikawa, H., Pulkkinen, L., Uitto, J., Shultz, L., et al. (1997). Targeted Disruption of the Pemphigus Vulgaris Antigen (Desmoglein 3) Gene in Mice Causes Loss of Keratinocyte Cell Adhesion with a Phenotype Similar to Pemphigus Vulgaris. J. Cel Biol. 137, 1091-1102. doi:10.1083/jcb.137.5.1091

Koga, H., Ohyama, B., Tsuruta, D., Ishii, N., Hamada, T., Dainichi, T., et al. (2012). Five Japanese Cases of Antidesmoglein 1 Antibody-positive and Antidesmoglein 3 Antibody-negative Pemphigus with Oral Lesions. $\mathrm{Br}$. J. Dermatol. 166, 976-980. doi:10.1111/j.1365-2133.2012.10827.x

Korman, N. J., Eyre, R. W., Klaus-Kovtun, V., and Stanley, J. R. (1989). Demonstration of an Adhering-Junction Molecule (Plakoglobin) in the Autoantigens of Pemphigus Foliaceus and Pemphigus Vulgaris. N. Engl. J. Med. 321, 631-635. doi:10.1056/NEJM198909073211002

Koutlas, I. G., Camara, R., Argyris, P. P., Davis, M. D. P., and Miller, D. D. (2021). Development of Pemphigus Vulgaris after the Second Dose of the mRNA-1273 SARS-Cov-2 Vaccine. Oral Dis. doi:10.1111/odi.14089
Kozlowska, A., Hashimoto, T., Jarzabek-Chorzelska, M., Amagai, A., Nagata, Y., Strasz, Z., et al. (2003). Pemphigus Herpetiformis with IgA and IgG Antibodies to Desmoglein 1 and IgG Antibodies to Desmocollin 3. J. Am. Acad. Dermatol. 48, 117-122. doi:10.1067/mjd.2003.23

Kridin, K., Zelber-Sagi, S., and Bergman, R. (2017). Pemphigus Vulgaris and Pemphigus Foliaceus: Differences in Epidemiology and Mortality. Acta Derm Venerol 97, 1095-1099. doi:10.2340/00015555-2706

Kridin, K., Patel, P. M., Jones, V. A., Cordova, A., and Amber, K. T. (2020). IgA Pemphigus: A Systematic Review. J. Am. Acad. Dermatol. 82, 1386-1392. doi:10.1016/j.jaad.2019.11.059

Kridin, K. (2018). Pemphigus Group: Overview, Epidemiology, Mortality, and Comorbidities. Immunol. Res. 66, 255-270. doi:10.1007/s12026-018-8986-7

Kushner, C. J., Wang, S., Tovanabutra, N., Tsai, D. E., Werth, V. P., and Payne, A. S. (2019). Factors Associated with Complete Remission after Rituximab Therapy for Pemphigus. JAMA Dermatol. 155, 1404. doi:10.1001/ jamadermatol.2019.3236

Lakshmi, M. J. D., Jaisankar, T. J., Rajappa, M., Thappa, D. M., Chandrashekar, L., Divyapriya, D., et al. (2017). Correlation of Antimuscarinic Acetylcholine Receptor Antibody Titers and Antidesmoglein Antibody Titers with the Severity of Disease in Patients with Pemphigus. J. Am. Acad. Dermatol. 76, 895-902. doi:10.1016/j.jaad.2016.11.039

Lambert, J., Bracke, S., Van Roy, F., Pas, H. H., Bonné, S., and De Schepper, S. (2010). Serum Plakophilin-3 Autoreactivity in Paraneoplastic Pemphigus. Br. J. Dermatol. 163, 630-632. doi:10.1111/j.1365-2133.2010.09845.x

Langenhan, J., Dworschak, J., Saschenbrecker, S., Komorowski, L., Schlumberger, W., Stöcker, W., et al. (2014). Specific Immunoadsorption of Pathogenic Autoantibodies in Pemphigus Requires the Entire Ectodomains of Desmogleins. Exp. Dermatol. 23, 253-259. doi:10.1111/exd.12355

Lee, C. W., Yang, H. Y., Kim, S.-C., Jung, J. H., and Hwang, J. J. (1998). HLA Class II Allele Associations in Korean Patients with Pemphigus. Dermatology 197, 349-352. doi:10.1159/000018030

Lee, H. E., Berkowitz, P., Jolly, P. S., Diaz, L. A., Chua, M. P., and Rubenstein, D. S. (2009). Biphasic Activation of p38MAPK Suggests that Apoptosis Is a Downstream Event in Pemphigus Acantholysis. J. Biol. Chem. 284, 12524-12532. doi:10.1074/jbc.M808204200

Lee, S. H., Hong, W. J., and Kim, S.-C. (2017). Analysis of Serum Cytokine Profile in Pemphigus. Ann. Dermatol. 29, 438. doi:10.5021/ad.2017.29.4.438

Lee, J., Lundgren, D. K., Mao, X., Manfredo-Vieira, S., Nunez-Cruz, S., Williams, E. F., et al. (2020). Antigen-specific B Cell Depletion for Precision Therapy of Mucosal Pemphigus Vulgaris. J. Clin. Invest. 130, 6317-6324. doi:10.1172/ JCI138416

Leger, S., Picard, D., Ingen-Housz-Oro, S., Arnault, J.-P., Aubin, F., Carsuzaa, F., et al. (2012). Prognostic Factors of Paraneoplastic Pemphigus. Arch. Dermatol. 148, 1165-1172. doi:10.1001/archdermatol.2012.1830

Leroy, D., Lebrun, J., Maillard, V., Mandard, J. C., and Deschamps, P. (1982). Pemphigus Vegetans, a Clinical Type of Chronic Pustular Dermatitis of Hallopeau. Ann. Dermatol. Venereol. 109, 549-555.

Li, S., Zhang, Q., Wang, P., Li, J., Ni, J., Wu, J., et al. (2018). Association between HLA-DQB1 Polymorphisms and Pemphigus Vulgaris: A Meta-Analysis. Immunological Invest. 47, 101-112. doi:10.1080/08820139.2017.1385622

Lightman, S. M., Utley, A., and Lee, K. P. (2019). Survival of Long-Lived Plasma Cells (LLPC): Piecing Together the Puzzle. Front. Immunol. 10, 965. doi:10.3389/fimmu.2019.00965

Lin, M. S., Swartz, S. J., Lopez, A., Ding, X., Fernandez-Vina, M. A., Stastny, P., et al. (1997). Development and Characterization of Desmoglein-3 Specific T Cells from Patients with Pemphigus Vulgaris. J. Clin. Invest. 99, 31-40. doi:10.1172/ JCI119130

Liu, Q., Bu, D.-F., Li, D., and Zhu, X.-J. (2008). Genotyping of HLA-I and HLA-II Alleles in Chinese Patients with Paraneoplastic Pemphigus. Br. J. Dermatol. 158, 587-591. doi:10.1111/j.1365-2133.2007.08361.x

Liu, J., Ge, Y., Zong, L., and Lu, S. (2020). Pemphigus Vegetans Localised to the Soles of Both Feet: Successful Clearance with Intralesional Corticosteroid. Australas. J. Dermatol. 61, e452-e453. doi:10.1111/ajd.13355

Lo, A. S., Mao, X., Mukherjee, E. M., Ellebrecht, C. T., Yu, X., Posner, M. R., et al. (2016). Pathogenicity and Epitope Characteristics Do Not Differ in IgG Subclass-Switched Anti-desmoglein 3 IgG1 and IgG4 Autoantibodies in Pemphigus Vulgaris. PLoS ONE 11, e0156800. doi:10.1371/ journal.pone. 0156800 
Loiseau, P., Lecleach, L., Prost, C., Lepage, V., Busson, M., Bastuji-Garin, S., et al. (2000). HLA Class II Polymorphism Contributes to Specify Desmoglein Derived Peptides in Pemphigus Vulgaris and Pemphigus Foliaceus. J. Autoimmun. 15, 67-73. doi:10.1006/jaut.2000.0388

Lombardi, M. L., de Angelis, E., Rossano, F., and Ruocco, V. (1993). Imbalance between Plasminogen Activator and its Inhibitors in Thiol-Lnduced Acantholysis. Dermatology 186, 118-122. doi:10.1159/000247321

Lombardi, M. L., Mercuro, O., Pirozzi, G., Manzo, C., Lombari, V., Ruocco, V., et al. (1999). Common Human Leukocyte Antigen Alleles in Pemphigus Vulgaris and Pemphigus Foliaceus Italian Patients. J. Invest. Dermatol. 113, 107-110. doi:10.1046/j.1523-1747.1999.00626.x

Lozada-Nur, F., Miranda, C., and Maliksi, R. (1994). Double-blind Clinical Trial of 0.05\% Clobetasol Propionate (Corrected from Proprionate) Ointment in Orabase and $0.05 \%$ Fluocinonide Ointment in Orabase in the Treatment of Patients with Oral Vesiculoerosive Diseases. Oral Surg. Oral Med. Oral Pathol. 77, 598-604. doi:10.1016/0030-4220(94)90318-2

Lua, A. C. Y., Ong, F. L. L., Choo, K. J. L., Yeo, Y. W., and Oh, C. C. (2021). An Unusual Presentation of Pemphigus Foliaceus Following COVID-19 Vaccination. Australas. J. Dermatol. doi:10.1111/ajd.13755

Lunardon, L., and Payne, A. S. (2012). Inhibitory Human Antichimeric Antibodies to Rituximab in a Patient with Pemphigus. J. Allergy Clin. Immunol. 130, 800-803. doi:10.1016/j.jaci.2012.03.022

Lund, F. E., and Randall, T. D. (2010). Effector and Regulatory B Cells: Modulators of CD4+ T Cell Immunity. Nat. Rev. Immunol. 10, 236-247. doi:10.1038/ nri2729

Mahé, A., Flageul, B., Cissé, I., Kéita, S., and Bobin, P. (1996). Pemphigus in Mali: a Study of 30 Cases. Br. J. Dermatol. 134, 114-119.

Mahoney, M. G., Aho, S., Uitto, J., and Stanley, J. R. (1998). The Members of the Plakin Family of Proteins Recognized by Paraneoplastic Pemphigus Antibodies Include Periplakin. J. Invest. Dermatol. 111, 308-313. doi:10.1046/j.15231747.1998.00279.x

Mahoney, M. G., Wang, Z., Rothenberger, K., Koch, P. J., Amagai, M., and Stanley, J. R. (1999). Explanations for the Clinical and Microscopic Localization of Lesions in Pemphigus Foliaceus and Vulgaris. J. Clin. Invest. 103, 461-468. doi:10.1172/JCI5252

Maho-Vaillant, M., Perals, C., Golinski, M.-L., Hébert, V., Caillot, F., Mignard, C., et al. (2021). Rituximab and Corticosteroid Effect on Desmoglein-specific B Cells and Desmoglein-specific T Follicular Helper Cells in Pemphigus. J. Invest. Dermatol. 141, 2132-2140. e1. doi:10.1016/j.jid.2021.01.031

Maier, L., Udvardi, A., Hertl, M., Eming, R., Schmidt, E., Zillikens, D., et al. (2017). Paraneoplastic Pemphigus with Anti-bp180 Autoantibodies and Castleman Disease. Br. J. Dermatol. 176, 824-826. doi:10.1111/bjd.14877

Makino, T., Seki, Y., Hara, H., Mizawa, M., Matsui, K., Shimizu, K., et al. (2014). Induction of Skin Lesions by Ultraviolet B Irradiation in a Case of Pemphigus Erythematosus. Acta Derm Venerol 94, 487-488. doi:10.2340/ 00015555-1781

Malik, M., and Ahmed, A. R. (2007). Concurrence of Systemic Lupus Erythematosus and Pemphigus: Coincidence or Correlation? Dermatology 214, 231-239. doi:10.1159/000099588

Mao, X., Sano, Y., Park, J. M., and Payne, A. S. (2011). p38 MAPK Activation Is Downstream of the Loss of Intercellular Adhesion in Pemphigus Vulgaris. J. Biol. Chem. 286, 1283-1291. doi:10.1074/jbc.M110.172874

Martel, P., Loiseau, P., Joly, P., Busson, M., Lepage, V., Mouquet, H., et al. (2003). Paraneoplastic Pemphigus Is Associated with the $\mathrm{DRB}^{\star} 03$ Allele. J. Autoimmun. 20, 91-95. doi:10.1016/s0896-8411(02)00092-6

Martin, L. K., Werth, V., Villanueva, E., Segall, J., and Murrell, D. F. (2009). Interventions for Pemphigus Vulgaris and Pemphigus Foliaceus. Cochrane Database Syst. Rev. 21 (1), CD006263. doi:10.1002/14651858.CD006263.pub2

Mauri, C., and Menon, M. (2017). Human Regulatory B Cells in Health and Disease: Therapeutic Potential. J. Clin. Invest. 127, 772-779. doi:10.1172/ JCI85113

Mergler, R., Kerstan, A., Schmidt, E., Goebeler, M., and Benoit, S. (2017). Atypical Clinical and Serological Manifestation of Pemphigus Vegetans: A Case Report and Review of the Literature. Case Rep. Dermatol. 9, 121-130. doi:10.1159/ 000468919

Mignard, C., Maho-Vaillant, M., Golinski, M.-L., Balayé, P., Prost-Squarcioni, C., Houivet, E., et al. (2020). Factors Associated with Short-Term Relapse in
Patients with Pemphigus Who Receive Rituximab as First-Line Therapy. JAMA Dermatol. 156, 545. doi:10.1001/jamadermatol.2020.0290

Mignogna, M. D., Muzio, L. L., and Ruocco, E. (2000). Pemphigus Induction by Influenza Vaccination. Int. J. Dermatol. 39, 795-800. doi:10.1046/j.13654362.2000.00051-5.x

Mindorf, S., Dettmann, I. M., Krüger, S., Fuhrmann, T., Rentzsch, K., Karl, I., et al. (2017). Routine Detection of Serum Antidesmocollin Autoantibodies Is Only Useful in Patients with Atypical Pemphigus. Exp. Dermatol. 26, 1267-1270. doi:10.1111/exd.13409

Mintz, E. M., and Morel, K. D. (2011). Clinical Features, Diagnosis, and Pathogenesis of Chronic Bullous Disease of Childhood. Dermatol. Clin. 29, 459-462. ix. doi:10.1016/j.det.2011.03.022

Miyagawa, S., Niizeki, H., Yamashina, Y., and Kaneshige, T. (2002). Genotyping for HLA-A, B and C Alleles in Japanese Patients with Pemphigus: Prevalence of Asian Alleles of the HLA-B15 Family. Br. J. Dermatol. 146, 52-58. doi:10.1046/ j.1365-2133.2002.04564.x

Möckel, T., Basta, F., Weinmann-Menke, J., and Schwarting, A. (2021). B Cell Activating Factor (BAFF): Structure, Functions, Autoimmunity and Clinical Implications in Systemic Lupus Erythematosus (SLE). Autoimmun. Rev. 20, 102736. doi:10.1016/j.autrev.2020.102736

Mohanty, R., Chowdhury, C., Arega, S., Sen, P., Ganguly, P., and Ganguly, N. (2019). CAR T Cell Therapy: A new era for Cancer Treatment (Review). Oncol. Rep. 42, 2183-2195. doi:10.3892/or.2019.7335

Morell-Dubois, S., Carpentier, O., Cottencin, O., Queyrel, V., Hachulla, E., Hatron, P.-Y., et al. (2008). Stressful Life Events and Pemphigus. Dermatology 216, 104-108. doi:10.1159/000111506

Morini, J. P., Jomaa, B., Gorgi, Y., Saguem, M. H., Nouira, R., Roujeau, J. C., et al. (1993). Pemphigus Foliaceus in Young Women. Arch. Dermatol. 129, 69-73. doi:10.1001/archderm.1993.01680220081019

Morita, R., Schmitt, N., Bentebibel, S.-E., Ranganathan, R., Bourdery, L., Zurawski, G., et al. (2011). Human Blood CXCR5+CD4+ T Cells Are Counterparts of T Follicular Cells and Contain Specific Subsets that Differentially Support Antibody Secretion. Immunity 34, 108-121. doi:10.1016/j.immuni.2010.12.012

Mosaad, Y. M., Fathy, H., Fawzy, Z., and El-Saied, M. A. (2012). Tumor Necrosis Factor- $\alpha-308 \mathrm{G}>\mathrm{A}$ and Interleukin-6 -174 G>C Promoter Polymorphisms and Pemphigus. Hum. Immunol. 73, 560-565. doi:10.1016/j.humimm.2012.02.001

Mouquet, H., Musette, P., Gougeon, M.-L., Jacquot, S., Lemercier, B., Lim, A., et al. (2008). B-cell Depletion Immunotherapy in Pemphigus: Effects on Cellular and Humoral Immune Responses. J. Invest. Dermatol. 128, 2859-2869. doi:10.1038/ jid.2008.178

Müller, R., Heber, B., Hashimoto, T., Messer, G., Müllegger, R., Niedermeier, A., et al. (2009). Autoantibodies against Desmocollins in European Patients with Pemphigus. Clin. Exp. Dermatol. 34, 898-903. doi:10.1111/j.13652230.2009.03241.x

Müller, R., Hunzelmann, N., Baur, V., Siebenhaar, G., Wenzel, E., Eming, R., et al. (2010). Targeted Immunotherapy with Rituximab Leads to a Transient Alteration of the IgG Autoantibody Profile in Pemphigus Vulgaris. Dermatol. Res. Pract. 2010, 1-9. doi:10.1155/2010/321950

Muramatsu, T., Iida, T., Ko, T., and Shirai, T. (1996). Pemphigus Vulgaris Exacerbated by Exposure to Sunlight. J. Dermatol. 23, 559-563. doi:10.1111/ j.1346-8138.1996.tb02652.x

Murrell, D. F., Patsatsi, A., Stavropoulos, P., Baum, S., Zeeli, T., Kern, J. S., et al. (2021). Proof of Concept for the Clinical Effects of Oral Rilzabrutinib, the First Bruton Tyrosine Kinase Inhibitor for Pemphigus Vulgaris: the Phase II BELIEVE Study*. Br. J. Dermatol. 185, 745-755. doi:10.1111/bjd.20431

Nagaraj, S., Schrum, A. G., Cho, H.-I., Celis, E., and Gabrilovich, D. I. (2010). Mechanism of T Cell Tolerance Induced by Myeloid-Derived Suppressor Cells. J.I. 184, 3106-3116. doi:10.4049/jimmunol.0902661

Nagasaka, T., Nishifuji, K., Ota, T., Whittock, N. V., and Amagai, M. (2004). Defining the Pathogenic Involvement of Desmoglein 4 in Pemphigus and Staphylococcal Scalded Skin Syndrome. J. Clin. Invest. 114, 1484-1492. doi:10.1172/JCI20480

Neri, D., Carevic-Neri, M., Brück, J., Holstein, J., Schäfer, I., Solimani, F., et al. (2021). Arginase 1 + IL-10 + Polymorphonuclear Myeloid-derived Suppressor Cells Are Elevated in Patients with Active Pemphigus and Correlate with an Increased Th2/Th1 Response. Exp. Dermatol. 30, 782-791. doi:10.1111/ exd.14298 
Nguyen, V. T., Lee, T. X., Ndoye, A., Shultz, L. D., Pittelkow, M. R., Dahl, M. V., et al. (1998). The Pathophysiological Significance of Nondesmoglein Targets of Pemphigus Autoimmunity. Arch. Dermatol. 134, 971-980. doi:10.1001/ archderm.134.8.971

Nguyen, V. T., Ndoye, A., and Grando, S. A. (2000a). Pemphigus Vulgaris Antibody Identifies Pemphaxin. J. Biol. Chem. 275, 29466-29476. doi:10.1074/jbc.M003174200

Nguyen, V. T., Ndoye, A., Shultz, L. D., Pittelkow, M. R., and Grando, S. A. (2000b). Antibodies against Keratinocyte Antigens Other Than Desmogleins 1 and 3 Can Induce Pemphigus Vulgaris-like Lesions. J. Clin. Invest. 106, 1467-1479. doi:10.1172/JCI10305

Niizeki, H., Kumagai, S., Kanagawa, S., Amagai, M., Yamashina, Y., Asada, H., et al. (2004). Exclusion of the TAP1 and TAP2 Genes within the HLA Class II Region as Candidate Susceptibility Genes to Pemphigus in the Japanese Population. J. Dermatol. Sci. 36, 122-124. doi:10.1016/j.jdermsci.2004.08.006

Nishikawa, T., Hashimoto, T., Teraki, Y., and Ebihara, T. (1991). The Clinical and Histopathological Spectrum of IgA Pemphigus. Clin. Exp. Dermatol. 16, 401-402. doi:10.1111/j.1365-2230.1991.tb00413.x

Nooka, A., Shenoy, P. J., Sinha, R., Lonial, S., and Flowers, C. R. (2011). Hepatitis C Reactivation in Patients Who Have Diffuse Large B-Cell Lymphoma Treated with Rituximab: A Case Report and Review of Literature. Clin. Lymphoma Myeloma Leuk. 11, 379-384. doi:10.1016/j.clml.2011.04.005

Numata, S., Teye, K., Tsuruta, D., Sogame, R., Ishii, N., Koga, H., et al. (2013). AntiAlpha-2-Macroglobulin-Like-1 Autoantibodies Are Detected Frequently and May Be Pathogenic in Paraneoplastic Pemphigus. J. Invest. Dermatol. 133, 1785-1793. doi:10.1038/jid.2013.65

O'Neil, L. J., Kaplan, M. J., and Carmona-Rivera, C. (2019). The Role of Neutrophils and Neutrophil Extracellular Traps in Vascular Damage in Systemic Lupus Erythematosus. JCM 8, 1325. doi:10.3390/jcm8091325

Odani, K., Itoh, A., Yanagita, S., Kaneko, Y., Tachibana, M., Hashimoto, T., et al. (2020). Paraneoplastic Pemphigus Involving the Respiratory and Gastrointestinal Mucosae. Case Rep. Pathol. 2020, 1-8. doi:10.1155/2020/ 7350759

Ohata, C., Higashi, Y., Yamagami, J., Koga, H., Ishii, N., Kanekura, T., et al. (2013). Coexistence of Pemphigus Herpetiformis with IgG Antibodies to Desmocollin 1 and Pemphigoid with IgG Antibodies to BP180 C-Terminal Domain and Laminin $\gamma 2$. JAMA Dermatol. 149, 502-504. doi:10.1001/ jamadermatol.2013.1916

Ohyama, M., Amagai, M., Tsunoda, K., Ota, T., Koyasu, S., Hata, J.-i., et al. (2002). Immunologic and Histopathologic Characterization of an Active Disease Mouse Model for Pemphigus Vulgaris. J. Invest. Dermatol. 118, 199-204. doi:10.1046/j.0022-202x.2001.01643.x

Ohzono, A., Sogame, R., Li, X., Teye, K., Tsuchisaka, A., Numata, S., et al. (2015). Clinical and Immunological Findings in 104 Cases of Paraneoplastic Pemphigus. Br. J. Dermatol. 173, 1447-1452. doi:10.1111/bjd.14162

Oktarina, D. A. M., Poot, A. M., Kramer, D., Diercks, G. F. H., Jonkman, M. F., and Pas, H. H. (2012). The IgG "Lupus-Band" Deposition Pattern of Pemphigus Erythematosus. Arch. Dermatol. 148, 1173. doi:10.1001/ archdermatol.2012.1896

Öktem, A., Hayran, Y., Uysal, P. İ., Atılan, A. U., and Yalçı, B. (2018). Evaluation of the Importance of Immunological Profile for Pemphigus Vulgaris in the Light of Necessity to Modify Compensation Theory. Acta Dermatovenerol Croat. 26, 100-104.

Oktem, A., Horzum, U., Ertop, P., Kundakci, N., Akay, B. N., Yalcin, B., et al. (2021). Clinical Relevance of Polymorphonuclear Myeloid-Derived Suppressor Cells in Autoimmune-Blistering Disorders Pemphigus Vulgaris and Bullous Pemphigoid. J. Invest. Dermatol. 141, 672-675. e1. doi:10.1016/j.jid.2020.07.015

Oliveira, M. E. F., Culton, D. A., Prisayanh, P., Qaqish, B. F., and Diaz, L. A. (2013). E-cadherin Autoantibody Profile in Patients with Pemphigus Vulgaris. $\mathrm{Br}$. J. Dermatol. 169, 812-818. doi:10.1111/bjd.12455

On, H. R., Hashimoto, T., and Kim, S.-C. (2015). Pemphigus Herpetiformis with IgG Autoantibodies to Desmoglein 1 and Desmocollin 1. Br. J. Dermatol. 172, 1144-1146. doi:10.1111/bjd.13419

Ouahes, N., Qureshi, T. A., and Ahmed, A. R. (1997). Infertility in Women with Pemphigus Vulgaris and Other Autoimmune Diseases. J. Am. Acad. Dermatol. 36, 383-387. doi:10.1016/S0190-9622(97)80213-7

Paolino, G., Didona, D., Magliulo, G., Iannella, G., Didona, B., Mercuri, S., et al. (2017). Paraneoplastic Pemphigus: Insight into the Autoimmune Pathogenesis, Clinical Features and Therapy. IJMS 18, 2532. doi:10.3390/ijms18122532
Párnická, Z., Švecová, D., Javor, J., Shawkatová, I., and Buc, M. (2013). High Susceptibility to Pemphigus Vulgaris Due to HLA-Drb1*14:54 in the Slovak Population. Int. J. Immunogenet. 40, 471-475. doi:10.1111/iji.12052

Pasricha, J. S., Khaitan, B. K., Raman, R. S., and Chandra, M. (1995). Dexamethasone-Cyclophosphamide Pulse Therapy for Pemphigus. Int. J. Dermatol. 34, 875-882. doi:10.1111/j.1365-4362.1995.tb04430.x

Pattullo, V. (2015). Hepatitis B Reactivation in the Setting of Chemotherapy and Immunosuppression - Prevention Is Better Than Cure. WJH 7, 954. doi:10.4254/wjh.v7.i7.954

Payne, A. S., Ishii, K., Kacir, S., Lin, C., Li, H., Hanakawa, Y., et al. (2005). Genetic and Functional Characterization of Human Pemphigus Vulgaris Monoclonal Autoantibodies Isolated by Phage Display. J. Clin. Invest. 115, 888-899. doi:10.1172/JCI24185

Pereira, N. F., Hansen, J. A., Lin, M.-T., Roxo, V. M. M. S., Braun, K., and PetzlErler, M. L. (2004). Cytokine Gene Polymorphisms in Endemic Pemphigus Foliaceus: a Possible Role for IL6 Variants. Cytokine 28, 233-241. doi:10.1016/ j.cyto.2004.08.006

Pérez-Pérez, M. E., Avalos-Díaz, E., and Herrera-Esparza, R. (20122012). Autoantibodies in Senear-Usher Syndrome: Cross-Reactivity or Multiple Autoimmunity? Autoimmune Dis. 2012, 1-7. doi:10.1155/2012/296214

Peterson, R. A. (2012). Regulatory T-Cells: Diverse Phenotypes Integral to Immune Homeostasis and Suppression. Toxicol. Pathol. 40, 186-204. doi:10.1177/ 0192623311430693

Petzl-Erler, M. L. (2020). Beyond the HLA Polymorphism: A Complex Pattern of Genetic Susceptibility to Pemphigus. Genet. Mol. Biol. 43, e20190369. doi:10.1590/1678-4685-gmb-2019-0369

Pietkiewicz, P., Bowszyc-Dmochowska, M., Gornowicz-Porowska, J., and Dmochowski, M. (2018). Involvement of Nail Apparatus in Pemphigus Vulgaris in Ethnic Poles Is Infrequent. Front. Med. 5, 227. doi:10.3389/ fmed.2018.00227

Pollmann, R., Schmidt, T., Eming, R., and Hertl, M. (2018). Pemphigus: a Comprehensive Review on Pathogenesis, Clinical Presentation and Novel Therapeutic Approaches. Clinic Rev. Allerg Immunol. 54, 1-25. doi:10.1007/ s12016-017-8662-z

Porro, A. M., Hans Filho, G., and Santi, C. G. (2019). Consensus on the Treatment of Autoimmune Bullous Dermatoses: Pemphigus Vulgaris and Pemphigus Foliaceus - Brazilian Society of Dermatology. Bras. Dermatol. 94, 20-32. doi:10.1590/abd1806-4841.2019940206

Probst, C., Schlumberger, W., Stöcker, W., Recke, A., Schmidt, E., Hashimoto, T., et al. (2009). Development of ELISA for the Specific Determination of Autoantibodies against Envoplakin and Periplakin in Paraneoplastic Pemphigus. Clinica Chim. Acta 410, 13-18. doi:10.1016/j.cca.2009.08.022

Puviani, M., Marconi, A., Pincelli, C., and Cozzani, E. (2003). Fas Ligand in Pemphigus Sera Induces Keratinocyte Apoptosis through the Activation of Caspase-8. J. Invest. Dermatol. 120, 164-167. doi:10.1046/j.15231747.2003.12014.x

Pyzik, M., Sand, K. M. K., Hubbard, J. J., Andersen, J. T., Sandlie, I., and Blumberg, R. S. (2019). The Neonatal Fc Receptor (FcRn): A Misnomer? Front. Immunol. 10, 1540. doi:10.3389/fimmu.2019.01540

Qian, Y., Jeong, J. S., Maldonado, M., Valenzuela, J. G., Gomes, R., Teixeira, C., et al. (2012). Cutting Edge: Brazilian Pemphigus Foliaceus Anti-desmoglein 1 Autoantibodies Cross-React with Sand Fly Salivary LJM11 Antigen. J.I. 189, 1535-1539. doi:10.4049/jimmunol.1200842

Radeva, M. Y., Walter, E., Stach, R. A., Yazdi, A. S., Schlegel, N., Sarig, O., et al. (2019). ST18 Enhances PV-IgG-Induced Loss of Keratinocyte Cohesion in Parallel to Increased ERK Activation. Front. Immunol. 10, 770. doi:10.3389/ fimmu.2019.00770

Rafei, D., Müller, R., Ishii, N., Llamazares, M., Hashimoto, T., Hertl, M., et al. (2011). IgG Autoantibodies against Desmocollin 3 in Pemphigus Sera Induce Loss of Keratinocyte Adhesion. Am. J. Pathol. 178, 718-723. doi:10.1016/ j.ajpath.2010.10.016

Ramadan, N., Kurban, M., and Abbas, O. (2019). Possible Role for Plasmacytoid Dendritic Cells in Pemphigus. Ann. Dermatol. 31, 454. doi:10.5021/ ad.2019.31.4.454

Rapp, M., Pentland, A., and Richardson, C. (2018). Successful Treatment of Pemphigus Vulgaris with Ofatumumab. J. Drugs Dermatol. 17, 1338-1339.

Razzaque Ahmed, A., and Moy, R. (1982). Death in Pemphigus. J. Am. Acad. Dermatol. 7, 221-228. doi:10.1016/S0190-9622(82)70111-2 
Reddy, K. R., Beavers, K. L., Hammond, S. P., Lim, J. K., and Falck-Ytter, Y. T. (2015). American Gastroenterological Association Institute Guideline on the Prevention and Treatment of Hepatitis B Virus Reactivation during Immunosuppressive Drug Therapy. Gastroenterology 148, 215-219. doi:10.1053/j.gastro.2014.10.039

Reis, V. M. S., Toledo, R. P., Lopez, A., Diaz, L. A., and Martins, J. E. C. (2000). UVB-induced Acantholysis in Endemic Pemphigus Foliaceus (Fogo Selvagem) and Pemphigus Vulgaris. J. Am. Acad. Dermatol. 42, 571-576. doi:10.1067/ mjd.2000.104891

Ren, Z., Hsu, D., Brieva, J., and Silverberg, J. I. (2019). Association between Climate, Pollution and Hospitalization for Pemphigus in the USA. Clin. Exp. Dermatol. 44, 135-143. doi:10.1111/ced.13650

Rizzo, C., Fotino, M., Zhang, Y., Chow, S., Spizuoco, A., and Sinha, A. A. (2005). Direct Characterization of Human $\mathrm{T}$ Cells in Pemphigus Vulgaris Reveals Elevated Autoantigen-specific Th2 Activity in Association with Active Disease. Clin. Exp. Dermatol. 30, 535-540. doi:10.1111/j.1365-2230.2005.01836.x

Ruocco, V., de Luca, M., Pisani, M., de Angelis, E., Vitale, O., and Astaritd, C. (1982). Pemphigus Provoked by D(-)Penicillamine. Dermatology 164, 236-248. doi:10.1159/000250097

Ruocco, V., De Angelis, E., and Lombardi, M. L. (1993). Drug-induced Pemphigus. II. Pathomechanisms and Experimental Investigations. Clin. Dermatol. 11, 507-513. doi:10.1016/0738-081x(93)90158-9

Ruocco, V., Brenner, S., and Ruocco, E. (2001). Pemphigus and Diet: Does a Link Exist? Int. J. Dermatol. 40, 161-163. doi:10.1046/j.1365-4362.2001.01099.x

Sagnelli, E., Pisaturo, M., Sagnelli, C., and Coppola, N. (20122012). RituximabBased Treatment, HCV Replication, and Hepatic Flares. Clin. Develop. Immunol. 2012, 1-5. doi:10.1155/2012/945950

Saha, M., Powell, A.-M., Bhogal, B., Black, M. M., and Groves, R. W. (2009). Pulsed Intravenous Cyclophosphamide and Methylprednisolone Therapy in Refractory Pemphigus. Br. J. Dermatol. 162, 790-797. doi:10.1111/j.13652133.2009.09590.x

Saito, M., Stahley, S. N., Caughman, C. Y., Mao, X., Tucker, D. K., Payne, A. S., et al. (2012). Signaling Dependent and Independent Mechanisms in Pemphigus Vulgaris Blister Formation. PLoS ONE 7, e50696. doi:10.1371/ journal.pone.0050696

Sakaguchi, S., Sakaguchi, N., Asano, M., Itoh, M., and Toda, M. (1995). Immunologic Self-Tolerance Maintained by Activated T Cells Expressing IL-2 Receptor Alpha-Chains (CD25). Breakdown of a Single Mechanism of Self-Tolerance Causes Various Autoimmune Diseases. J. Immunol. 155, 1151-1164.

Saleh, M. A., Hashimoto, R., Kase, Y., Amagai, M., and Yamagami, J. (2015). Low Pathogenicity of Anti-desmoglein 3 Immunoglobulin G Autoantibodies Contributes to the Atypical Clinical Phenotypes in Pemphigus. J. Dermatol. 42, 685-689. doi:10.1111/1346-8138.12888

Salihbegović-Opalić, N., Dobl, O., and Simojlović, V. (1975). Incidence of Pemphigus in Newborn Infants Born at the Gynecologic-Obstetrical Department in Bijeljina. Med. Arh 29, 623-625.

Salopeka, T. G., Logsettyb, S., and Tredgetb, E. E. (2002). Anti-CD20 Chimeric Monoclonal Antibody (Rituximab) for the Treatment of Recalcitrant, LifeThreatening Pemphigus Vulgaris with Implications in the Pathogenesis of the Disorder. J. Am. Acad. Dermatol. 47, 785-788. doi:10.1067/ mjd.2002.126273

Sardana, K., Garg, V. K., and Agarwal, P. (2013). Is There an Emergent Need to Modify the Desmoglein Compensation Theory in Pemphigus on the Basis of Dsg ELISA Data and Alternative Pathogenic Mechanisms? Br. J. Dermatol. 168, 669-674. doi:10.1111/bjd.12012

Sarig, O., Bercovici, S., Zoller, L., Goldberg, I., Indelman, M., Nahum, S., et al. (2012). Population-Specific Association between a Polymorphic Variant in ST18, Encoding a Pro-apoptotic Molecule, and Pemphigus Vulgaris. J. Invest. Dermatol. 132, 1798-1805. doi:10.1038/jid.2012.46

Satyam, A., Khandpur, S., Sharma, V. K., and Sharma, A. (2009). Involvement of TH1/TH2 Cytokines in the Pathogenesis of Autoimmune Skin DiseasePemphigus Vulgaris. Immunological Invest. 38, 498-509. doi:10.1080/ 08820130902943097

Sayar, S. K., and Küçükoğlu, R. (2021). Evaluation of Non-endemic Pemphigus Foliaceus in a Large Series of Patients: a Single-center Retrospective Study from Turkey Focuses on the Relapses. Anais Brasileiros de Dermatologia 96, 422-428. doi:10.1016/j.abd.2020.12.009
Schepens, I., Jaunin, F., Begre, N., Läderach, U., Marcus, K., Hashimoto, T., et al. (2010). The Protease Inhibitor Alpha-2-Macroglobuline-Like-1 Is the P170 Antigen Recognized by Paraneoplastic Pemphigus Autoantibodies in Human. PLoS ONE 5, e12250. doi:10.1371/journal.pone.0012250

Schmidt, E., Dähnrich, C., Rosemann, A., Probst, C., Komorowski, L., Saschenbrecker, S., et al. (2010). Novel ELISA Systems for Antibodies to Desmoglein 1 and 3: Correlation of Disease Activity with Serum Autoantibody Levels in Individual Pemphigus Patients. Exp. Dermatol. 19, 458-463. doi:10.1111/j.1600-0625.2010.01069.x

Schmidt, T., Willenborg, S., Hünig, T., Deeg, C. A., Sonderstrup, G., Hertl, M., et al. (2016). Induction of T Regulatory Cells by the Superagonistic Anti-CD28 Antibody D665 Leads to Decreased Pathogenic IgG Autoantibodies against Desmoglein 3 in a HLA-Transgenic Mouse Model of Pemphigus Vulgaris. Exp. Dermatol. 25, 293-298. doi:10.1111/exd.12919

Schmidt, E., Kasperkiewicz, M., and Joly, P. (2019). Pemphigus. The Lancet 394, 882-894. doi:10.1016/S0140-6736(19)31778-7

Schmitt, T., and Waschke, J. (2021). Autoantibody-Specific Signalling in Pemphigus. Front. Med. 8, 701809. doi:10.3389/fmed.2021.701809

Schulze, K., Galichet, A., Sayar, B. S., Scothern, A., Howald, D., Zymann, H., et al. (2012). An Adult Passive Transfer Mouse Model to Study Desmoglein 3 Signaling in Pemphigus Vulgaris. J. Invest. Dermatol. 132, 346-355. doi:10.1038/jid.2011.299

Sekiguchi, M., Futei, Y., Fujii, Y., Iwasaki, T., Nishikawa, T., and Amagai, M. (2001). Dominant Autoimmune Epitopes Recognized by Pemphigus Antibodies Map to the N-Terminal Adhesive Region of Desmogleins. J. Immunol. 167, 5439-5448. doi:10.4049/jimmunol.167.9.5439

Shamim, T., Varghese, V. I., Shameena, P. M., and Sudha, S. (2008). Pemphigus Vulgaris in Oral Cavity: Clinical Analysis of 71 Cases. Med. Oral Patol Oral Cir Bucal 13 (10), E622-E626.

Shams, S., Amirzargar, A. A., Yousefi, M., Rezaei, N., Solgi, G., Khosravi, F., et al. (2009). HLA Class II (DRB, DQA1 and DQB1) Allele and Haplotype Frequencies in the Patients with Pemphigus Vulgaris. J. Clin. Immunol. 29, 175-179. doi:10.1007/s10875-008-9244-x

Shimba, A., and Ikuta, K. (2020). Control of Immunity by Glucocorticoids in Health and Disease. Semin. Immunopathol 42, 669-680. doi:10.1007/s00281020-00827-8

Shoenfeld, Y., Aharon-Maor, A., and Sherer, Y. (2000). Vaccination as an Additional Player in the Mosaic of Autoimmunity. Clin. Exp. Rheumatol. 18 (2), 181-184.

Slomov, E., Loewenthal, R., Korostishevsky, M., Goldberg, I., Brenner, S., and Gazit, E. (2005). Pemphigus Vulgaris Is Associated with the Transporter Associated with Antigen Processing (TAP) System. Hum. Immunol. 66, 1213-1222. doi:10.1016/j.humimm.2005.11.004

Solimani, F., Mansour, Y., Didona, D., Dilling, A., Ghoreschi, K., and Meier, K. (2021). Development of Severe Pemphigus Vulgaris Following SARS-CoV-2 Vaccination with BNT162b2. J. Eur. Acad. Dermatol. Venereol. 35, e649-e651. doi: $10.1111 /$ jdv. 17480

Spindler, V., Heupel, W.-M., Efthymiadis, A., Schmidt, E., Eming, R., Rankl, C., et al. (2009). Desmocollin 3-mediated Binding Is Crucial for Keratinocyte Cohesion and Is Impaired in Pemphigus. J. Biol. Chem. 284, 30556-30564. doi:10.1074/jbc.M109.024810

Spindler, V., Eming, R., Schmidt, E., Amagai, M., Grando, S., Jonkman, M. F., et al. (2018). Mechanisms Causing Loss of Keratinocyte Cohesion in Pemphigus. J. Invest. Dermatol. 138, 32-37. doi:10.1016/j.jid.2017.06.022

Suzan, F., Ammor, M., and Ribrag, V. (2001). Fatal Reactivation of Cytomegalovirus Infection after Use of Rituximab for a PostTransplantation Lymphoproliferative Disorder. N. Engl. J. Med. 345, 1000. doi:10.1056/NEJM200109273451315

Taams, L. S., Steel, K. J. A., Srenathan, U., Burns, L. A., and Kirkham, B. W. (2018). IL-17 in the Immunopathogenesis of Spondyloarthritis. Nat. Rev. Rheumatol. 14, 453-466. doi:10.1038/s41584-018-0044-2

Takahashi, H., Amagai, M., Nishikawa, T., Fujii, Y., Kawakami, Y., and Kuwana, M. (2008). Novel System Evaluating In Vivo Pathogenicity of Desmoglein 3reactive T Cell Clones Using Murine Pemphigus Vulgaris. J. Immunol. 181, 1526-1535. doi:10.4049/jimmunol.181.2.1526

Tamazian, S., and Simpson, C. L. (2020). Autoimmune Bullous Disease in Skin of Color: A Case Series. JAAD Case Rep. 6, 1173-1178. doi:10.1016/ j.jdcr.2020.08.035 
Tanasilovic, S., Popadic, S., Medenica, L., and Popadic, D. (2017). Pemphigus Vulgaris and Pemphigus Foliaceus Determined by CD86 and CTLA4 Polymorphisms. Clin. Dermatol. 35, 236-241. doi:10.1016/ j.clindermatol.2016.05.021

Tay, Y. E., Lee, S. S. J., and Lim, Y. L. (2018). Pemphigus Herpetiformis with Autoantibodies to Desmocollins 1, 2 and 3. Clin. Exp. Dermatol. 43, 360-362. doi:10.1111/ced.13355

Thongprasom, K., Pengpis, N., Phattarataratip, E., and Samaranayake, L. (2021). Oral Pemphigus after COVID-19 Vaccination. Oral Dis. doi:10.1111/odi.14034

Timoteo, R. P., da Silva, M. V., Miguel, C. B., Silva, D. A. A., Catarino, J. D. S., Rodrigues Junior, V., et al. (20172017). Th1/Th17-Related Cytokines and Chemokines and Their Implications in the Pathogenesis of Pemphigus Vulgaris. Mediators Inflamm. 2017, 1-9. doi:10.1155/2017/7151285

Torzecka, J. D., Narbutt, J., Sysa-Jedrzejowska, A., Borowiec, M., Ptasinska, A., Woszczek, G., et al. (2003). Tumour Necrosis Factor- $\alpha$ Polymorphism as One of the Complex Inherited Factors in Pemphigus. Mediators Inflamm. 12, 303-307. doi:10.1080/09629350310001619735

Toumi, A., Abida, O., Ben Ayed, M., Masmoudi, A., Turki, H., and Masmoudi, H. (2013). Cytokine Gene Polymorphisms in Tunisian Endemic Pemphigus Foliaceus: a Possible Role of Il-4 Variants. Hum. Immunol. 74, 658-665. doi:10.1016/j.humimm.2013.01.009

Tron, F., Gilbert, D., Joly, P., Mouquet, H., Drouot, L., Ayed, M. B., et al. (2006). Immunogenetics of Pemphigus: an Update. Autoimmunity 39, 531-539. doi:10.1080/08916930600971497

Tsankov, N., Vassileva, S., Kamarashev, J., Kazandjieva, J., and Kuzeva, V. (2000). Epidemiology of Pemphigus in Sofia, Bulgaria. A 16-year Retrospective Study (1980-1995). Int. J. Dermatol. 39, 104-108. doi:10.1046/j.13654362.2000.00864.x

Tsuchisaka, A., Numata, S., Teye, K., Natsuaki, Y., Kawakami, T., Takeda, Y., et al. (2016). Epiplakin Is a Paraneoplastic Pemphigus Autoantigen and Related to Bronchiolitis Obliterans in Japanese Patients. J. Invest. Dermatol. 136, 399-408. doi:10.1038/JID.2015.408

Tsunoda, K., Ota, T., Aoki, M., Yamada, T., Nagai, T., Nakagawa, T., et al. (2003). Induction of Pemphigus Phenotype by a Mouse Monoclonal Antibody against the Amino-Terminal Adhesive Interface of Desmoglein 3. J. Immunol. 170, 2170-2178. doi:10.4049/jimmunol.170.4.2170

Tsuruta, D., Ishii, N., Hamada, T., Ohyama, B., Fukuda, S., Koga, H., et al. (2011). IgA Pemphigus. Clin. Dermatol. 29, 437-442. doi:10.1016/ j.clindermatol.2011.01.014

Tunca, M., Musabak, U., Sagkan, R. I., Koc, E., and Akar, A. (2010). Association of Human Leukocyte Antigen Class II Alleles with Pemphigus Vulgaris in a Turkish Population. J. Dermatol. 37, 246-250. doi:10.1111/j.13468138.2009.00743.x

Turrentine, J. E., Sokumbi, O., and Agim, N. G. (2014). Blisters and Erosions in a Neonate. JAMA Dermatol. 150, 1223. doi:10.1001/jamadermatol.2014.2087

Ueda, A., Ishii, N., Teye, K., Dainichi, T., Ohyama, B., Hamada, T., et al. (2013). Unique Herpetiform Bullous Dermatosis with IgG Antibodies to Desmocollins 1/3 and LAD-1. Br. J. Dermatol. 169, 719-721. doi:10.1111/bjd.12398

Valikhani, M., Kavusi, S., Chams-Davatchi, C., Daneshpazhooh, M., Barzegari, M., Ghiasi, M., et al. (2007). Pemphigus and Associated Environmental Factors: a Case?control Study. Clin. Exp. Dermatol. 32, 256-260. doi:10.1111/j.13652230.2007.02390.x

Valikhani, M., Kavusi, S., Chams-Davatchi, C., Hallaji, Z., Esmaili, N., Ghandi, N., et al. (2008). Impact of Smoking on Pemphigus. Int. J. Dermatol. 47, 567-570. doi:10.1111/j.1365-4632.2008.03645.x

Veldman, C., Stauber, A., Wassmuth, R., Uter, W., Schuler, G., and Hertl, M. (2003). Dichotomy of Autoreactive Th1 and Th2 Cell Responses to Desmoglein 3 in Patients with Pemphigus Vulgaris (PV) and Healthy Carriers of PVAssociated HLA Class II Alleles. J. Immunol. 170, 635-642. doi:10.4049/ jimmunol.170.1.635

Veldman, C., Höhne, A., Dieckmann, D., Schuler, G., and Hertl, M. (2004). Type I Regulatory T Cells Specific for Desmoglein 3 Are More Frequently Detected in Healthy Individuals Than in Patients with Pemphigus Vulgaris. J. Immunol. 172, 6468-6475. doi:10.4049/jimmunol.172.10.6468

Veldman, C., Pahl, A., Beissert, S., Hansen, W., Buer, J., Dieckmann, D., et al. (2006). Inhibition of the Transcription Factor Foxp3 Converts Desmoglein 3Specific Type 1 Regulatory T Cells into Th2-like Cells. J. Immunol. 176, 3215-3222. doi:10.4049/jimmunol.176.5.3215
Verma, G., Tegta, G., Sharma, A., Kaur, M., and Sharma, S. (2020). A Rare Case of Extensive Pemphigus Vegetans. Indian Dermatol. Online J. 11, 87-90. doi:10.4103/idoj.IDOJ_83_19

Vinay, K., Kanwar, A. J., Mittal, A., Dogra, S., Minz, R. W., and Hashimoto, T. (2015). Intralesional Rituximab in the Treatment of Refractory Oral Pemphigus Vulgaris. JAMA Dermatol. 151, 878. doi:10.1001/jamadermatol.2014.3674

Vodo, D., Sarig, O., Geller, S., Ben-Asher, E., Olender, T., Bochner, R., et al. (2016). Identification of a Functional Risk Variant for Pemphigus Vulgaris in the ST18 Gene. Plos Genet. 12, e1006008. doi:10.1371/journal.pgen.1006008

Vodo, D., Sarig, O., and Sprecher, E. (2018). The Genetics of Pemphigus Vulgaris. Front. Med. 5, 226. doi:10.3389/fmed.2018.00226

Völlner, F., Ali, J., Kurrle, N., Exner, Y., Eming, R., Hertl, M., et al. (2016). Loss of Flotillin Expression Results in Weakened Desmosomal Adhesion and Pemphigus Vulgaris-like Localisation of Desmoglein-3 in Human Keratinocytes. Sci. Rep. 6, 28820. doi:10.1038/srep28820

von Köckritz, A., Ständer, S., Zeidler, C., Metze, D., Luger, T., and Bonsmann, G. (2017). Successful Monotherapy of Pemphigus Vegetans with Minocycline and Nicotinamide. J. Eur. Acad. Dermatol. Venereol. 31, 85-88. doi:10.1111/ jdv. 13779

Warren, S. J. P., Lin, M.-S., Giudice, G. J., Hoffmann, R. G., Hans-Filho, G., Aoki, V., et al. (2000). The Prevalence of Antibodies against Desmoglein 1 in Endemic Pemphigus Foliaceus in Brazil. N. Engl. J. Med. 343, 23-30. doi:10.1056/ NEJM200007063430104

Weber, A. N. R., Bittner, Z., Liu, X., Dang, T.-M., Radsak, M. P., and Brunner, C. (2017). Bruton's Tyrosine Kinase: An Emerging Key Player in Innate Immunity. Front. Immunol. 8, 1454. doi:10.3389/fimmu.2017.01454

Werth, V. P., Fivenson, D., Pandya, A. G., Chen, D., Rico, M. J., Albrecht, J., et al. (2008). Multicenter Randomized, Double-Blind, Placebo-Controlled, Clinical Trial of Dapsone as a Glucocorticoid-Sparing Agent in Maintenance-phase Pemphigus Vulgaris. Arch. Dermatol. 144, 25-32. doi:10.1001/ archderm.144.1.25

Werth, V. P., Culton, D. A., Concha, J. S. S., Graydon, J. S., Blumberg, L. J., Okawa, J., et al. (2021). Safety, Tolerability, and Activity of ALXN1830 Targeting the Neonatal Fc Receptor in Chronic Pemphigus. J. Invest. Dermatol. 141 (21), 2858-2865. doi:10.1016/j.jid.2021.04.031

Werth, V. P. (1996). Treatment of Pemphigus Vulgaris with Brief, High-Dose Intravenous Glucocorticoids. Arch. Dermatol. 132, 1435. doi:10.1001/ archderm.1996.03890360021005

Czernik, A., and Wieczorek, M. (2016). Paraneoplastic Pemphigus: a Short Review. Ccid Vol. 9, 291-295. doi:10.2147/CCID.S100802

Wilson, C. L., Wojnarowska, F., Dean, D., and Pasricha, J. S. (1993). IgG Subclasses in Pemphigus in Indian and UK Populations. Clin. Exp. Dermatol. 18, 226-230. doi:10.1111/j.1365-2230.1993.tb02175.x

Wolf, R., and Ruocco, V. (1997). Gaining More Insight into the Pathomechanisms of Thiol-Induced Acantholysis. Med. Hypotheses 48, 107-110. doi:10.1016/ s0306-9877(97)90277-2

Xu, R.-C., Zhu, H.-Q., Li, W.-P., Zhao, X.-Q., Yuan, H.-J., Zheng, J., et al. (2013). The Imbalance of Th17 and Regulatory T Cells in Pemphigus Patients. Eur. J. Dermatol. 23, 795-802. doi:10.1684/ejd.2013.2177

Yalçin, B., and Alli, N. (2007). Pemphigus Vulgaris Following Antirabies Vaccination. J. Dermatol. 34, 734-735. doi:10.1111/j.1346-8138.2007.00373.x

Yamagami, J., Kacir, S., Ishii, K., Payne, A. S., Siegel, D. L., and Stanley, J. R. (2009). Antibodies to the Desmoglein 1 Precursor Proprotein but Not to the Mature Cell Surface Protein Cloned from Individuals without Pemphigus. J. Immunol. 183, 5615-5621. doi:10.4049/jimmunol.0901691

Yan, L., Wang, J. M., and Zeng, K. (2012). Association between HLA-DRB1 Polymorphisms and Pemphigus Vulgaris: a Meta-analysis. Br. J. Dermatol. 167, 768-777. doi:10.1111/j.1365-2133.2012.11040.x

Yasuda, H., Kobayashi, H., Hashimoto, T., Itoh, K., Yamane, M., and Nakamura, J. (2000). Subcorneal Pustular Dermatosis Type of IgA Pemphigus: Demonstration of Autoantibodies to Desmocollin-1 and Clinical Review. Br. J. Dermatol. 143, 144-148. doi:10.1046/j.13652133.2000.03604.x

Yatim, A., Bohelay, G., Grootenboer-Mignot, S., Prost-Squarcioni, C., Alexandre, M., Le Roux-Villet, C., et al. (2019). Paraneoplastic Pemphigus Revealed by Anti-programmed Death-1 Pembrolizumab Therapy for Cutaneous Squamous Cell Carcinoma Complicating Hidradenitis Suppurativa. Front. Med. 6, 249. doi:10.3389/fmed.2019.00249 
Yeo, W., Chan, T. C., Leung, N. W. Y., Lam, W. Y., Mo, F. K. F., Chu, M. T., et al. (2009). Hepatitis B Virus Reactivation in Lymphoma Patients with Prior Resolved Hepatitis B Undergoing Anticancer Therapy with or without Rituximab. JCO 27, 605-611. doi:10.1200/JCO.2008.18.0182

Yokoyama, T., Matsuda, S., Takae, Y., Wada, N., Nishikawa, T., Amagai, M., et al. (2011). Antigen-independent Development of Foxp3+ Regulatory T Cells Suppressing Autoantibody Production in Experimental Pemphigus Vulgaris. Int. Immunol. 23, 365-373. doi:10.1093/intimm/dxr020

Yoshida, K., Ishii, K., Shimizu, A., Yokouchi, M., Amagai, M., Shiraishi, K., et al. (2017). Non-pathogenic Pemphigus Foliaceus (PF) IgG Acts Synergistically with a Directly Pathogenic PF IgG to Increase Blistering by p38MAPKdependent Desmoglein 1 Clustering. J. Dermatol. Sci. 85, 197-207. doi:10.1016/j.jdermsci.2016.12.010

Yu, Y., and Su, K. (2013). Neutrophil Extracellular Traps and Systemic Lupus Erythematosus. J. Clin. Cel Immunol 04, 139. doi:10.4172/2155-9899.1000139

Yusof, M. Y. M., Vital, E. M., McElvenny, D. M., Hensor, E. M. A., Das, S., Dass, S., et al. (2019). Predicting Severe Infection and Effects of Hypogammaglobulinemia during Therapy with Rituximab in Rheumatic and Musculoskeletal Diseases. Arthritis Rheumatol. 71, 1812-1823. doi:10.1002/art.40937

Zaraa, I., Sellami, A., Bouguerra, C., Sellami, M. K., Chelly, I., Zitouna, M., et al. (2011). Pemphigus Vegetans: a Clinical, Histological, Immunopathological and Prognostic Study. J. Eur. Acad. Dermatol. Venereol. 25, 1160-1167. doi:10.1111/ j.1468-3083.2010.03939.x

Zhao, C. Y., Chiang, Y. Z., and Murrell, D. F. (2016). Neonatal Autoimmune Blistering Disease: A Systematic Review. Pediatr. Dermatol. 33, 367-374. doi:10.1111/pde.12859

Zhou, S. H., Lin, L., Jin, P. Y., and Ye, S. Z. (2003). Association between HLADRB1, DQB1 Genes and Pemphigus Vulgaris in Chinese Hans. Zhonghua Yi Xue Yi Chuan Xue Za Zhi 20 (1), 79-81.

Zhou, S., Liu, Z., Yuan, H., Zhao, X., Zou, Y., Zheng, J., et al. (2020). Autoreactive B Cell Differentiation in Diffuse Ectopic Lymphoid-like Structures of Inflamed Pemphigus Lesions. J. Invest. Dermatol. 140, 309-318. e8. doi:10.1016/ j.jid.2019.07.717
Zotos, D., Coquet, J. M., Zhang, Y., Light, A., D’Costa, K., Kallies, A., et al. (2010). IL-21 Regulates Germinal center B Cell Differentiation and Proliferation through a B Cell-Intrinsic Mechanism. J. Exp. Med. 207, 365-378. doi:10.1084/jem.20091777

Zou, Y., Yuan, H., Zhou, S., Zhou, Y., Zheng, J., Zhu, H., et al. (2021). The Pathogenic Role of CD4+ Tissue-Resident Memory T Cells Bearing T Follicular Helper-like Phenotype in Pemphigus Lesions. J. Invest. Dermatol. 141, 2141-2150. doi:10.1016/j.jid.2021.01.030

Zuercher, A. W., Spirig, R., Baz Morelli, A., Rowe, T., and Käsermann, F. (2019). Next-generation Fc Receptor-Targeting Biologics for Autoimmune Diseases. Autoimmun. Rev. 18, 102366. doi:10.1016/j.autrev.2019.102366

Conflict of Interest: BJ receives research funding from Evonik. PM is a consultant for Servier.

The remaining authors declare that the research was conducted in the absence of any commercial or financial relationships that could be construed as a potential conflict of interest.

Publisher's Note: All claims expressed in this article are solely those of the authors and do not necessarily represent those of their affiliated organizations, or those of the publisher, the editors and the reviewers. Any product that may be evaluated in this article, or claim that may be made by its manufacturer, is not guaranteed or endorsed by the publisher.

Copyright (c) 2022 Lim, Bohelay, Hanakawa, Musette and Janela. This is an openaccess article distributed under the terms of the Creative Commons Attribution License (CC BY). The use, distribution or reproduction in other forums is permitted, provided the original author(s) and the copyright owner(s) are credited and that the original publication in this journal is cited, in accordance with accepted academic practice. No use, distribution or reproduction is permitted which does not comply with these terms. 